\title{
GEOPHYSICAL INVESTIGATIONS AT THE ENGINE TEST AREA OF CAMP CROWDER, MISSOURI
}

\author{
Final
}

Energy Systems Division

Argonne National Laboratory

Operated by The University of Chicago, under Contract W-31-109-Eng-38, for the

United States Department of Energy 
Argonne National Laboratory, with facilities in the states of Illinois and Idaho, is owned by the United States Government and operated by The University of Chicago under the provisions of a contract with the Department of Energy.

This technical memo is a product of Argonne's Energy Systems (ES) Division. For information on the division's scientific and engineering activities, contact:

\author{
Director, Energy Systems Division \\ Argonne National Laboratory \\ Argonne, Illinois 60439-4815 \\ Telephone: 630-252-3724 \\ http://www.es.anl.gov/
}

Presented in this technical memo are preliminary results of ongoing work or work that is more limited in scope and depth than that described in formal reports issued by the ES Division.

\title{
DISCLAIMER
}

This report was prepared as an account of work sponsored by an agency of the United States Government. Neither the United States Government nor any agency thereof, nor The University of Chicago, nor any of their employees or officers, makes any warranty, express or implied, or assumes any legal liability or responsibility for the accuracy, completeness, or usefulness of any information, apparatus, product, or process disclosed, or represents that its use would not infringe privately owned rights. Reference herein to any specific commercial product, process, or service by trade name, trademark, manufacturer, or otherwise, does not necessarily constitute or imply its endorsement, recommendation, or favoring by the United States Government or any agency thereof. The views and opinions of document authors expressed herein do not necessarily state or reflect those of the United States Government or any agency thereof, Argonne National Laboratory, or The University of Chicago.

Available electronically at http://www.doe.gov/bridge

Available for a processing fee to U.S. Department of Energy and its contractors, in paper, from:

U.S. Department of Energy

Office of Scientific and Technical Information

P.O. Box 62

Oak Ridge, TN 37831-0062

phone: (865) 576-8401

fax: (865) 576-5728

email: reports@adonis.osti.gov 


\section{GEOPHYSICAL INVESTIGATIONS AT THE ENGINE TEST AREA OF CAMP CROWDER, MISSOURI}

\section{Final}

by

S.F. Miller, M.D. Thompson, J.M. Cooper, and W. Mandell*

Center for Environmental Restoration Systems

Energy Systems Division

Argonne National Laboratory, 9700 South Cass Avenue, Argonne, Illinois 60439

*U.S. Army Environmental Center, Hoadley Road, Aberdeen Proving Ground, Edgewood, Maryland

March 2000

prepared for

U.S. Army Environmental Center, Aberdeen Proving Ground, Edgewood, Maryland 


\section{CONTENTS}

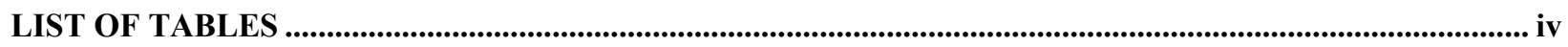

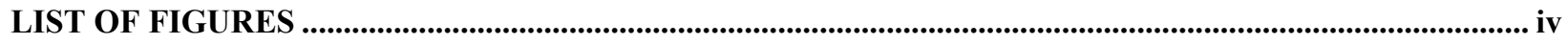

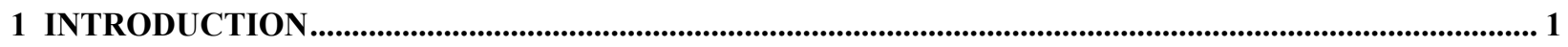

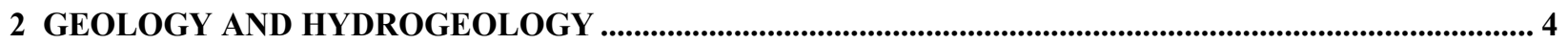

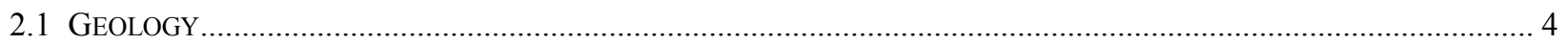

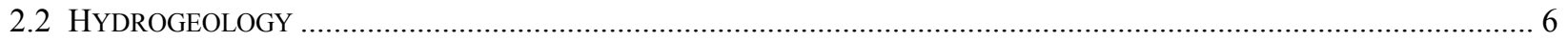

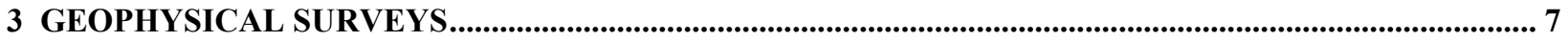

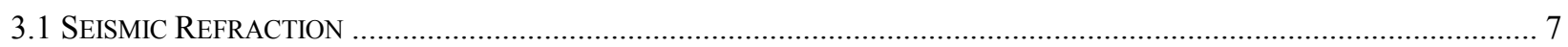

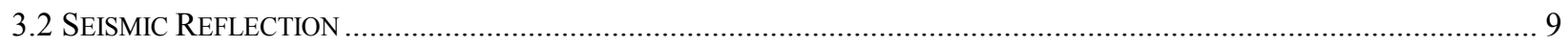

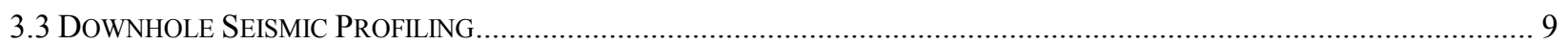

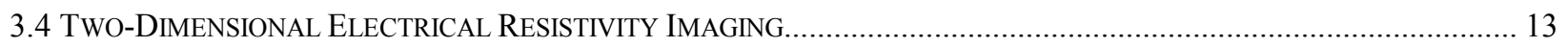

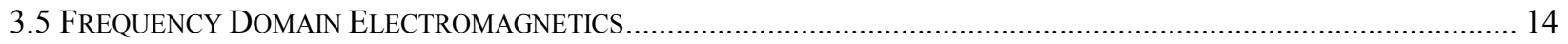

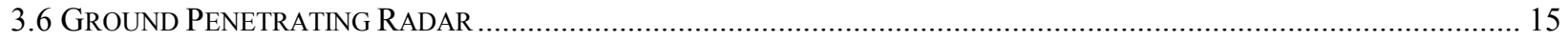

4 GEOPHYSICAL RESULTS .................................................................................................................................. 16

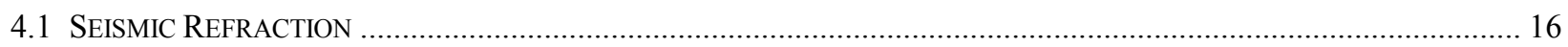

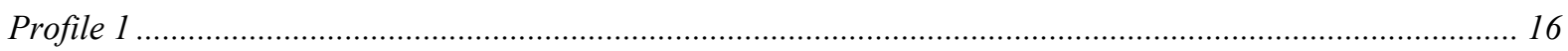

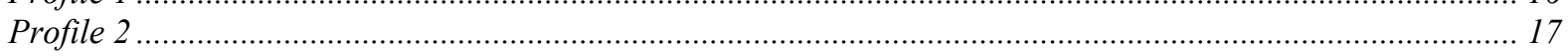

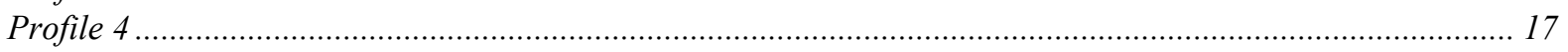

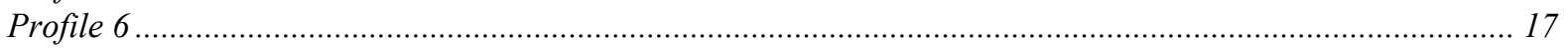

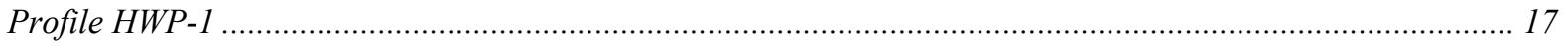

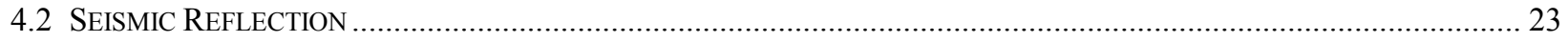

RFL-1 .

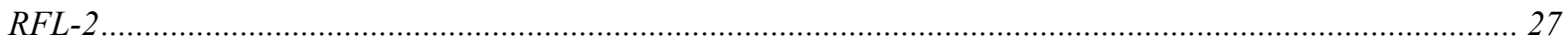

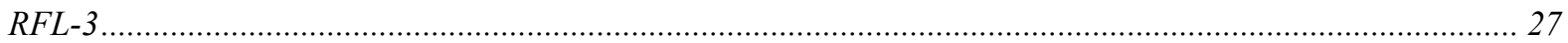

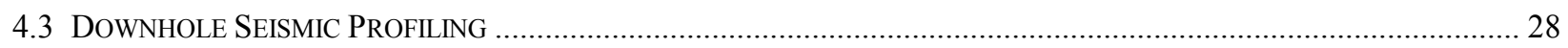

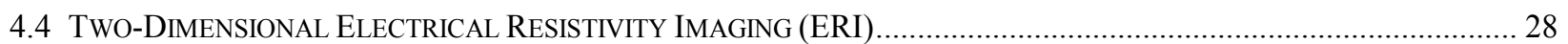

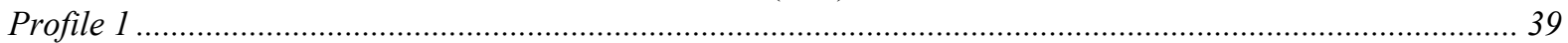

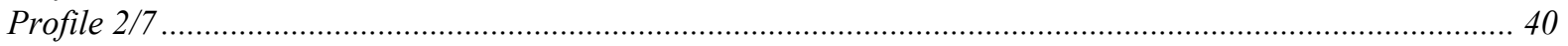

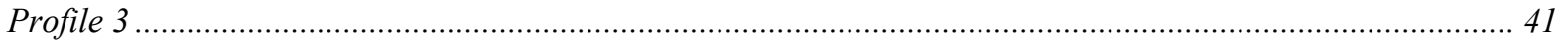

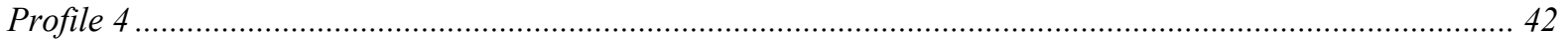

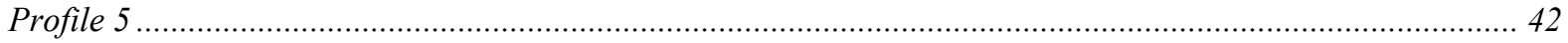

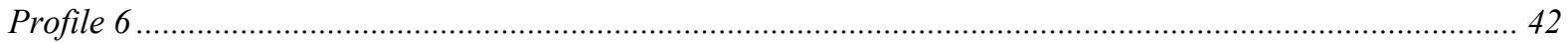

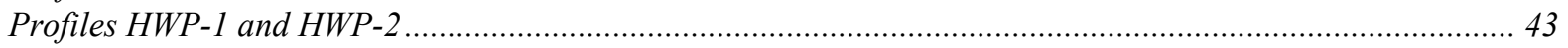

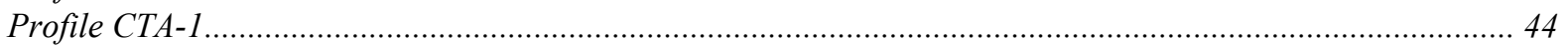

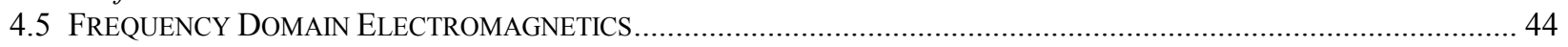

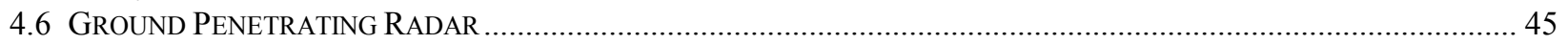

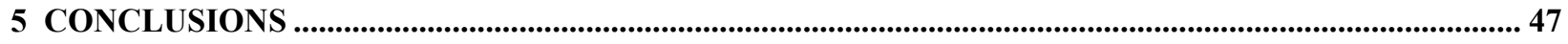

6 RECOMMENDATIONS................................................................................................................................... 50

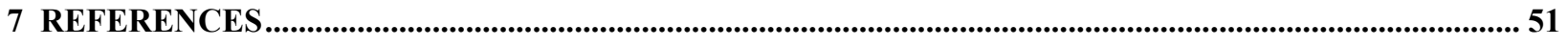

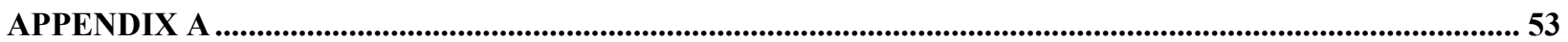




\section{TABLES}

TABLE 1. Regional Bedrock StratigraPhy In the SouthweSt Missouri AREA. .............................................. 5

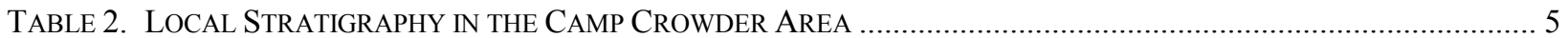

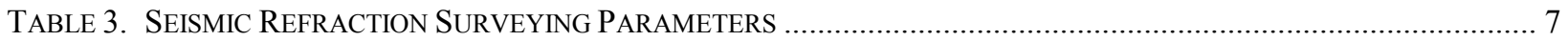

TABLE 4. PROCEDURES USED IN PROCESSING SEISMIC REFLECTION DATA............................................................ 11

TABLE 5. EFFECTIVE PENETRATION DEPTH OF THE EM-34 INSTRUMENT ……...................................................... 15

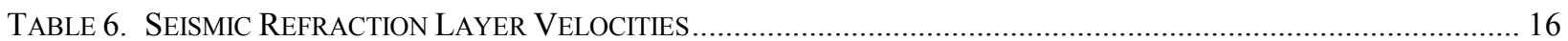

TABLE 7. STACKING VELOCITIES USED IN PROCESSING SEISMIC REFLECTION PROFILE.............................................. 23

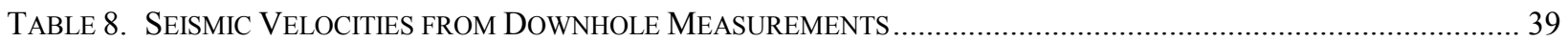

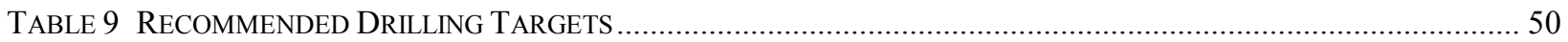

\section{FIGURES}

FIGURE 1 MAP SHOWING THE LOCATION OF CAMP CROWDER ………............................................................... 2

Figure 2 LoCATION OF GEOPHYSICAL PROFILES, Wells, AND AIR-PhOto LinEAMENTS AT CAMP Crowder............. 3

FIGURE 3 BOREHOLE LOCATIONS AND LILTHOLOGY ADJACENT TO PROFILE 1 …....................................................... 8

FiguRE 4 EXAMPLE SEISMIC REFRACTION DATA COLLECTED ON PROFILE 1 ......................................................... 10

FIGURE 5 CONFIGURATION FOR DOWNHOLE SEISMIC VELOCITY LOGGING …....................................................... 12

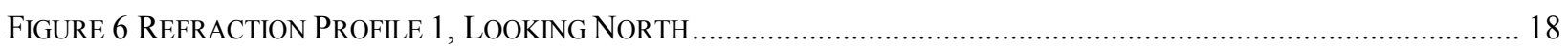

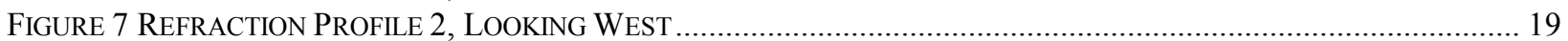

FigURE 8 REFRACTION PROFILE 4, LOOKING TOWARD THE EAST-SOUTHEAST …................................................. 20

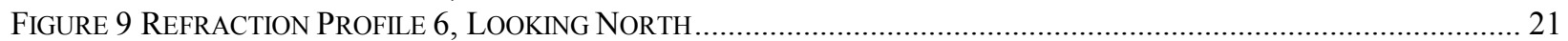

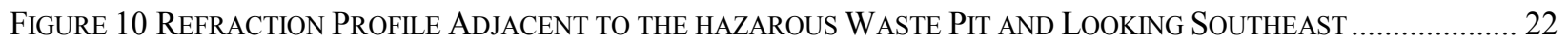

FIGURE 11 SEISMIC REFLECTION PROFILE 1, LOOKING NORTH ........................................................................... 24

FIGURE 12 SEISMIC REFLECTION PROFILE 2, LOOKING SOUTH ........................................................................... 25

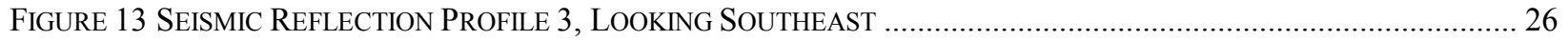

FIGURE 14 RESISTIVITY PROFILE 1, LOOKING NORTH...................................................................................... 29

Figure 15 Western Portion of Resistivity Profile 1 Collected With 12-M-EleCtrode-SePARATION Dipole-

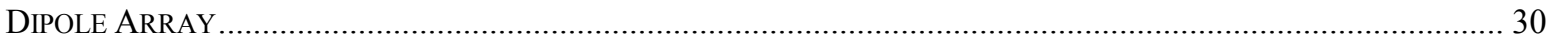

Figure 16 Electrical Resistivity Profile 2, Dipole-Dipole ARRAy at 5-M-EleCtrode SEPARATION ................ 31

FigURE 17 ReSISTIVITY PRofILE 7, 12-M DIPOLE-DIPOLE ARRAY, LOOKING WEST ................................................. 32

Figure 18 Resistivity Profile 3, Dipole-Dipole Array at 12-M-Electrode SeParation, Looking North.... 33

Figure 19 Resistivity Profile 4, Dipole-Dipole ArRay at 12-M-EleCtrode SeParation................................. 34

Figure 20 Resistivity Profile 5, Dipole-Dipole ArRay at 12-M-Electrode SeParation, Looking North.... 35

Figure 21 Resistivity Profile 6, Dipole-Dipole Array at 12-M-Electrode SePARATion, Looking North.... 36

FiguRE 22 Resistivity PRofILES AT THE HAZARdous WASTE PIT...................................................................... 37

Figure 23 Resistivity Profile through CTA Lagoon, Dipole-Dipole ARray WJith 5-M-Electrode Spacing,

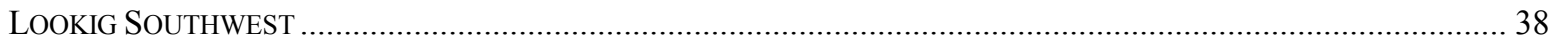

Figure 24 EM-34 Vertical Dipole SuRVEys along Profile 1 at 20-M AND 4-M CoIl SEPARATION..................... 46

Figure 25 Resistivity Profile 1, EM-34, AND NP SURVEY DATA, LOOKING NorTH............................................. 49

FIGURE A1 DOWNHOLE VELOCITY LOGGING FOR WELL IA-MW-1 ..................................................................... 54

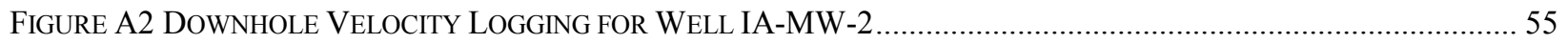

FIGURE A3 DOWNHOLE VELOCITY LOGGING FOR WELL IA-MW-3 …................................................................ 56

FIGURE A4 DOWNHOLE VELOCITY LOGGING FOR WELL IA-MW-4 ..................................................................... 57

Figure A5 DOWNHOLE SEISMIC PROFILE FOR WELL MW-26, 15-FT-SHOT OFFSET …………….......................... 58

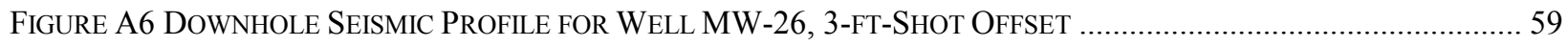

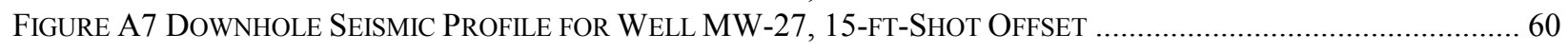




\title{
GEOPHYSICAL INVESTIGATIONS AT THE ETA OF CAMP CROWDER, MISSOURI
}

\author{
by
}

S.F. Miller, M.D. Thompson,

J.M. Cooper, and W. Mandell

\section{INTRODUCTION}

Camp Crowder, which is located south of Neosho, Missouri, is currently a Missouri Army National Guard training facility (Figure 1). The site was established as Camp Crowder during World War II and served as a U.S. Army Signal Corps Replacement Training Center. During the height of the war, Camp Crowder occupied an area of about 43,000 acres, which is much larger than its current dimensions. From 1957 to 1972, a portion of Camp Crowder was operated for the federal government as a rocket and jet engine manufacturing plant and testing area. One testing area was known as the ETA (ETA) and remains a part of Camp Crowder (Figure 2). The other test area was termed the Components Test Area (CTA) and is now privately owned.

Recent site investigations have indicated that contamination is present in both the soil and groundwater at the ETA and the CTA (Rust 1993). Dye tracer studies conducted on and near Camp Crowder show that the site provides groundwater recharge to several nearby springs (Vandike and Brookshire 1996). Photogeologic analysis by Frano (1999) indicates the presence of several lineament sets, which are likely to represent fracture systems in the underlying bedrock.

Argonne National Laboratory (ANL) has been tasked to identify and apply appropriate geophysical techniques that will assist in the development of a more thorough understanding of the complex interrelationships between groundwater flow and geologic structure at the Camp Crowder site. The specific goal of this effort is to locate zones for preferential groundwater and/or contaminant migration. 


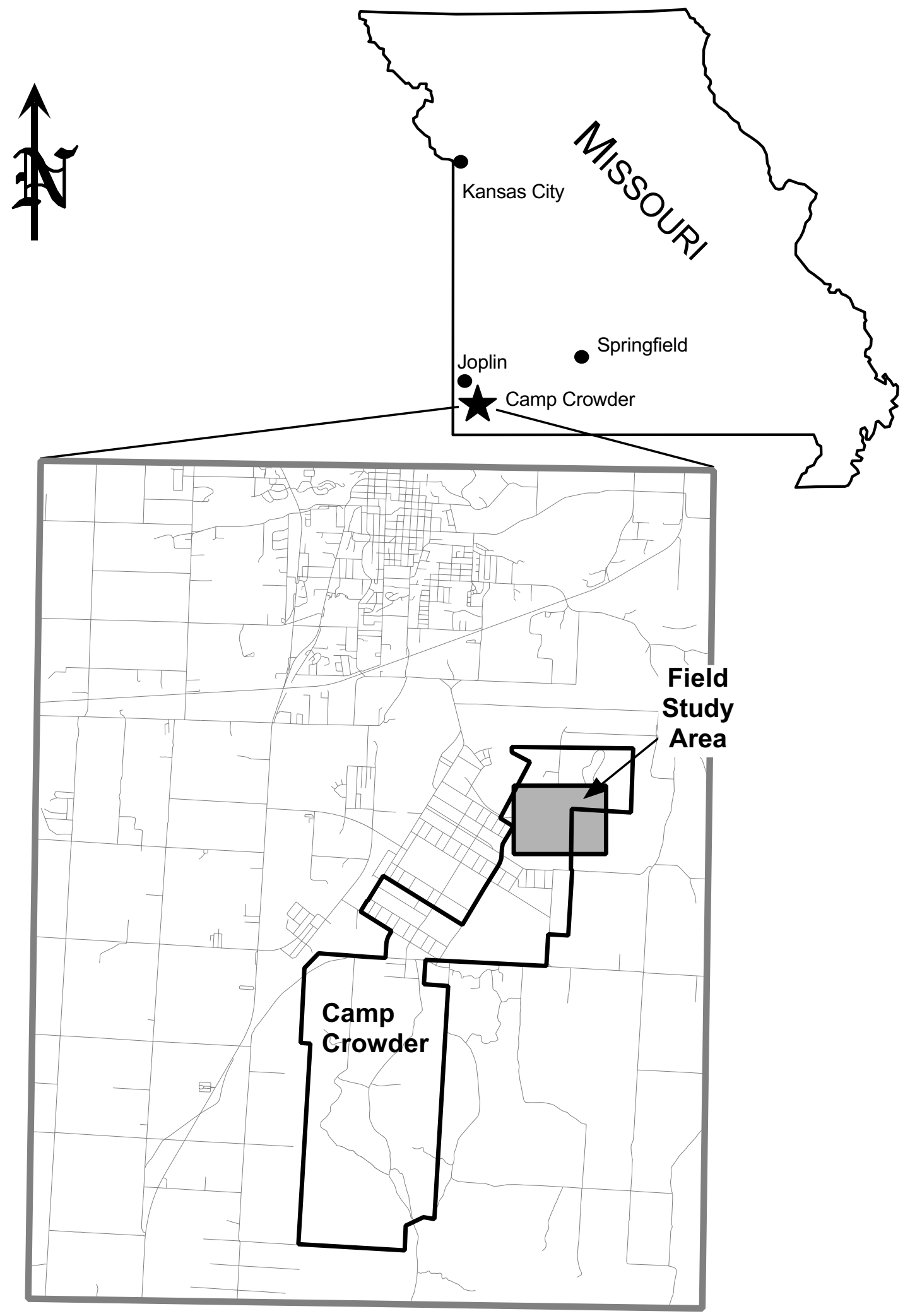

Figure 1. Map Showing the Location of Camp Crowder 


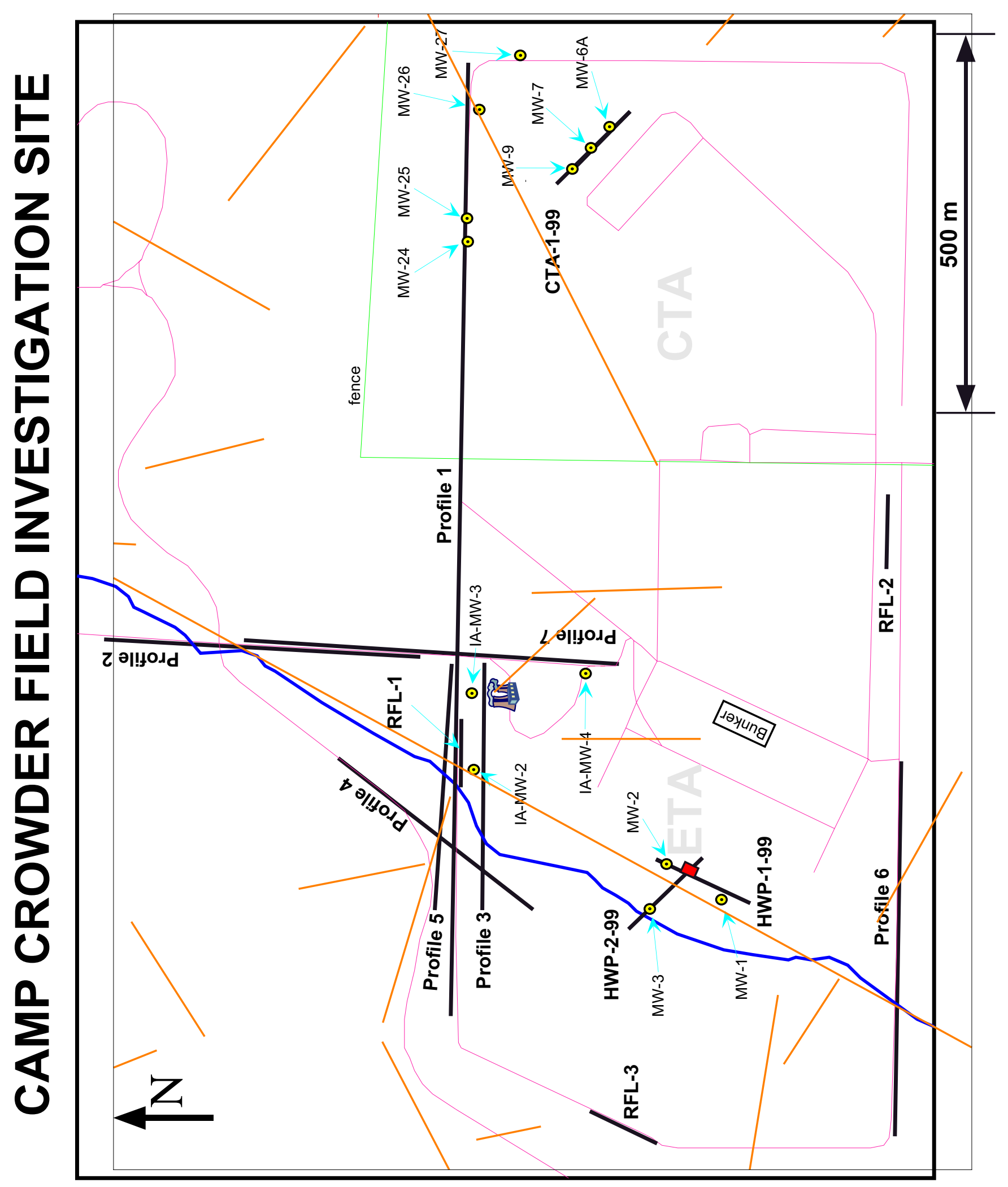

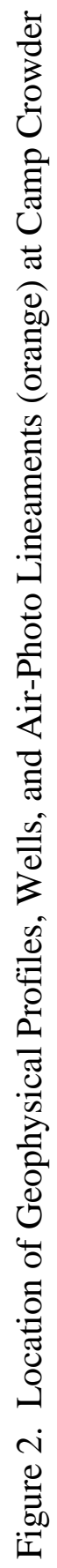




\section{GEOLOGY AND HYDROGEOLOGY}

The following discussion is summarized from Rust Environment and Infrastructure (1993) and Vandyke and Brookshire (1996). Camp Crowder is located in Newton County in southwestern Missouri, within the Springfield Plateau portion of the Ozark Plateau. The Springfield Plateau is an unglaciated, maturely dissected plateau characterized by a gently rolling landscape. Most of Camp Crowder lies on Pool's Prairie, a relatively flat portion of the Springfield Plateau. Karst features are locally prominent in the plateau (Vineyard and Feder 1982).

\subsection{Geology}

The near-surface bedrock underlying southwest Missouri consists of Mississippian-aged limestones and dolomites with a total thickness of 107-122 $\mathrm{m}$ (see Table 1 for the generalized stratigraphy). Underlying the shallower Paleozoic sedimentary strata are Precambrian igneous and metamorphic undifferentiated units. Geologic mapping and examination of well logs by Whitfield (1996) show that the Warsaw Formation overlies the Burlington-Keokuk beneath much of Camp Crowder (Vandyke and Brookshire 1996) and that fracture zones are common within the Warsaw formation. The fracture zones are, in general, mineralized with either calcite or marcasite, or they are filled with clay (Vandyke and Brookshire 1996). The Burlington-Keokuk is estimated to be about $45 \mathrm{~m}(150 \mathrm{ft})$ thick in the area, and the Warsaw is estimated to be about $15 \mathrm{~m}(50 \mathrm{ft})$ thick (see Table 2; Whitfield 1996; Vandyke and Brookshire 1996). Underlying these units are the Mississippian-aged Northview and Compton Formations and the Devonian Chattanooga Shale (see Table 1).

Surficial materials consist of residual material derived from weathering of dolomite or limestone (Vandyke and Brookshire 1996). Lithologic descriptions from recent borings within the ETA show that the overburden sediments consist mainly of silty or sandy clay with or without zones of chert near the surface of each borehole. The upper part of the bedrock is found to be extremely weathered and fractured where wells penetrate into rock. A gradational change from overburden sediment to weathered bedrock then competent bedrock likely exists under Camp Crowder. 
Table 1. Regional Bedrock Stratigraphy in the Southwest Missouri Area*

\begin{tabular}{|c|c|c|c|c|}
\hline & Series & Formation & Characteristics & $\begin{array}{c}\text { Unit } \\
\text { Thickness } \\
(\mathbf{m})\end{array}$ \\
\hline & \multirow[t]{3}{*}{ Maramecian } & Warsaw & $\begin{array}{l}\text { Slightly cherty limestone. Bryozoan and brachiopod } \\
\text { fossils common. }\end{array}$ & $>46$ \\
\hline $\begin{array}{l}\text { M } \\
\text { I } \\
\mathbf{S}\end{array}$ & & Keokuk & $\begin{array}{l}\text { Widespread unit. Medium to coarsely crystalline, } \\
\text { medium bedded limestone with abundant chert nodules. } \\
\text { Contains the Short Creek Member. }\end{array}$ & 30 \\
\hline $\begin{array}{l}\text { S } \\
\text { I } \\
\text { S }\end{array}$ & & Burlington & $\begin{array}{l}\text { Widespread unit. Very coarsely crystalline, } \\
\text { fossiliferous, crinoidal limestone. Layers of chert } \\
\text { nodules }\end{array}$ & 30 \\
\hline $\begin{array}{l}\text { S } \\
\text { I } \\
\mathbf{P}\end{array}$ & \multirow[t]{4}{*}{ Osagean } & Elsey & $\begin{array}{l}\text { Limited to Southwest Missouri. Finely crystalline, gray } \\
\text { limestone with abundant chert nodules in massively } \\
\text { bedded layers. }\end{array}$ & $7-12$ \\
\hline P & & Reeds Spring & $\begin{array}{l}\text { Equal parts of alternating bands of hard, finely } \\
\text { crystalline limestone and nodular, irregularly bedded } \\
\text { chert. Base of formation marked by thin sandy shale. }\end{array}$ & $30-69$ \\
\hline $\mathbf{N}$ & & Pierson & $\begin{array}{l}\text { Lower unit: medium to massively bedded brown } \\
\text { dolomite. Upper unit: medium bedded cherty limestone } \\
\text { and dolomitic limestone. }\end{array}$ & $<17$ \\
\hline $\begin{array}{l}\mathbf{G} \\
\mathbf{E}\end{array}$ & & Northview & $\begin{array}{l}\text { Tan or blue/green siltstone or shale. May be less than } \\
1 \mathrm{~m} \text { thick under Camp Crowder. }\end{array}$ & $<24$ \\
\hline & Kinder-hookian & Compton & Shaly limestone, thinly bedded. & 4 \\
\hline $\begin{array}{l}\text { D } \\
\text { E } \\
\text { V } \\
\mathbf{O} \\
\mathbf{N} \\
\text { I } \\
\text { A } \\
\mathbf{N}\end{array}$ & Late Devonian & Chattanooga & $\begin{array}{l}\text { Black shale, fissile, carbonaceous, slightly arenaceous, } \\
\text { spore-bearing, pyrite nodules common. }\end{array}$ & $3-10$ \\
\hline
\end{tabular}

*After Rust Environment and Infrastructure 1993.

Table 2. Local Stratigraphy in the Camp Crowder Area*

\begin{tabular}{l|c}
\hline \multicolumn{1}{c|}{ Formation } & Thickness (m) \\
\hline Overburden & $0-15$ \\
Warsaw & $\approx 15$ \\
Burlington-Keokuk & 45 \\
\hline
\end{tabular}

*After Whitfield 1996. 


\subsection{Hydrogeology}

Two aquifer systems and a perched water-bearing zone are in this area. The shallow aquifer is found in the upper $90 \mathrm{~m}$ of Mississippian carbonate stratigraphy. The Northview and Compton Formations, together with the underlying Chattanooga Shale, form a thick, confining unit 8-12 m $(25-40 \mathrm{ft})$ between the upper and lower aquifers. On the basis of nearby water-well logs, the Chattanooga Shale occurs at a depth of 107-122 m (350-400 ft) under the ETA. Groundwater exists within the shallow aquifer in solution fractures, collapse features filled with breccia, and porous carbonate zones. (Wilkinson 1998). The perched water-bearing zones are found within the residuum and epikarst, with the upper surface of the competent bedrock apparently acting as an aquitard.

Karst features, such as sinkholes, losing streams, caves, and springs, are observed in the Neosho area, although sinkholes are not common in the immediate area of Camp Crowder. Losing streams are more common and are responsible for significant groundwater recharge (Vandike and Brookshire 1996). Groundwater recharged through sinkholes and losing streams rapidly enters conduit or cave-like feeder systems and is quickly transported to a receiving spring or springs.

Dye tracer studies conducted on and near Camp Crowder show that the site provides groundwater recharge to several springs in Hickory Creek watershed, which is located north and northeast of the site (Vandike and Brookshire 1996). 


\section{GEOPHYSICAL SURVEYS}

During the fall of 1998 and summer of 1999, ANL staff conducted geophysical surveys by using the following techniques: two-dimensional (2D) resistivity imaging, seismic refraction and reflection profiling, frequency domain electromagnetics (EM) surveying, and ground-penetrating radar (GPR) profiling. An elevation survey was also performed for each transect. Geophysical data were collected along six profiles within the ETA and along two profiles within the CTA. The locations of the survey profiles are shown in Figure 2. Three short seismic-reflection profiles were collected in the ETA, and supplemental data were collected by means of downhole seismic profiling in four wells within the ETA and two wells in the CTA. Borehole control for Profile 1 is shown in Figure 3.

\subsection{Seismic Refraction}

Refraction profiles were collected along the survey lines shown in Figure 2. Five refraction profiles were acquired. Profiles 2, 4, 6, and HWP-1-99 were located adjacent to access roads within the ETA, and Profile 1 was collected along the northern boundary road to both the ETA and CTA. Shot-receiver geometries, profile orientation, and length of profile are given in Table 3.

Table 3. Seismic Refraction Surveying Parameters

\begin{tabular}{c|c|c|c|c}
\hline Profile & Spacing $(\mathbf{m})$ & No. of Spreads & Orientation & Length $(\mathbf{m})$ \\
\hline P-1 & 5 & $9(216$ phones $)$ & W-to-E & 1,250 \\
P-2 & 5 & $3(72$ phones $)$ & S-to-N & 360 \\
P-4 & 5 & $1(24$ phones $)$ & NE-SW & 120 \\
P-6 & 5 & $5(120$ phones $)$ & W-to-E & 600 \\
HWP-1 & 5 & $1.5(36$ phones $)$ & NNE-SSW & 180 \\
\hline
\end{tabular}

A Geometrics ES-2401 24-channel seismograph was used to record the seismic refraction information, and a Bison Elastic Wave Generator (EWG) was used as the energy source. Receivers were Geosense 14.5-Hz geophones and were spaced at 5-m intervals along each profile. Reversespread shooting was performed for each refraction line, resulting in one shot point located near the center of the geophone spread, one located at each end, and two located off the ends of the spread at a distance of $60 \mathrm{~m}$ from the end of the profile. Reverse-spread geometries allow mapping of more complex interfaces between layers and allow computing of the true seismic velocity through individual layers.

The processing sequence for the refraction data consisted of the following:

1. Picking first arrival times of return energy for each shot,

2. Plotting time-distance graphs and assigning layer numbers to arrival times, and

3. Inverting the first-arrival information for velocity and depth by using the SIPT algorithm of Scott (1973 and 1977) and RIMROCK Geophysics (1992).

The SIPT method takes advantage of the reverse-spread geometry and far offset shot points of the survey to compute depths to interfaces below each geophone. The algorithm employs the delaytime method of Pakiser and Black (1957) to calculate depth and position of refraction horizons. The 


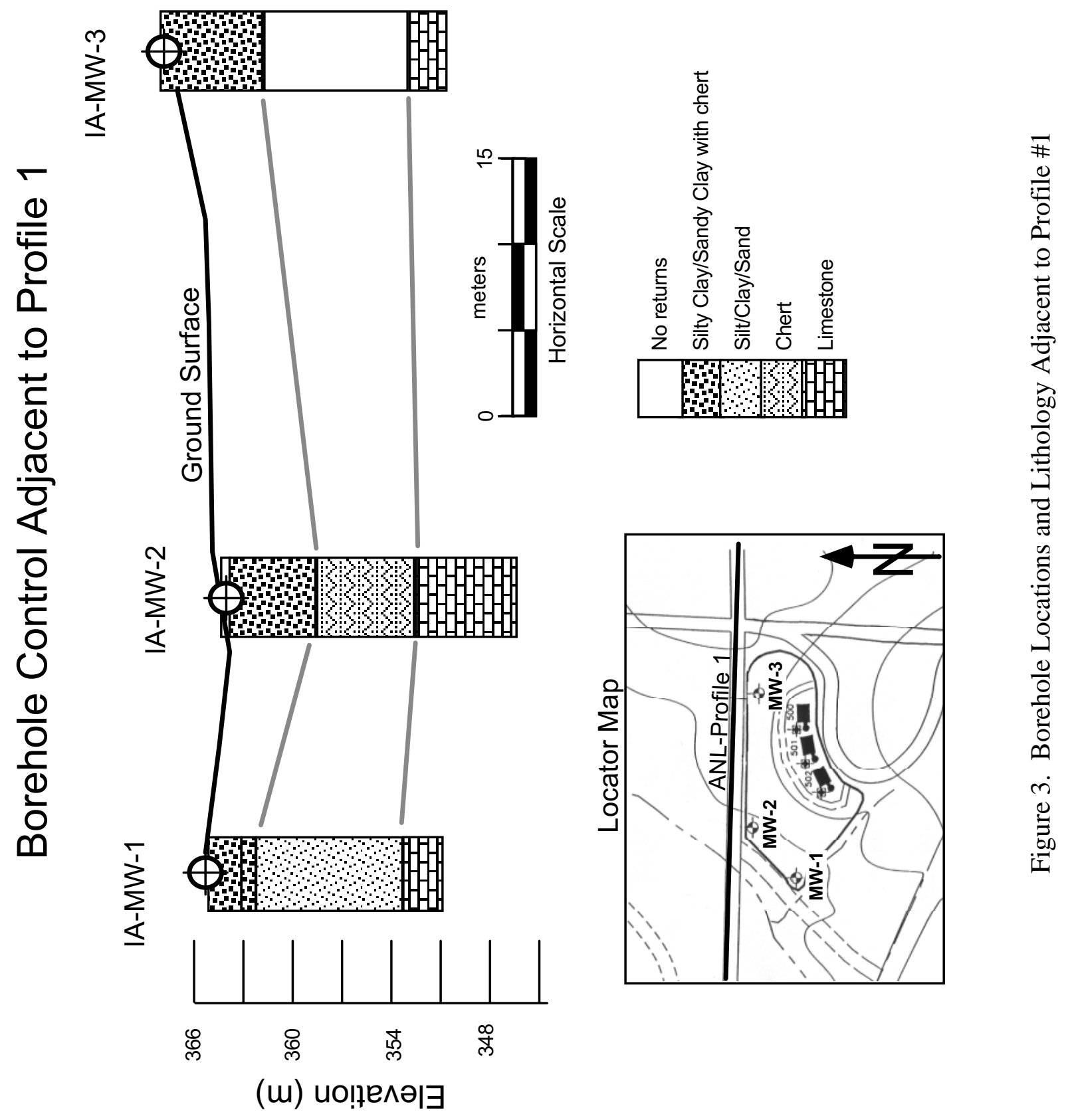


generated refraction model is further refined by using a ray-tracing algorithm, which overcomes difficulties associated with dipping or undulating horizons. Care must be taken when interpreting the generated models as the refractor surfaces may either tail-up or tail-down at the edges of the model.

Examples of seismic refraction data collected along Profile 1 are shown in Figure 4. Refracted arrivals are unmistakable for the central and off end shot locations (middle and left panel). Background noise is more pronounced on the far-off shot (right panel); however, the refracted arrivals are still distinct.

\subsection{Seismic Reflection}

Three short seismic profiles, RFL-1, RFL-2, and RFL-3, were collected within the ETA to ascertain the appropriateness of this method to the problem. Probable targets would be the top of the aquitard formed by the Northview, Compton, and Chattanooga Shale units; lithologic variations in the Warsaw and Burlington-Keokuk Formations; and variations in the depth to bedrock. Line RFL-1 was the initial test profile acquired along geophysical survey Profile \#1 starting at position 1300E and ending near position 1388E. Profile RFL-2 was collected adjacent to the east-to-west access road in the southeast corner of the ETA, and profile RFL-3 was collected on the western boundary road (see Figure 2).

Each profile consisted of one spread of 48 geophones, spaced at 6-ft intervals, with the shot point walked through the spread at a 6-ft spacing. The data were recorded by using the Geometrics ES-2401 24-channel seismograph and Mark Products 60-Hz geophones. A sledgehammer striking a steel plate was used as the energy source. Geophones were planted from 6 in. to $1 \mathrm{ft}$ below ground level to improve coupling with the ground. For each shot point, two field records were acquired in order to construct shot records consisting of 48 channels. Plate-bounce effects were observed on many of the shot records, which resulted in limiting the useful reflection data to approximately 250$300 \mathrm{~ms}$ in record time.

The commercially available software package SEISTRIX (INTERPEX Limited 1993) was used to process the seismic reflection data. Steps used in processing the seismic reflection profile are listed in Table 4. Each step in the process was designed to enhance reflection information while simultaneously decreasing other seismic events, such as ground roll, refracted arrivals, and airwave energy.

\subsection{Downhole Seismic Profiling}

Downhole seismic surveys (check shot) were used to measure, in-situ, the velocity of the sediment and rock underlying Camp Crowder. These data provides confirmatory velocity information for the refraction models and help guide the velocity modeling of the reflection data. Four boreholes, IA-MW-1 through IA-MW-4, were entered in the ETA, and two boreholes, MW-26 and MW-27, were surveyed in the CTA. An ongoing dye-trace experiment precluded collecting additional downhole seismic data in the CTA. For wells IA-MW-1 through IA-MW-4, two sets of downhole data were collected: one with the shot point $2 \mathrm{ft}$ from the borehole and the second with the shot $15 \mathrm{ft}$ from the borehole. For well MW-26, shot points were placed $3 \mathrm{ft}$ and $15 \mathrm{ft}$ from the borehole; for well MW-27, only a 15-ft-shot offset was used. 


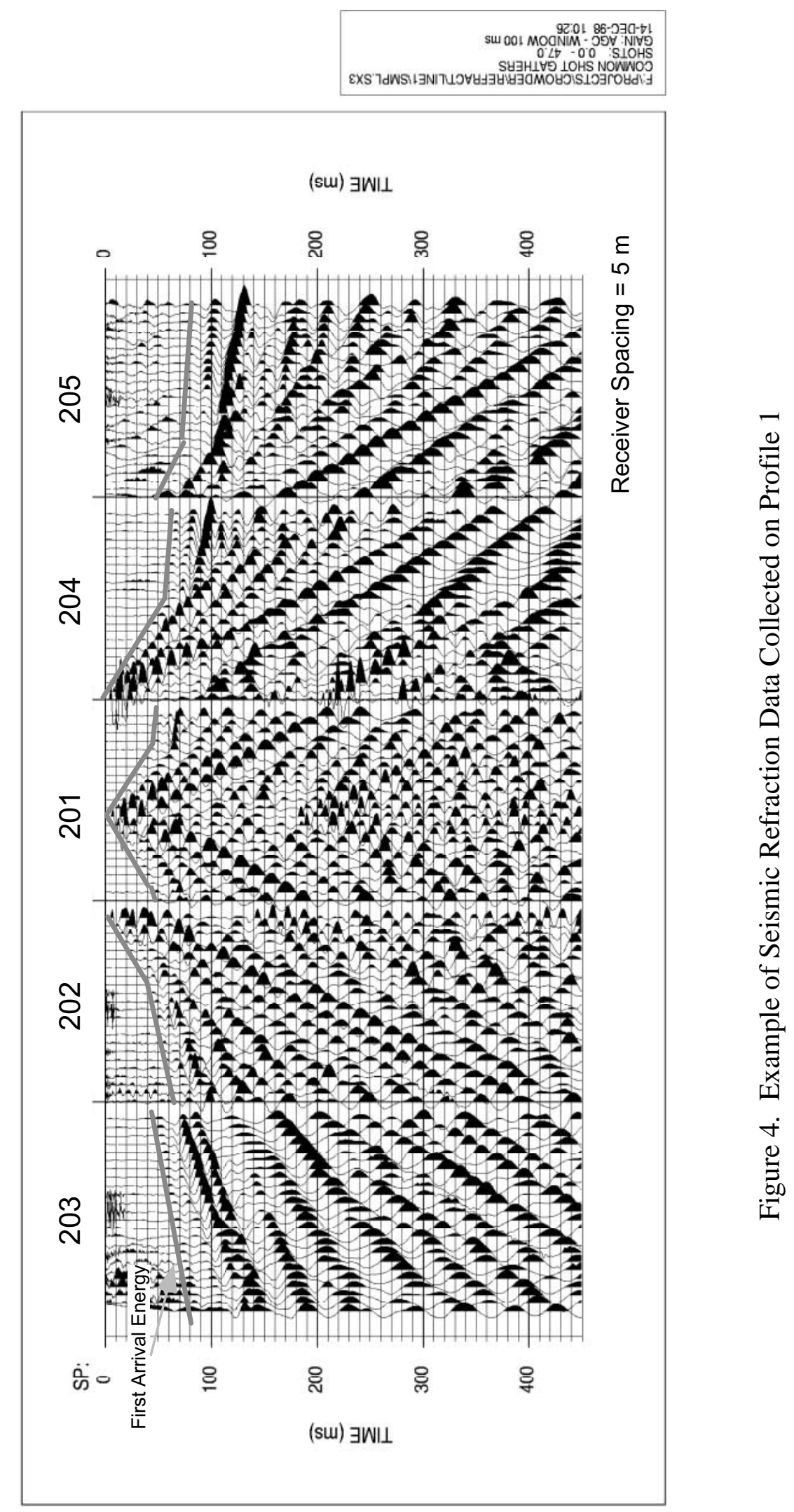


Table 4. Procedures Used in Processing Seismic Reflection Data

\begin{tabular}{|c|c|c|}
\hline Step & Process & Purpose \\
\hline 1 & Import Field Records & \\
\hline 2 & Sort Data & Define spread geometry and offsets. \\
\hline 3 & Trace Edit & Remove bad traces \\
\hline 4 & Spectral Balance & $\begin{array}{l}\text { Balance amplitude spectrum of data within } \\
\text { frequency range of } 40-300 \mathrm{~Hz} \text {. }\end{array}$ \\
\hline 5 & $\begin{array}{l}\text { Bandpass Filtering } \\
\text { (Butterworth) }\end{array}$ & $\begin{array}{l}\text { Enhance signals within frequency range of } 65- \\
200 \mathrm{~Hz}\end{array}$ \\
\hline 6 & Trace Gain & Apply a $65-m s$ windowed AGC gain function \\
\hline 7 & Mute First Breaks & Remove refraction information \\
\hline 8 & Surgical Mute & Mute air-coupled wave and ground roll \\
\hline 9 & Datum Statics & Account for topographic variations \\
\hline 10 & Normal Moveout & $\begin{array}{l}\text { Stretches the time axis as a function of offset } \\
\text { distance in order to shift a reflection event to the } \\
\text { position where it would occur if the source offset } \\
\text { distance was zero }\end{array}$ \\
\hline 11 & $\begin{array}{l}\text { CMP (Common Mid-Point)- } \\
\text { Consistent Residual Statics }\end{array}$ & $\begin{array}{l}\text { Correct for near-surface abnormalities not } \\
\text { corrected by datum statics; maximum time shift } \\
\text { of } 4 \mathrm{~ms} \text { allowed }\end{array}$ \\
\hline 12 & CMP Stack & $\begin{array}{l}\text { Sum the CMP gathers into a stacked seismic } \\
\text { section; maximum of } 24 \text {-fold stack produced }\end{array}$ \\
\hline
\end{tabular}

The general configuration for recording the downhole seismic data is shown in Figure 5. A GeoStuff, BH-G2, three-component geophone, implementing 40-Hz receiver elements, was used to record the downhole data. The downhole geophone was moved up or down the borehole at 5-ft intervals. A sledgehammer was used as the energy source and was placed at offsets up to $15 \mathrm{ft}$ from the borehole. Three additional geophones were placed on the surface at offsets of 5, 10, and $15 \mathrm{ft}$ from the borehole and were required to resolve any shot-timing variations that occur when using impact sources. Data were recorded at a $0.1-\mathrm{ms}$ interval (10,000 samples per second) by using the Geometrics ES-2401 engineering seismograph. This fast rate of sampling was required so that changes in arrival time as brief as $0.3-0.4 \mathrm{~ms}$ could be detected. The brief arrival time changes are due to the presence of fast-velocity limestones and dolomites.

Data processing consisted of the following tasks:

1. Pick first arrival energy at the downhole and reference geophones.

2. Sort the arrival-time data by depth point.

3. Compute and apply shot-timing variation corrections by using the reference geophones.

4. Compute the average velocity to a receiver station by using the straight-line distance from the shot to the receiver and the corrected arrival time.

5. Convert to vertical travel time by using the depth point for the receiver and the computed average velocities.

6. Compute interval velocities by using a least-squares line-fitting algorithm to estimate the slope (inverse of velocity) between measurement points. The least-squares operator has the advantage of smoothing over small time-picking errors. 


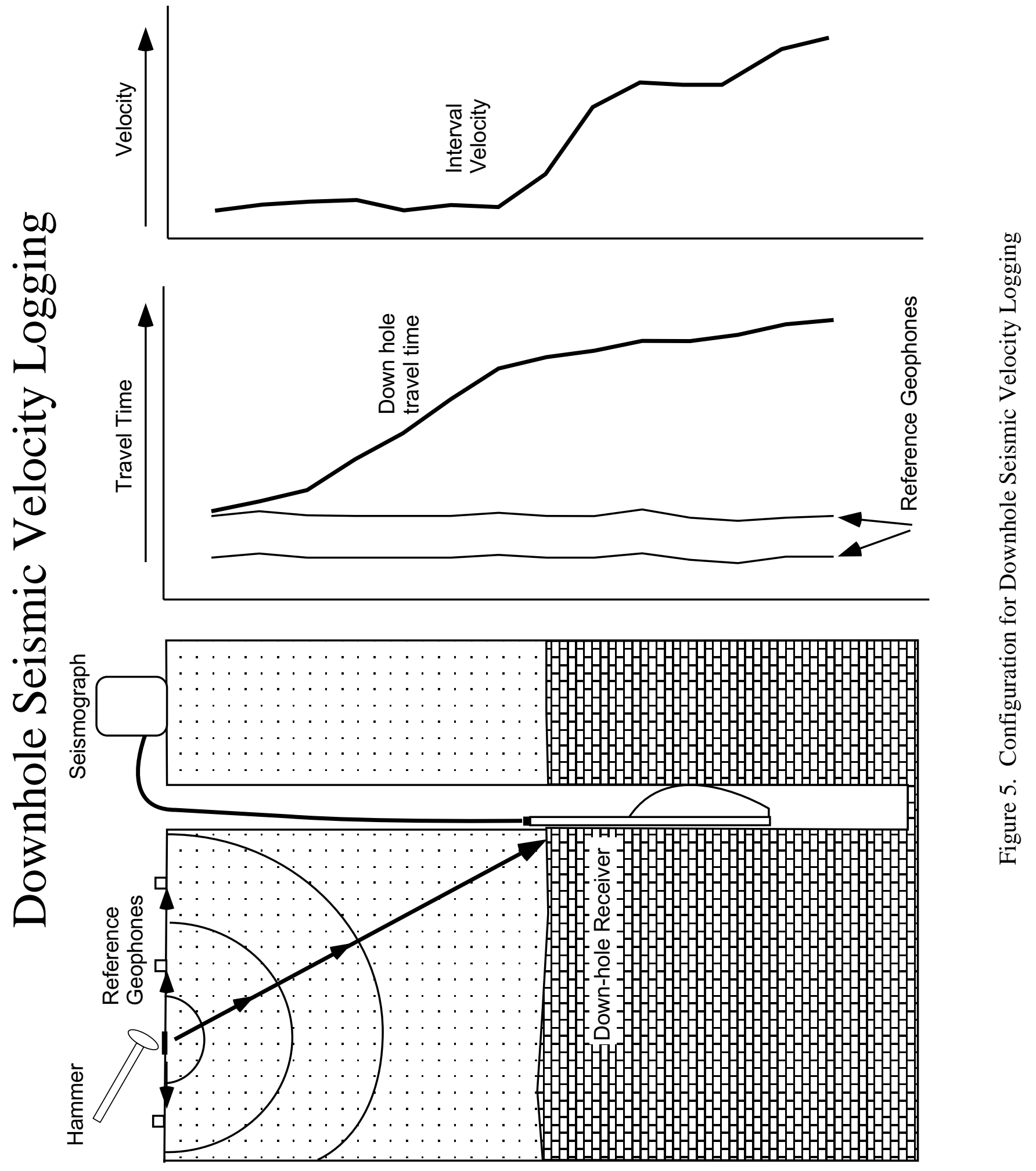


The results from the downhole seismic analysis are presented in Appendix A as plots of the raw first-arrival data, the corrected arrival times, and the resulting average and interval velocities versus borehole depth. Where available, the data are correlated with the lithologic log from the borehole.

\subsection{Two-Dimensional Electrical Resistivity Imaging}

Two-dimensional (2-D) electrical resistivity imaging (ERI) was conducted by using an Advanced Geosciences, Inc. (AGI), Sting/Swift ${ }^{\mathrm{TM}}$ automatic multi-electrode system and earth resistivity meter. ERI surveys were conducted along 10 profiles (Figure 2). Profiles 2, 3, 4, 5, and 7 were collected in the northern part of the ETA (adjacent to the incinerator buildings), profiles HWP1 and HWP-2 were collected adjacent to the hazardous waste disposal pit, Profile 6 was collected along the south boundary road to the ETA, and profile CTA-1-99 was collected across the primary lagoon in the CTA. Profile 1 was recorded along the northern boundary road of the ETA and CTA.

Earth resistivity measurements are accomplished by passing an electric current between two electrodes and measuring the potential difference (voltage) between two separate electrodes. The measured voltage is a factor of the resistance of earth materials and the geometry of the electrode array from which a value termed the "apparent resistivity" can be calculated. Apparent resistivity is not generally equivalent to "true earth-layer" resistivities, except for the homogenous subsurface case. Instead, the measured apparent resistivity reflects inhomogeneities in the earth materials (natural or induced) and/or changes in earth layers that are encountered by the electric current. ERI surveys take advantage of this by attempting to simultaneously map lateral and vertical electrical variations within the subsurface.

The electrodes used to measure the voltage difference are arranged in various geometries called arrays, and the calculated apparent resistivity value is interpreted to represent the center of an individual array. Depth of measurement can be related to width of electrode separation, with greater separations resulting in greater depths of penetration. Classically, two different techniques are used to determine the electrical resistivity of earth materials. In vertical electrical sounding (VES), electrodes are expanded about the center of an array to generate a layered electrical section at a single point. The horizontal profiling technique uses a fixed electrode separation, and the entire array is marched along a line to image lateral variations at a constant depth.

Two-dimensional ERI combines VES and lateral profiling in a single survey without the timeconsuming process of constantly moving electrodes and reconnecting cables. In 2-D ERI, a single cable connects a line of many electrodes ( 28 to 56 in this study) with on/off switches located at each electrode takeout. Command files control switch positions in programmed sequences, automatically expanding or shifting the array to gain maximum depth of penetration and lateral coverage. The raw data set is typically displayed as an apparent resistivity pseudosection.

Data processing was performed by using the RES2DINV software, which converts the measured apparent resistivity pseudosection into a 2-D resistivity-depth model through a process called inversion (Loke 1996 and 1998). During the inversion, the subsurface is divided into a

\footnotetext{
${ }^{1}$ Advanced Geosciences, Inc., 1997, Sting R1 Instruction Manual, release 2.5.5, Advanced Geosciences, Inc., Austin, Texas, 82 pp.
} 
number of blocks equal to or less than the number of measurement points. A smoothnessconstrained, least-squares inversion routine is used to estimate the resistivity value of each block, and finite-element or finite-difference forward modeling is used to calculate the resulting pseudosection. The model is iteratively corrected until an apparent resistivity pseudosection calculated from the model converges with the measured apparent resistivity pseudosection. The difference between the two apparent resistivity pseudosections is measured as a root-mean-square (RMS) error. Maximum convergence often occurs within 3 to 5 iterations, after which RMS values do not change significantly, and the model may start to become unstable (Loke 1996 and 1998).

For these data, a least-squares inversion routine with a convergence limit of $5 \%$ was run to a maximum of five iterations. Prior to inversion, the apparent resistivity data were manually edited to remove "bad" data points and the interference effects from cultural features, such as metal culverts, which produce characteristic "bow-tie" patterns in the unprocessed data. Topographic data were appended to raw data files prior to inversion. No smoothing filters were applied to these data. To help improve data quality, contact resistance checks were conducted prior to measurement, and those electrode positions that exhibited high resistance values ( $>1$ kilo-ohm) were soaked with a saltwater solution to enhance electrode/earth coupling.

\subsection{Frequency Domain Electromagnetics}

The Geonics EM-34 electrical-conductivity (terrain-conductivity) meter was used to measure variations in terrain conductivity along Profile 1. Both 20- and 40-m vertical dipole surveys were conducted by using the Argonne-designed mobile backpack and the EM-34's automatic collection mode. Data were collected at approximately one sample per meter, and fiducial marker points were recorded at $100-\mathrm{m}$ intervals to help mitigate measurement point location errors due to uneven walking speeds.

Conductivity values obtained during frequency domain electromagnetic (FEM) surveys represent weighted mean values of all the layer conductivities from the ground surface to the maximum depth that are sensed by the EM instrument (McNeill 1980a and 1980b). If the underlying rock or sediment is uniform, the measured conductivity value will be the true conductivity. At sites where electrically conductive pore fluids are present, the specific conductance of the pore fluid will dominate the measurement. The amount of contribution to the measured conductivity from a single layer depends on its conductivity, depth, and thickness. Deeper layers contribute less to the final weighted-value than do near-surface layers (McNeill 1990).

Table 5 lists the depth of investigation for different coil orientations and separations for the Geonics EM34. The "Maximum Depth" is roughly the depth at which $90 \%$ of the instrument response has occurred $(0.75 \times$ horizontal coil spacing; $1.5 \times$ vertical coil spacing). The "Effective Depth" is the depth range where the instrument's overall response is the greatest. Thus, layers within the "Effective Depth" range contribute the most to the measured conductivity value.

\footnotetext{
${ }^{2}$ Geonics Limited, 1991, EM34 Operating Manual, Mississauga, Ontario Canada.
} 
Table 5. Effective Penetration Depth of the EM-34 Instrument

\begin{tabular}{clcc}
\hline Instrument & Coil Orientation & Maximum Depth $(\mathbf{m})$ & Effective Depth $(\mathbf{m})$ \\
\hline EM-34 $(20 \mathrm{~m})$ & Horizontal Dipole & 7.5 & $0-6.5$ \\
& Vertical Dipole & 15 & $1.5-8.0$ \\
EM-34 $(40 \mathrm{~m})$ & Horizontal Dipole & 15 & $0-12.5$ \\
& Vertical Dipole & 30 & $3-16$ \\
\hline
\end{tabular}

\subsection{Ground-Penetrating Radar}

Ground-penetrating radar surveying and data processing were accomplished by using Geophysical Survey Systems, Inc., Radan III software (1992) and a model SIR-2 radar connected to a transceiver with a cable approximately $100 \mathrm{~m}$ long. Data from the SIR-2 system were downloaded directly to the personal computer. The control unit/thermal printer was located in the transport vehicle. A computer was located in a field office, so that the radar operator could download, check data quality, and do preliminary processing after a day's run.

Ground-penetrating radar profiles were collected along survey profile \#1 and around the hazardous waste pits by using $100-\mathrm{MHz}$ antennae in a bistatic configuration. 


\section{GEOPHYSICAL RESULTS}

The geophysical data are presented as either cross-sectional images of the near surface or as profile plots of the acquired data. To aid the reader, specific features discussed will be indicated by the profile coordinate system used for each figure. For example, a value of $440 \mathrm{X}$ will represent a feature at profile coordinate $440 \mathrm{~m}$. 4.1 Seismic Refraction

Seismic refraction models generated for each line are shown in Figures 6-10. The SIPT modeling algorithm used for processing the refraction data may produce artifacts at the edges of the refraction models. These artifacts appear either tailing up or tailing down the refractor horizon, and apparent bedrock highs and lows may occur where adjacent refraction spreads abut. The interpretations given below will point out these artifacts when appropriate.

For each profile, a three-layer solution was required to model the refraction data, with individual layers interpreted as follows: Layer 1, dry-unconsolidated fill and/or quaternary sediment; Layer 2, wet or dry unconsolidated sediment; and Layer 3, either competent or weathered limestone or dolomitic bedrock. The range of velocities for Layer 3, 2,812-5,544 m/s, is consistent with published seismic velocities $(2,700-6,400 \mathrm{~m} / \mathrm{s})$ for hard limestone or dolomite (Waters 1981). Seismic velocities of layers 1 and 2 are consistent with those published for wet and dry unconsolidated sediments (Waters 1981), and thus layers 1 and 2 are interpreted as either overburden and/or residuum sediment. Table 6 lists the resulting velocities determined for each profile by layer.

Table 6. Seismic Refraction Layer Velocities

\begin{tabular}{c|r|r|r}
\hline & \multicolumn{3}{|c}{ Velocity (m/s) } \\
\cline { 2 - 4 } Seismic Line & Layer 1 & Layer 2 & Layer 3 \\
\hline Profile 1 & $383-570$ & $926-1339$ & $3670-5478$ \\
Profile 2 & $406-549$ & $1339-1416$ & $4985-5544$ \\
Profile 4 & 421 & 1037 & 4807 \\
Profile 6 & $490-605$ & $885-1365$ & $2812-4818$ \\
HWP-1 & 619 & 915 & 4926 \\
\hline
\end{tabular}

\section{Profile 1}

Profile 1 was acquired along the north boundary road to the ETA/CTA, and the resulting seismic refraction model is shown in Figure 6. Also shown on Figure 6 are the positions of wells adjacent to the profile, as well as the top-of-rock indicated from the drilling logs. There is a fair degree of correlation between the elevation of the bedrock surface determined from the drilling versus that from the refraction model. The bedrock surface is relatively flat in the western half of the profile and averages approximately $346 \mathrm{~m}$ in elevation. Minor undulations of 3-10 m are evident, as is a pinnacle feature near $1800 \mathbf{X}$, which rises to $360 \mathrm{~m}$ in elevation. Toward the east, the bedrock surface rises from an elevation of approximately $350 \mathrm{~m}$ to about $360 \mathrm{~m}$ at the eastern end of the profile. Because the bedrock surface is relatively flat, the thickness of the overburden is greatest under the topographic highs $(\approx 40 \mathrm{~m})$ and thins to $2-15 \mathrm{~m}$ in the valley lows. 
Note that from the seismic refraction perspective, the overburden (Layer 2) may include a substantial thickness of weathered bedrock, and thus the interpreted bedrock surface shown is most likely the top-of-competent rock (base of the weathering horizon). Wells MW-24 and MW-25 support this assumption as both penetrate through heavily weathered and fractured rock. Well MW-25 penetrates competent bedrock at a depth consistent with that determined by the seismic refraction model.

\section{Profile 2}

Profile 2 was collected along the north-south access road that bisects the ETA, and the resulting velocity-depth model is shown in Figure 7. As with Profile 1, the bedrock surface appears to be relatively flat and averages $344 \mathrm{~m}$ in elevation. Minor undulations of 3-4 m are observed in the southern two-thirds of the profile, and a bedrock-high is observed near the northern end between $260 X$ and $325 X$.

\section{Profile 4}

The refraction data for Profile 4 (Figure 8) consists of a single spread of 24 geophones (120 m) along the northern one-third of the associated resistivity profile. Inclement weather shortened the allotted survey collection time. The interpreted bedrock surface is flat with only 1-2 $\mathrm{m}$ of relief and averages $350 \mathrm{~m}$ in elevation.

\section{Profile 6}

Figure 9 shows the velocity-depth model obtained for Profile 6, which is located along the southern boundary road to the ETA (see Figure 2). The top of competent bedrock is interpreted to average $355 \mathrm{~m}$ in elevation and shows local topographic changes of up to $10 \mathrm{~m}$ in relief. Two bedrock lows were imaged by the refraction data, one at $1490 \mathrm{X}$ and the other at $1200 \mathrm{X}$. Another apparent low near $1100 \mathbf{X}$ may be a processing artifact because it is manifested as a refractor tailing down at the edge of the left-most refraction model. The topographic high at the western end of the profile is also interpreted as a processing artifact.

\section{Profile HWP-1}

Profile HWP-1 (Figure 10) crosses NE-SW through the hazardous waste pit in the central part of the ETA (see Figure 2). The interpreted bedrock surface slopes gently to the southwest, deepening from approximately $15 \mathrm{~m}$ below ground level on the northeast end to $23 \mathrm{~m}$ below ground level at the southwest end. Small-scale undulations on this surface are modeled between $210 \mathbf{X}$ and 260X. Depth to bedrock determined from wells MW-01 and MW-02 (shown as horizontal bars on Figure 10) is shallower than that determined by using the refraction method. Examination of the lithologic descriptions for both these wells indicates that the upper part of the bedrock was heavily fractured with numerous voids (note this is similar to wells MW-24 and MW-25 in the CTA along Profile 1). Competent rock was encountered at $14 \mathrm{~m}$ for Well MW-02 and approximately $16 \mathrm{~m}$ for Well MW-01. These latter two depths are closer to what the seismic data are predicting, and thus it is argued that the seismic refraction data are imaging a more competent bedrock horizon, which is located below the weathered zone first encountered by the wells. Alternately, an unaccounted for "hidden layer" or low-velocity zone would cause an increase in travel time and result in a deeper refracting layer. 


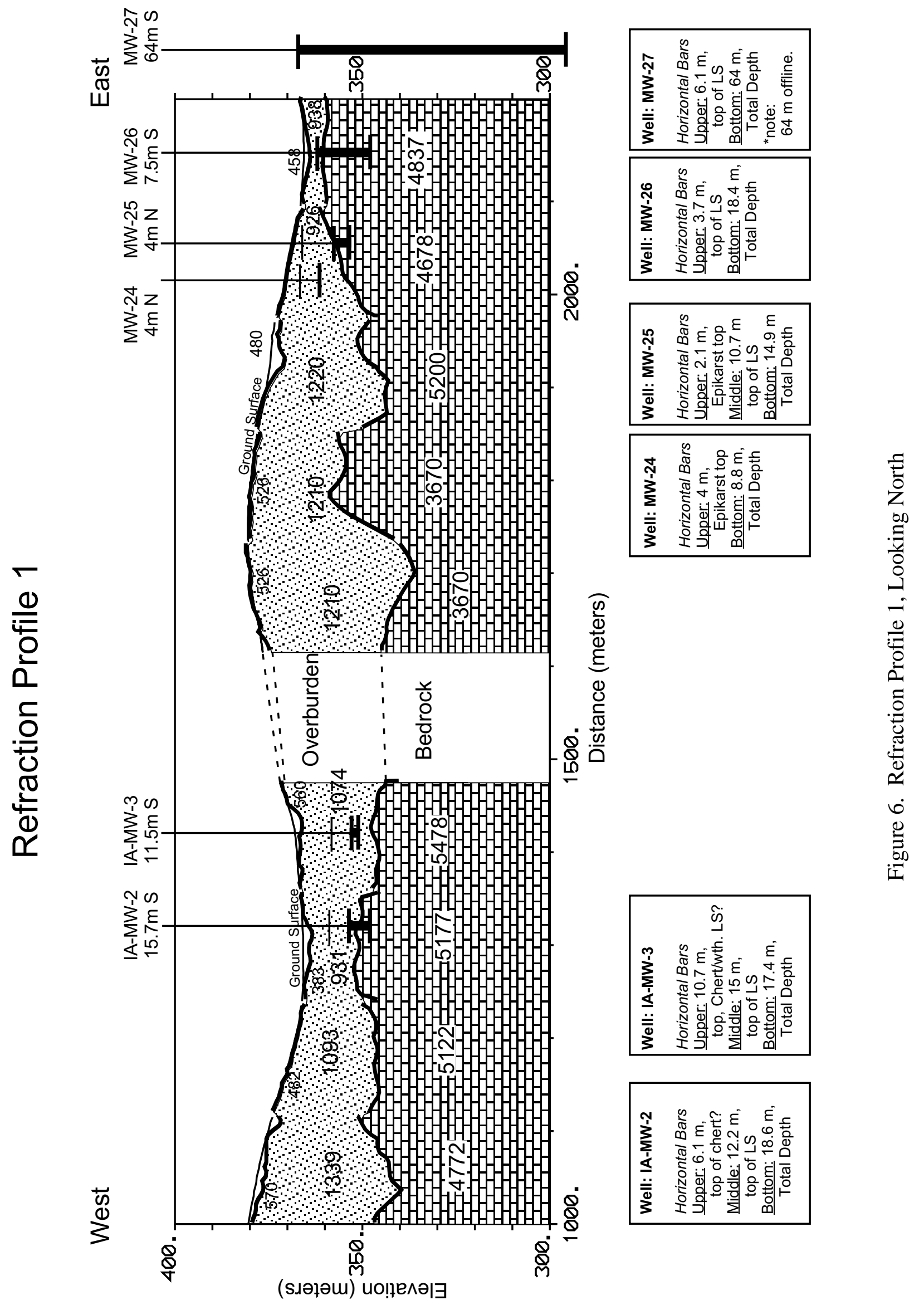




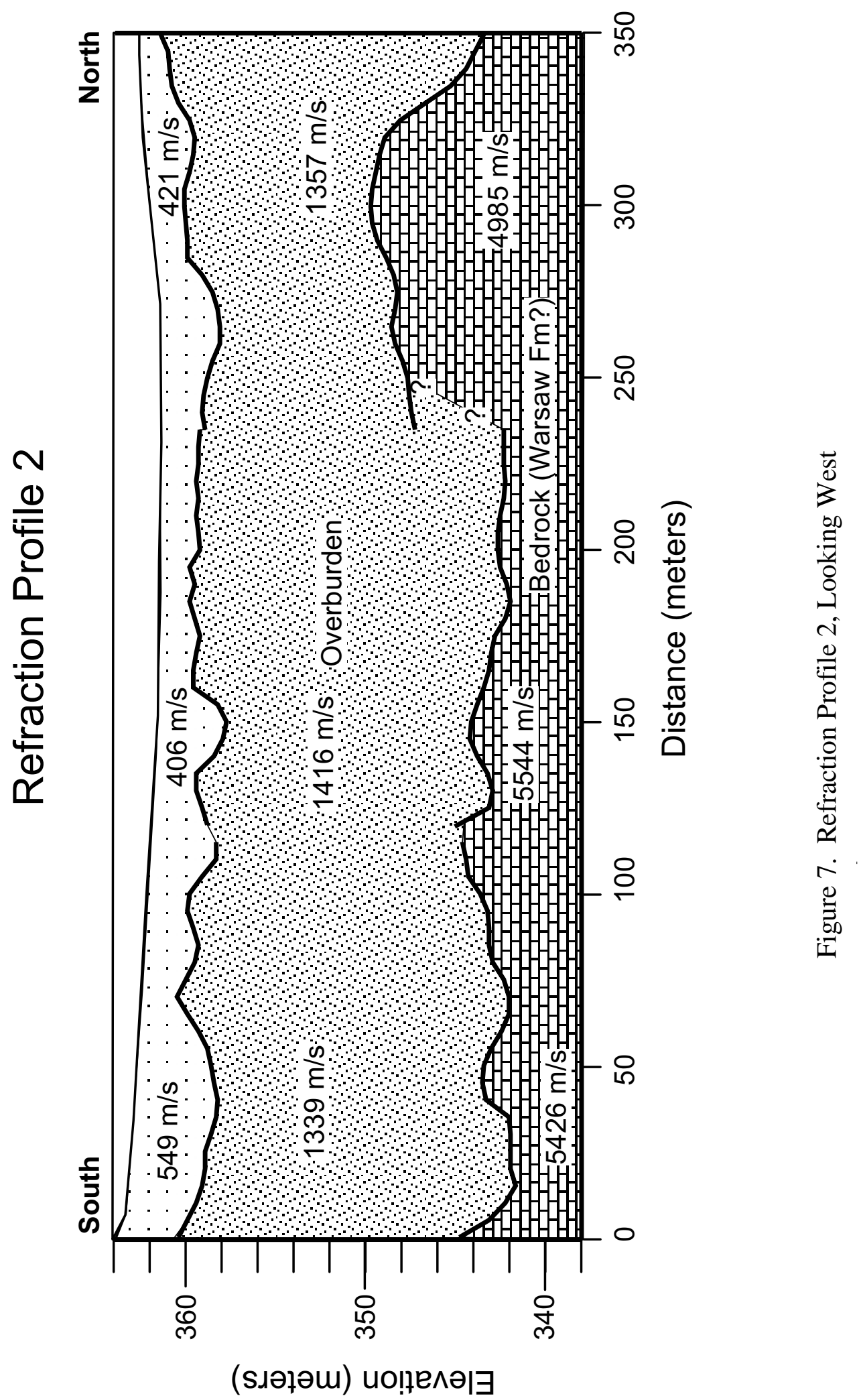




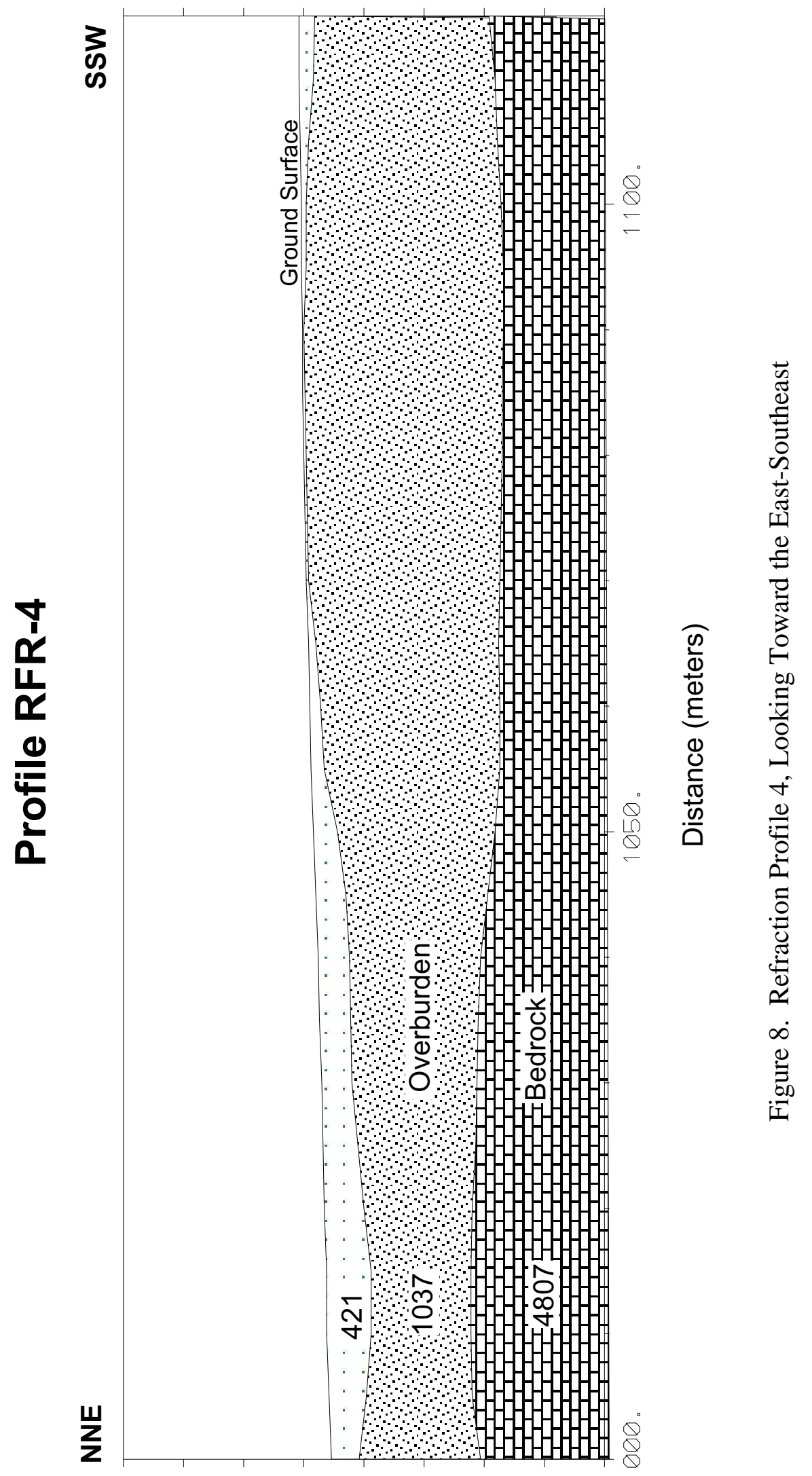

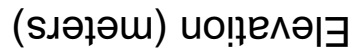




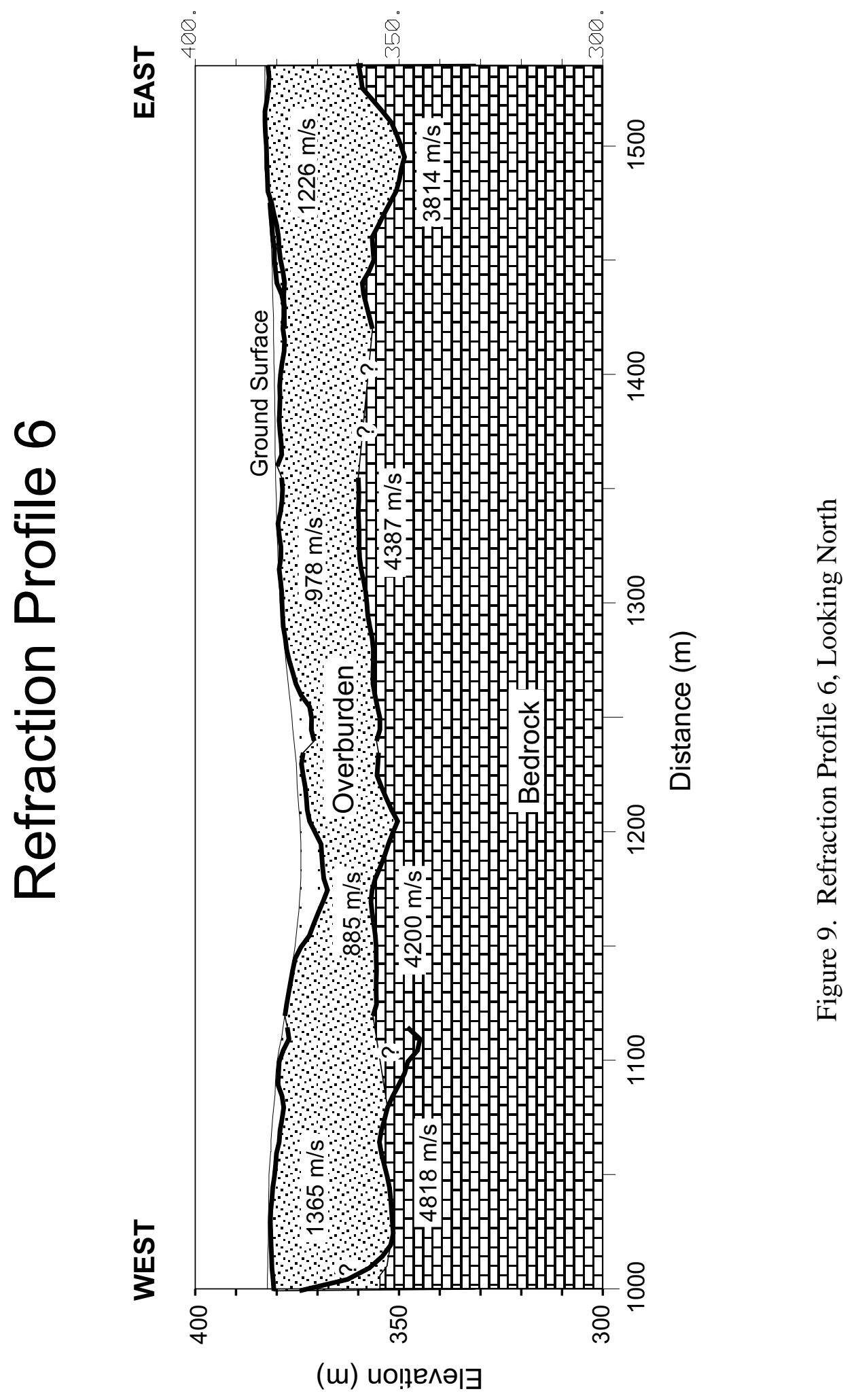




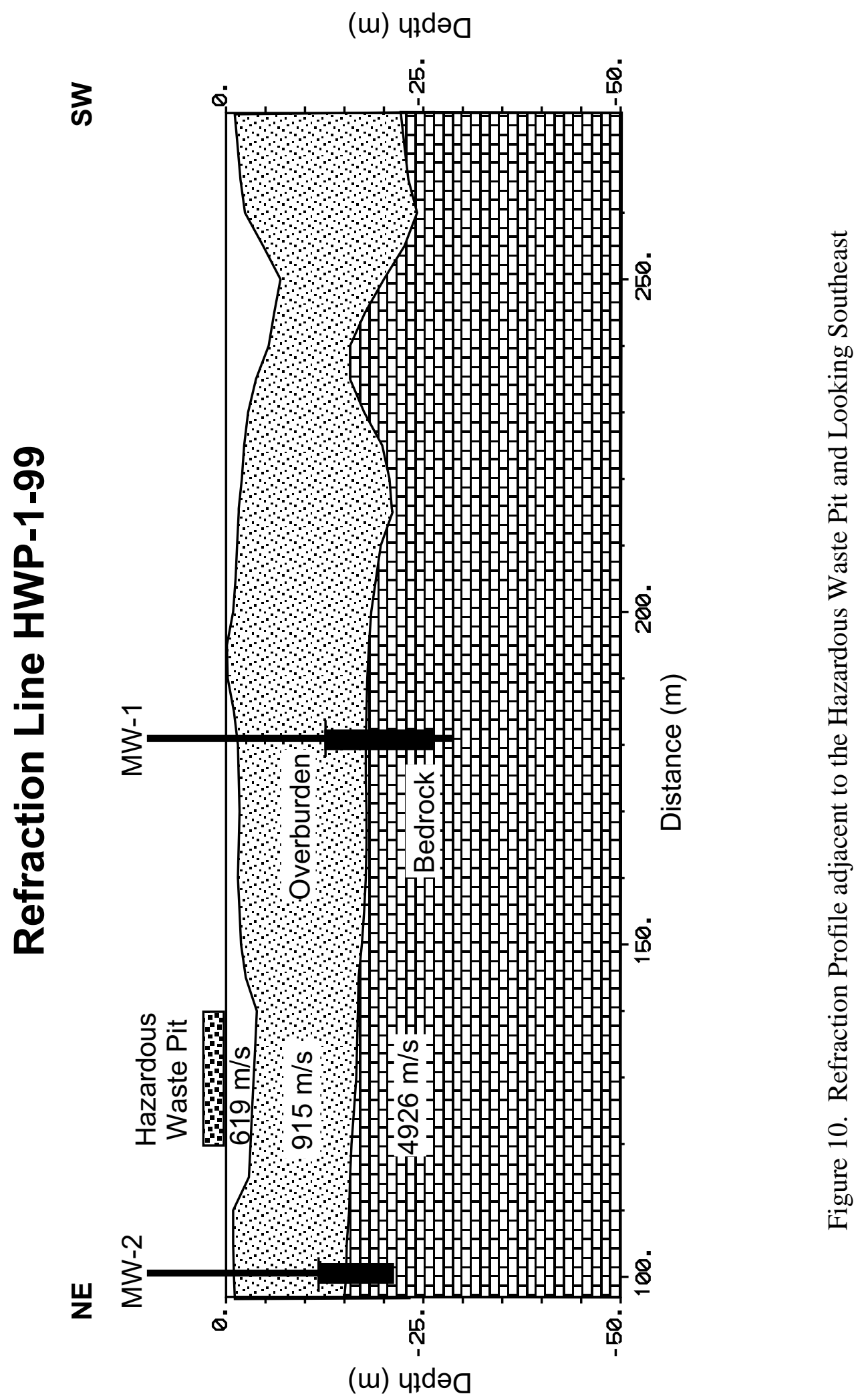




\subsection{Seismic Reflection}

The results from the three test reflection surveys are shown in Figures 11-13. The vertical axis on the left side of each figure is in units of two-way travel time (TWT), and the right-hand vertical axis is in units of depth. The nonlinearity in the depth axis is the result of an increase in velocity with depth, with the average (or normal move out) velocities determined during the interactive analysis of common midpoint gathers (CMP) used to compute the depth scale (see Table 7).

Also shown on Figures 11-13 are the probable interfaces for the Warsaw, Burlington-Keokuk, and Northview-Compton-Chattanooga sequences. It must be stressed that these reflector horizon picks are tentative and do not have confirmatory borehole information to support the interpretation.

Velocities determined by the seismic refraction surveys (see Table 6) were used as a starting point in the CMP velocity analysis. Changes in average velocities along the seismic reflection profiles were evident and are primarily attributed to variations in the near-surface, low-velocity layer. The listed interval velocities (computed from the NMO data) are lower than the layer velocities determined by the refraction data, although they are consistent with velocities determined from the downhole seismic surveys (see below and Appendix A).

Table 7. Stacking Velocities Used in Processing Seismic Reflection Profile

\begin{tabular}{c|c|c|c}
\hline $\begin{array}{c}\text { Two-way travel time } \\
\text { (TWT, ms) }\end{array}$ & $\begin{array}{c}\text { Average NMO Velocity } \\
\text { Range (m/s) }\end{array}$ & $\begin{array}{c}\text { Interval Velocities } \\
(\mathbf{m} / \mathbf{s})\end{array}$ & $\begin{array}{c}\text { Depth Range } \\
(\mathbf{m})\end{array}$ \\
\hline 25 & $686-884$ & $686-884$ & $8.5-11$ \\
65 & $1,123-1,525$ & $1,400-2,050$ & $36.5-49.5$ \\
100 & $1,787-2,050$ & $3,000-3,771$ & $89-102.5$ \\
\hline
\end{tabular}

RFL-1

Figure 11 shows the seismic reflection section obtained for test profile RFL-1. Two nearly continuous reflectors, labeled R1 and R2, are observed at TWT of 35-40 ms and at 110-120 ms TWT, respectively, and correspond to depths of approximately 13-16 m (42-50 ft) for R1 and 94$104 \mathrm{~m} \mathrm{(310-350} \mathrm{ft)} \mathrm{for} \mathrm{R2} \mathrm{reflector.} \mathrm{A} \mathrm{deeper,} \mathrm{and} \mathrm{weaker,} \mathrm{reflection} \mathrm{event,} \mathrm{R3,} \mathrm{is} \mathrm{tentatively}$ identified at a TWT of approximately $220 \mathrm{~ms}(\approx 245 \mathrm{~m})$, al though it is less continuous than the R1 and R2 reflectors. The source for the discontinuous reflectors observed between the R1 and R2 reflector horizons is not known, although preliminary results from downhole sampling in the CTA reveals density variations from 2.09 to $2.66-\mathrm{g} / \mathrm{cm}^{3}$. One of these intermediate and discontinuous reflector horizons is indicated on the section as a dashed line.

The R1 reflector shows minor undulations across the length of the profile and most likely represents the bedrock surface. The depth computed to this reflector corresponds closely with the depth to bedrock indicated in boreholes adjacent to the profile and with the depth determined from the refraction and 2-D resistivity data. The time-depth agrees with that computed from the downhole seismic data for wells IA-MW-1, IA-MW-2, and IA-MW-3 (see Appendix A). Poor coupling between the receivers and the ground most likely cause the loss in reflector continuity adjacent to shot point 13 . The intermediate reflector, dashed line, is tentatively interpreted as the WarsawBurlington-Keokuk contact. 


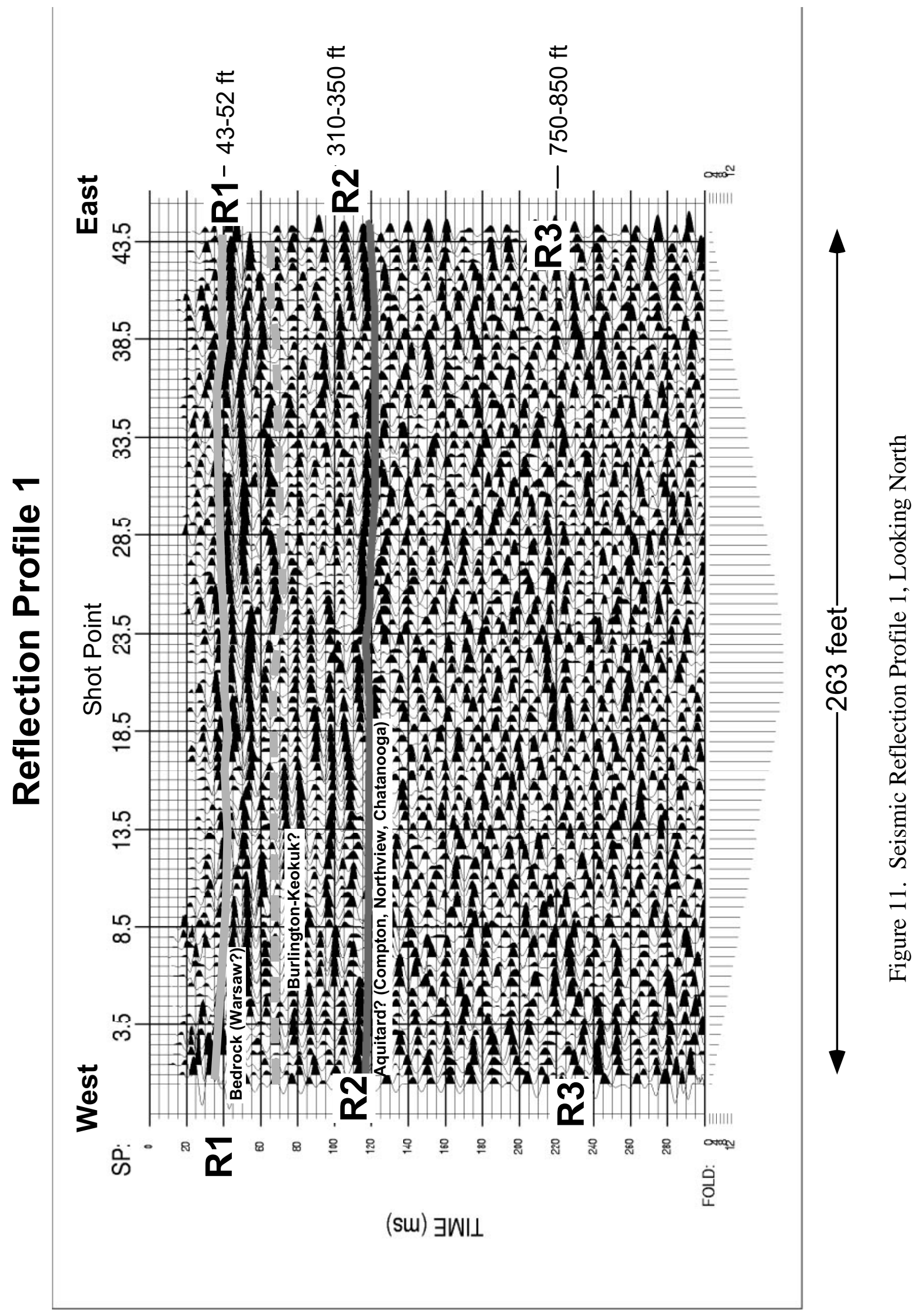




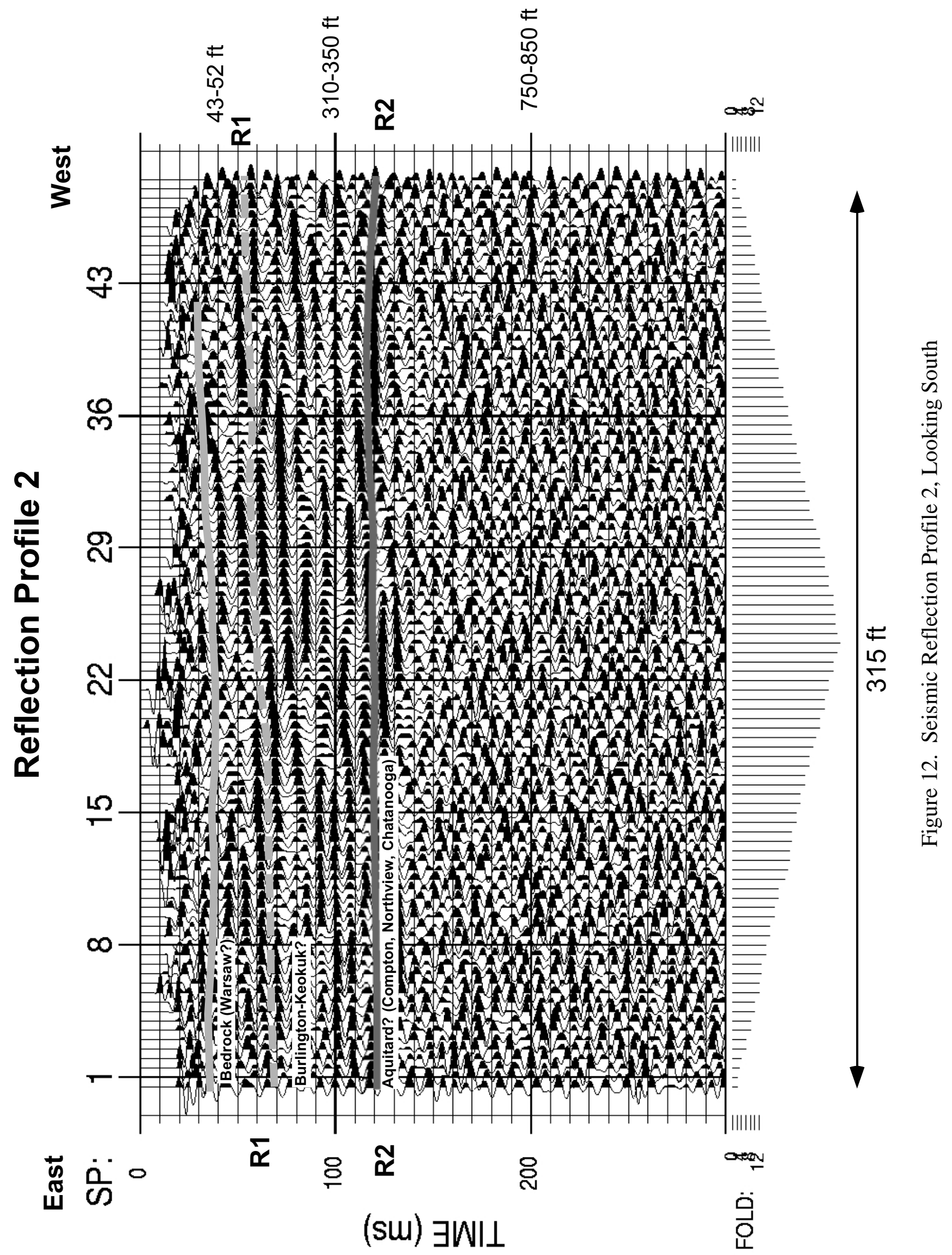




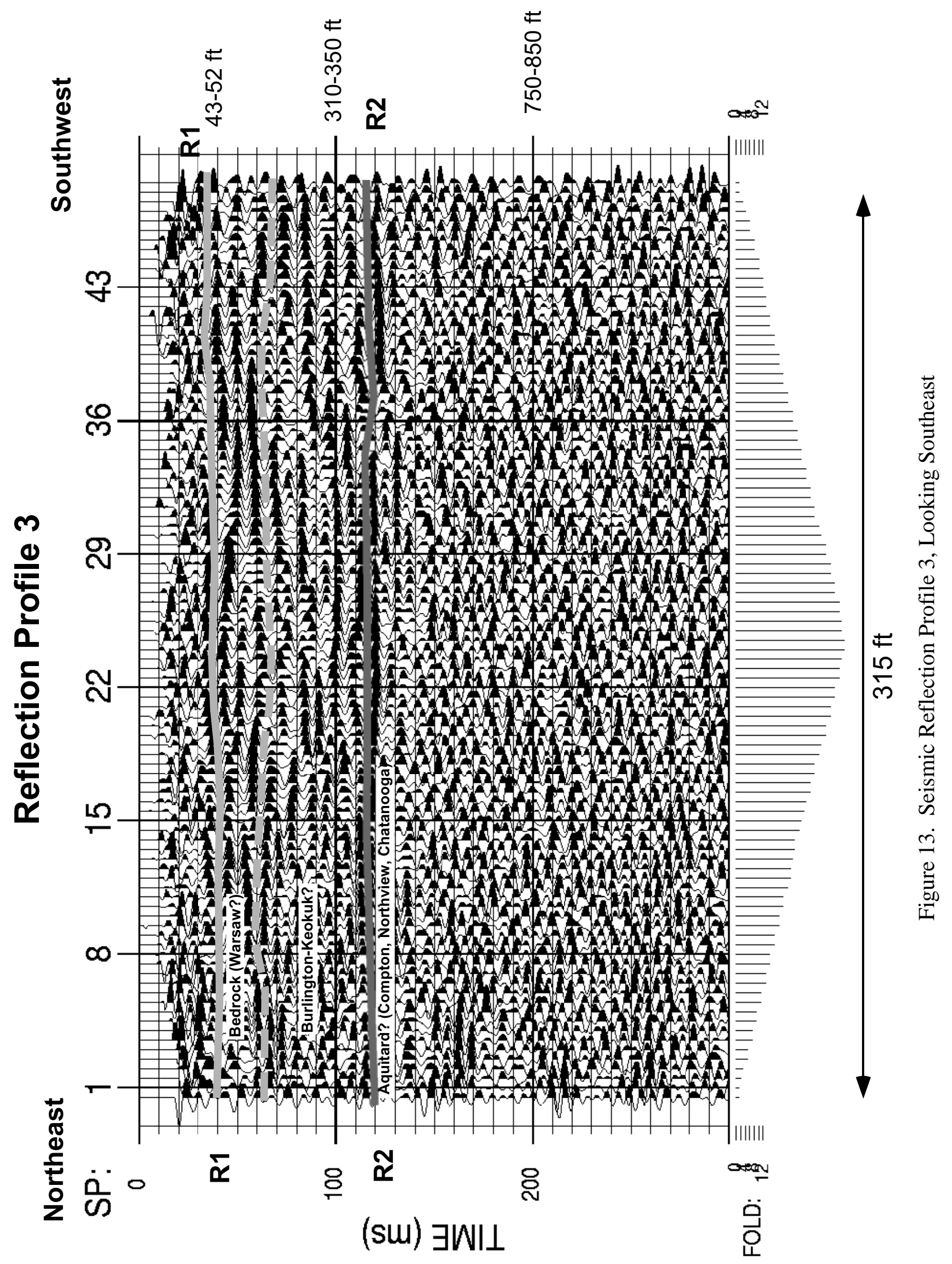


The R2 reflector is tentatively interpreted as the top of the aquiclude that is made up by the Northview, Compton, and Chattanooga Shale. Wells within a 4-mi radius indicate an elevation of 238 to $274 \mathrm{~m}$ (780 to $900 \mathrm{ft}$ ) in the Camp Crowder area for the Chattanooga Shale (Wilkinson 1998). The seismic line had a ground elevation of $367 \mathrm{~m}$, and, thus, given a depth of 94-104 $\mathrm{m}$ to the R2 reflector, this horizon has an elevation of 263-273 $\mathrm{m}$ along Profile 1.

\section{RFL-2}

RFL-2 was acquired in the southeast corner of the ETA along an east-to-west transect, and the resulting seismic section in shown in Figure 12. Two reflections identified as R1 and R2 are indicated, and a weaker, unlabeled reflection horizon is also shown (shallowest reflector). The deeper R3 event image on RFL-1 is not present on this profile. Also note that the packet character (ringing) of the reflectors may indicate the presence of multiples, and that the signal-to-noise levels for this profile, as well as those for RFL-3, were, in general, lower than those observed for RFL-1.

The reflector packet, R1, shows a consistent dip toward the east, changing from $45 \mathrm{~ms}$ travel time $(\approx 18 \mathrm{~m})$ in the west to $60-65 \mathrm{~ms}$ travel time $(\approx 30 \mathrm{~m})$ in the east. This surface is tentatively interpreted as the Warsaw-Burlington-Keokuk contact, but it may also correlate with the top-ofunweathered-bedrock. A weaker reflecting horizon located above R1 is probably the top-ofweathered rock. No confirmatory borings are located close enough to the line to support or refute this interpretation.

The R2 reflector packet tops near $110 \mathrm{~ms}$ in travel time $(91-104 \mathrm{~m})$, which is approximately the same time depth indicated for the R2 reflector on profile RFL-1. Its interpretation as the top of the aquitard is based solely on its modeled depth, which is consistent with where wells outside Camp Crowder place this unit (Wilkinson 1998).

\section{RFL-3}

Profile RFL-3 was collected on a northeast-to-southwest transect along the western boundary road to the ETA (see Figure 2), and the seismic reflection section is shown in Figure 13. Two reflectors are identified as R1 and R2 on the section, and a third unlabeled but dashed horizon is also indicated. As with profile RFL-2, the signal-to-noise level is fairly low, resulting in weakly defined reflectors on the section. No confirmatory boreholes are adjacent to the profile.

The $\mathrm{R} 1$ reflector ranges between 40 and $60 \mathrm{~ms}$ in travel time across the section, which would put it at 14-27 $\mathrm{m}$ in depth. This is interpreted as the top-of-bedrock, as refraction Profiles 1 and 6 indicate that the top of bedrock could be in this depth range. The undulations are likely due to variations in near-surface velocity, although changes in bedrock elevation cannot be discounted. The dashed horizon is tentatively interpreted as the Warsaw-Burlington-Keokuk contact. The R2 reflector tops out near $105-110 \mathrm{~ms}$ in travel time $(101-113 \mathrm{~m})$ and remains relatively horizontal along the length of the profile. The $\mathrm{R} 2$ interpretation as the top of the aquitard is based on its modeled depth. 


\subsection{Downhole Seismic Profiling}

Velocity with depth models computed from the downhole measurements are shown in Appendix A, and the resulting velocities for the overburden and bedrock are shown in Table 8 . Interval velocity measurements from the downhole data confirm that underlying bedrock transmits acoustic energy at high velocities that average $3,700 \mathrm{~m} / \mathrm{s}(12,000 \mathrm{ft} / \mathrm{s})$ and that the overburden material has an average velocity of approximately $950 \mathrm{~m} / \mathrm{s}(3,100 \mathrm{ft} / \mathrm{s})$. Note that the refraction models tend to promote higher velocities for the bedrock than do the downhole seismic data. One possible explanation is that a horizontal-to-vertical velocity anisotropy exists within the bedrock, which results in seismic energy traveling faster in the horizontal direction than in the vertical.

\subsection{Two-Dimensional Electrical Resistivity Imaging (ERI)}

ERI profile cross-sections are shown in Figures 14-23. Also shown on each figure, where available, are seismic refraction surfaces representing the top of competent rock (bedrock), wells showing depth to rock and significant overburden features, and the positions of culverts and other man-made features. Red to white colors represent zones of higher electrical resistivity whereas blue to magenta colors are lower resistivity. Carbonate rock and coarser-grain intervals within the overburden are likely sources for high resistivity, and clays and fine-grain sediments are candidates for low resistivities. The presence of electrically conductive pore fluids, which can develop because of the degradation of organic compounds, could also be a source for zones of low resistivity.

Five iterations were allowed for modeling the resistivity data in order to avoid introducing artifacts into the modeling process. Model errors ranged from 3\% to $12 \%$ root mean square error for all the profiles. Models with higher errors were generally caused by poor ground conditions (e.g., could not get sufficient electrode couple with the ground). 


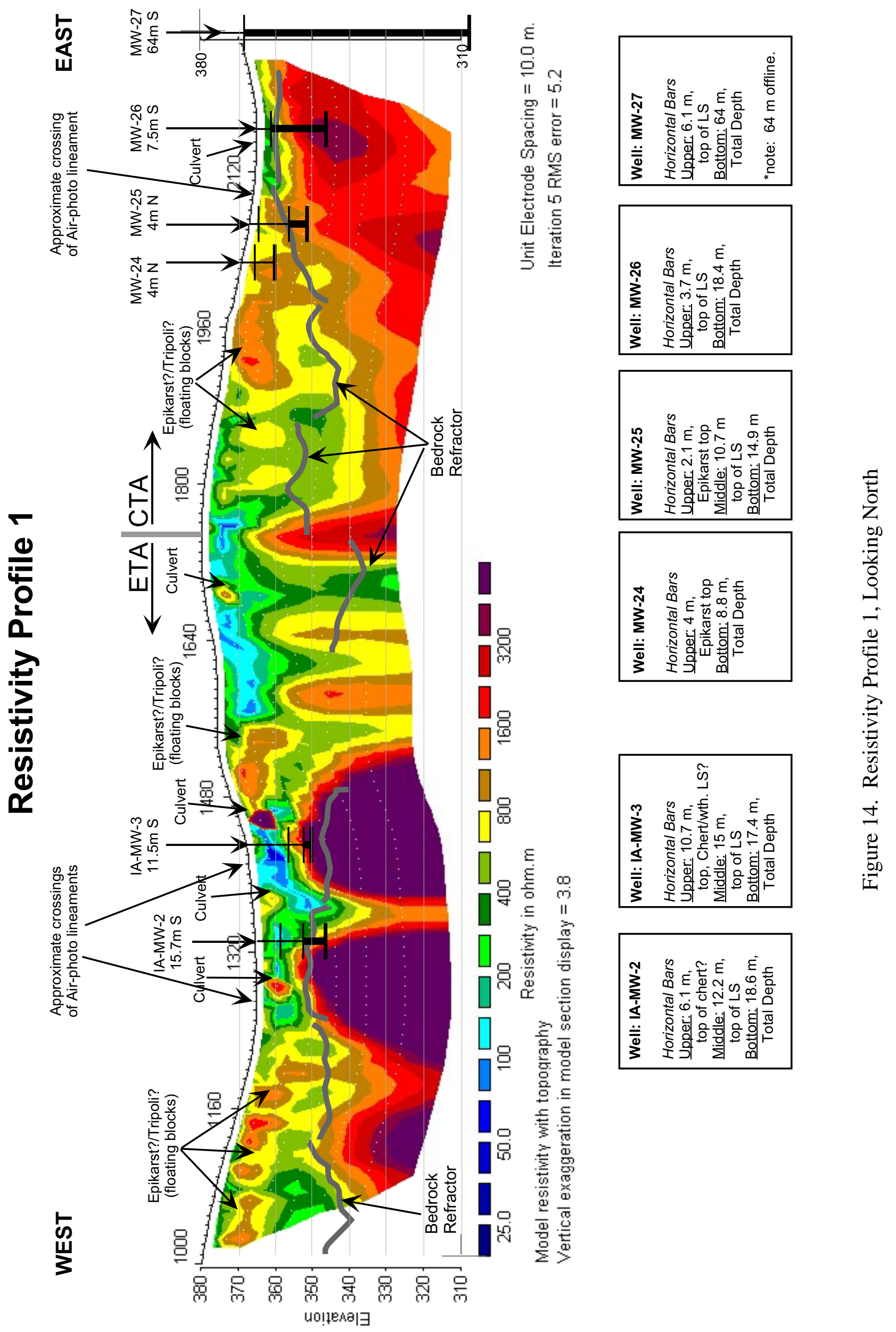




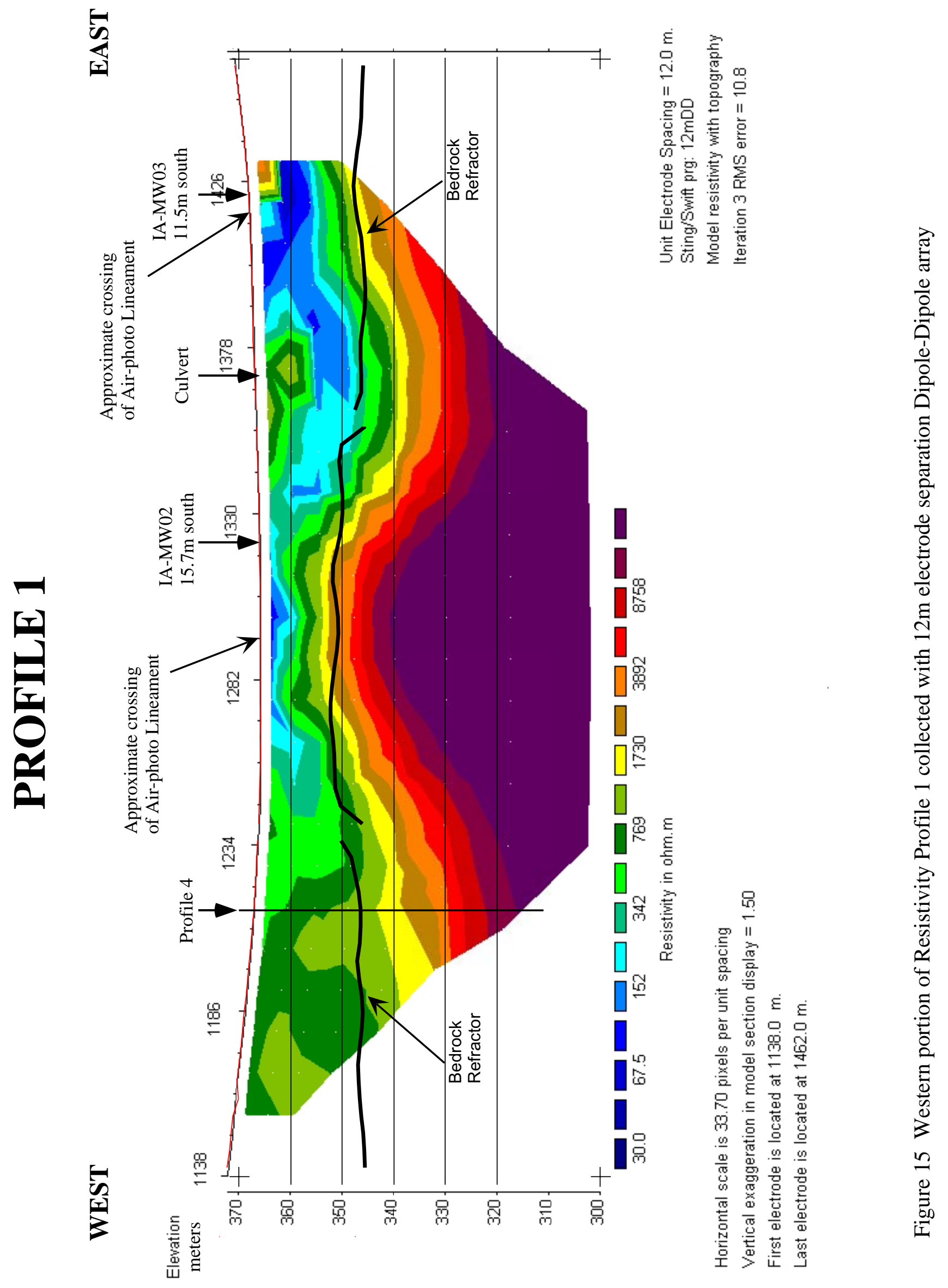




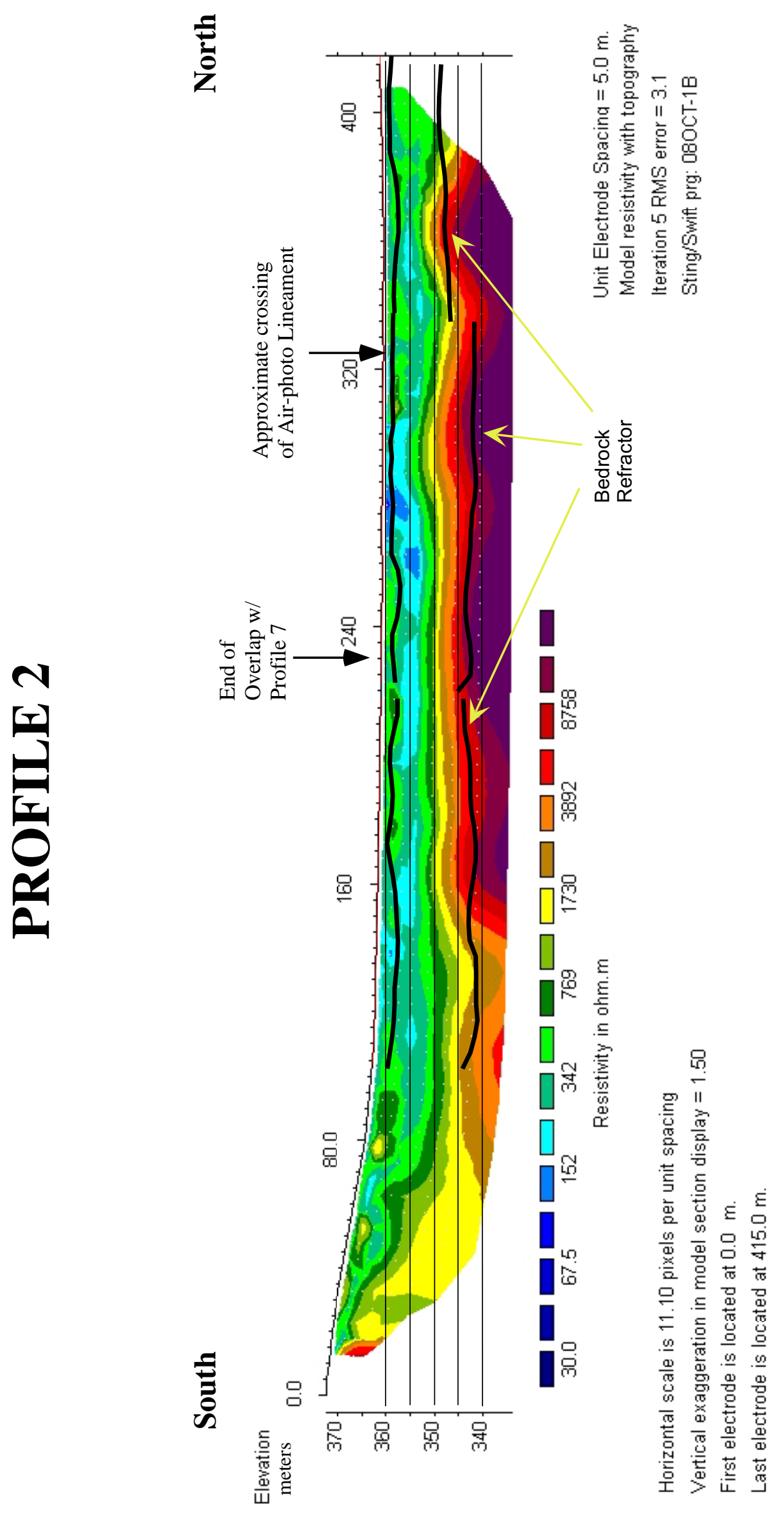

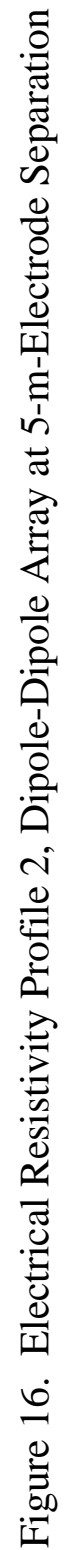



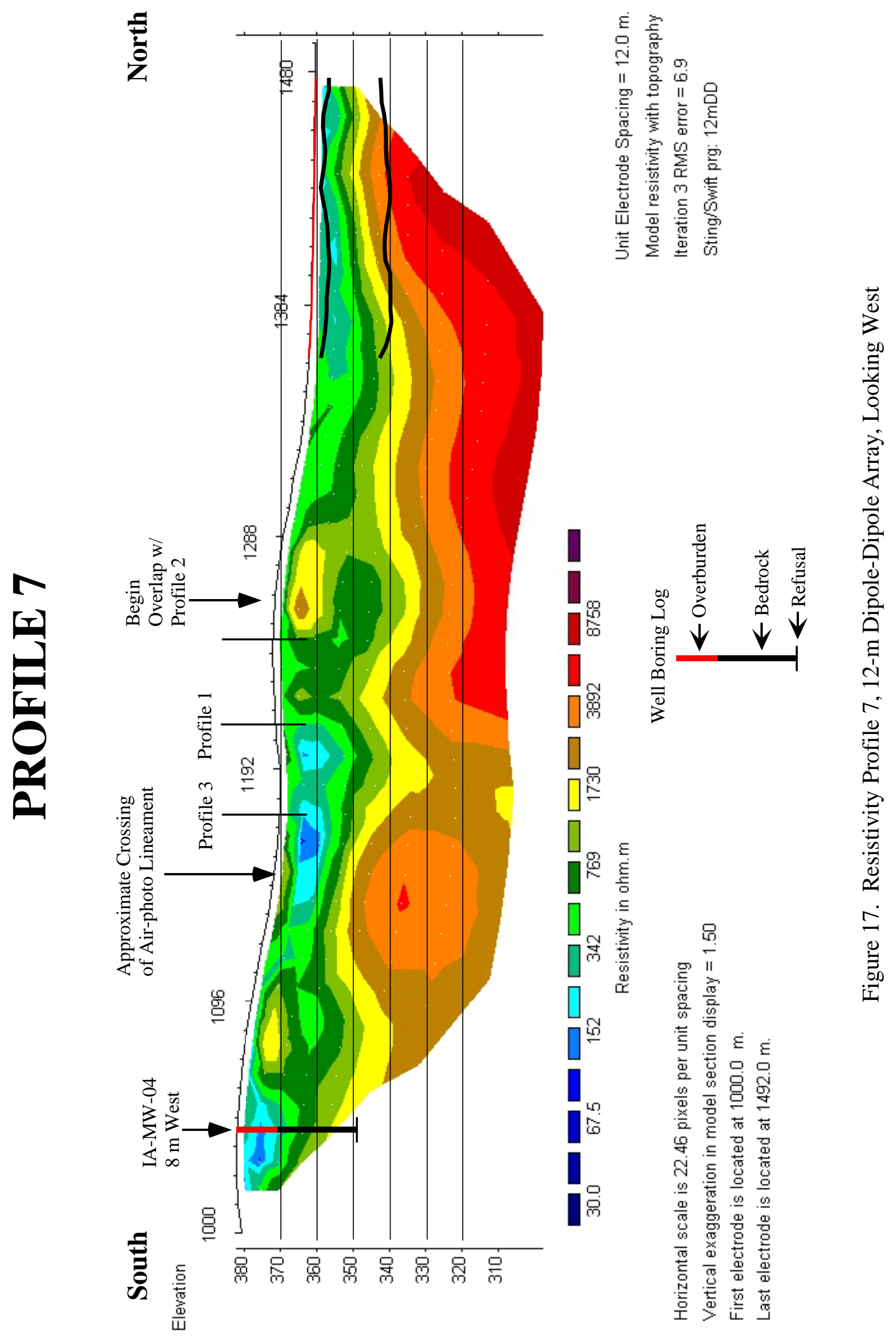


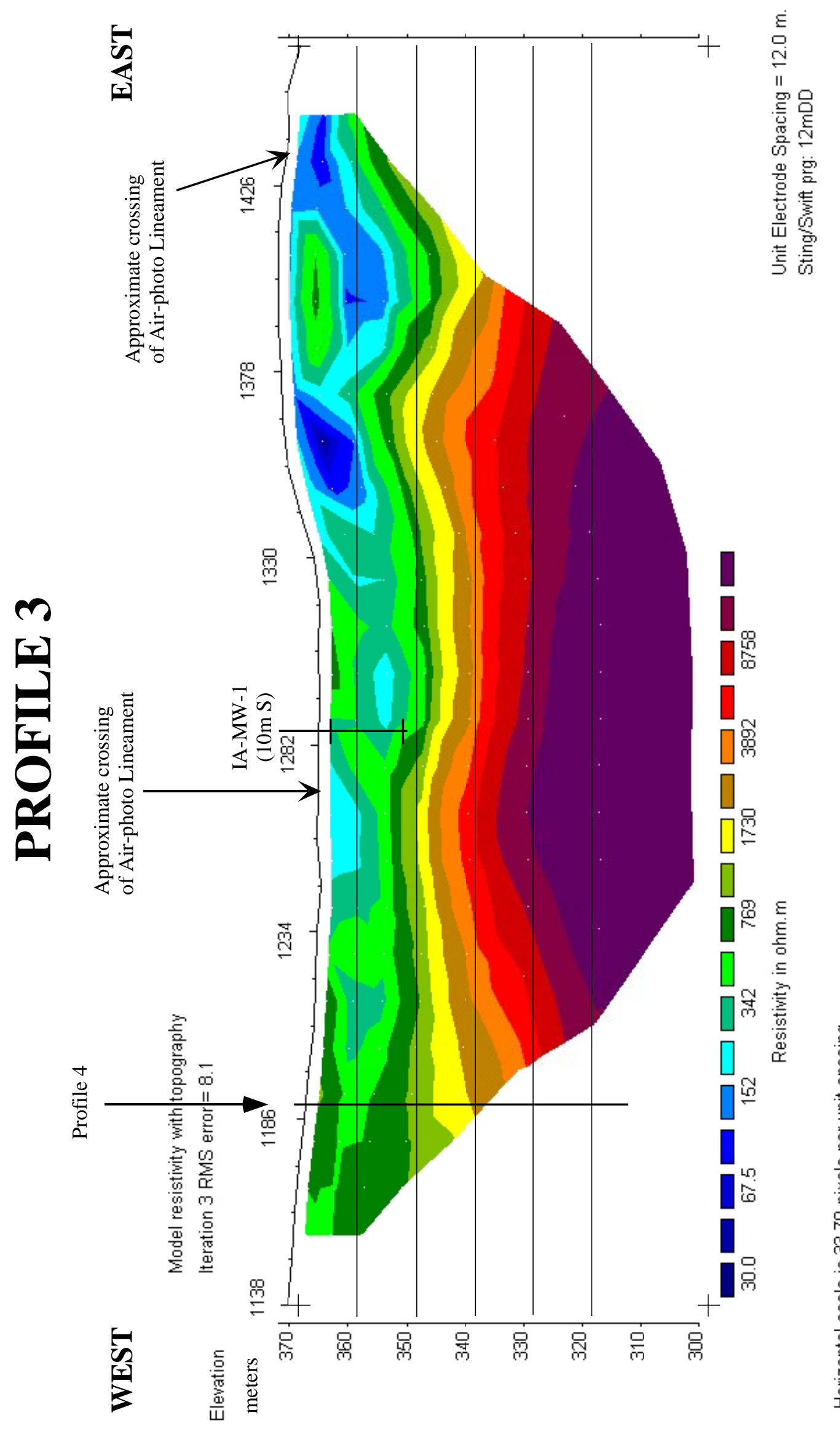

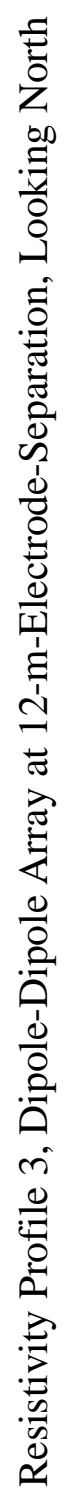

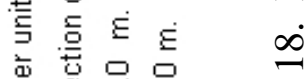

产总品只

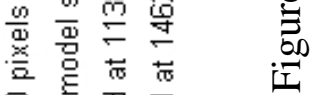

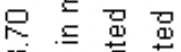

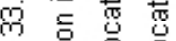

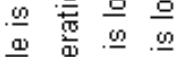

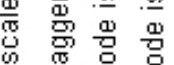
焉茶喜 焉离菏 


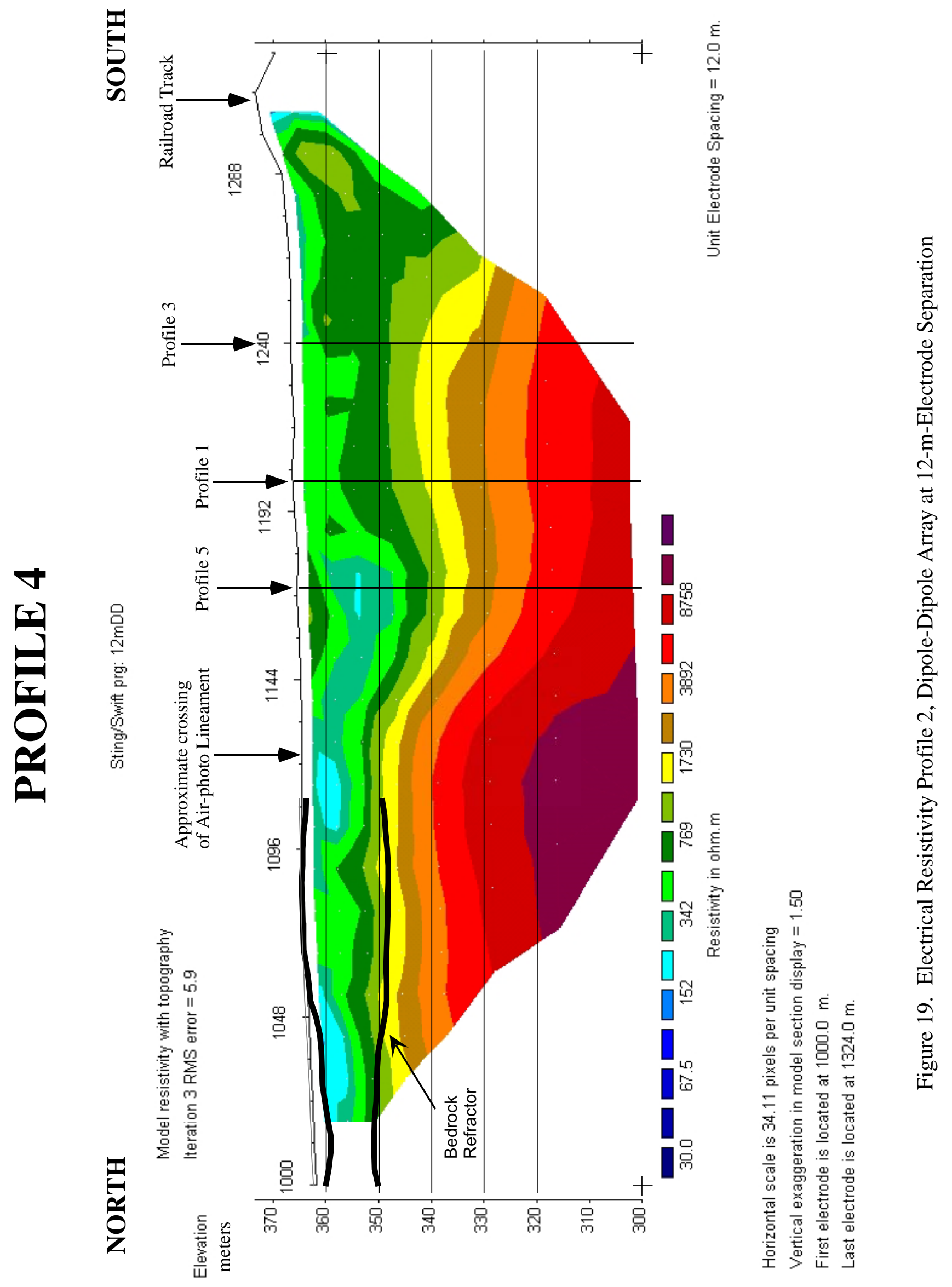




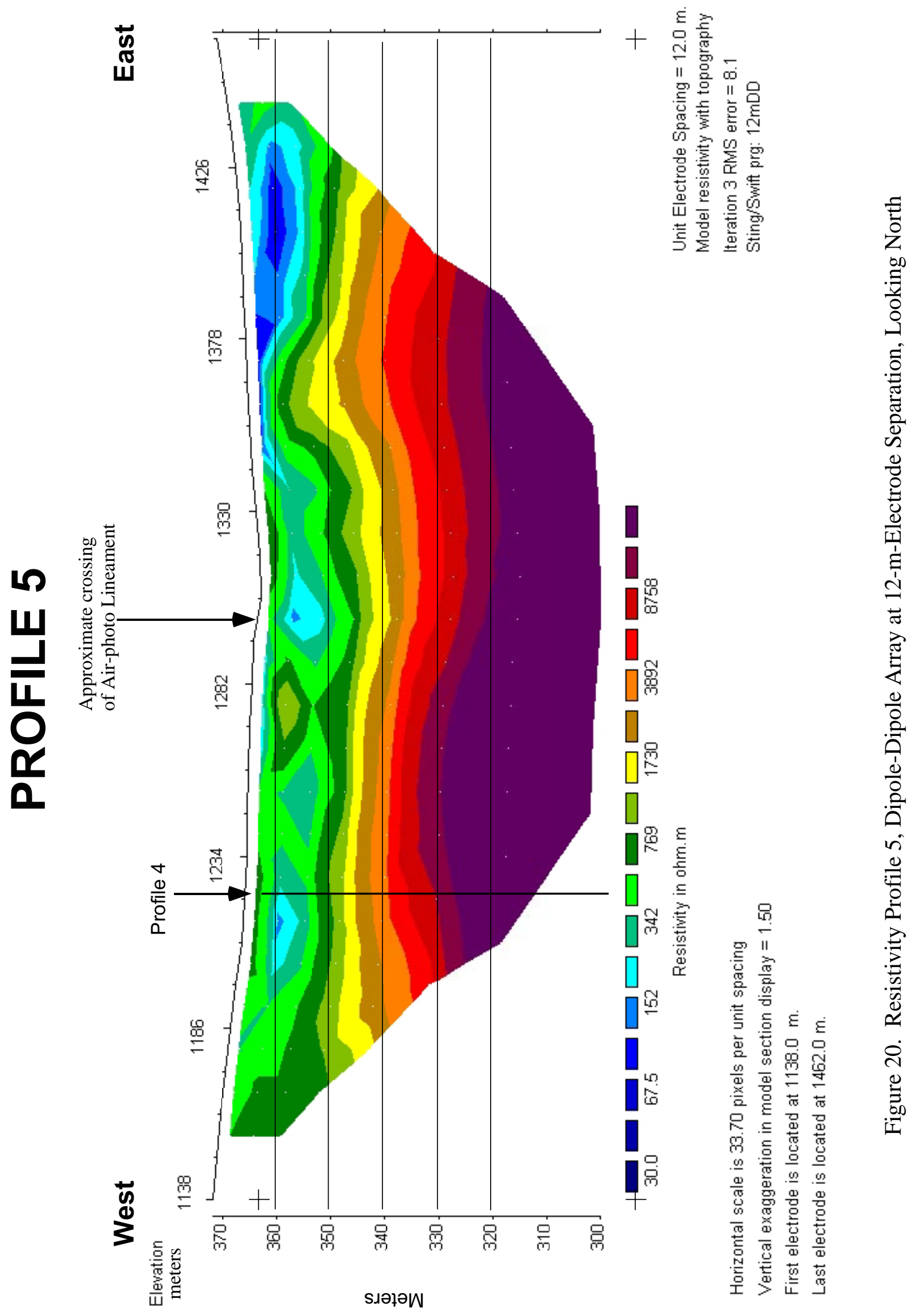



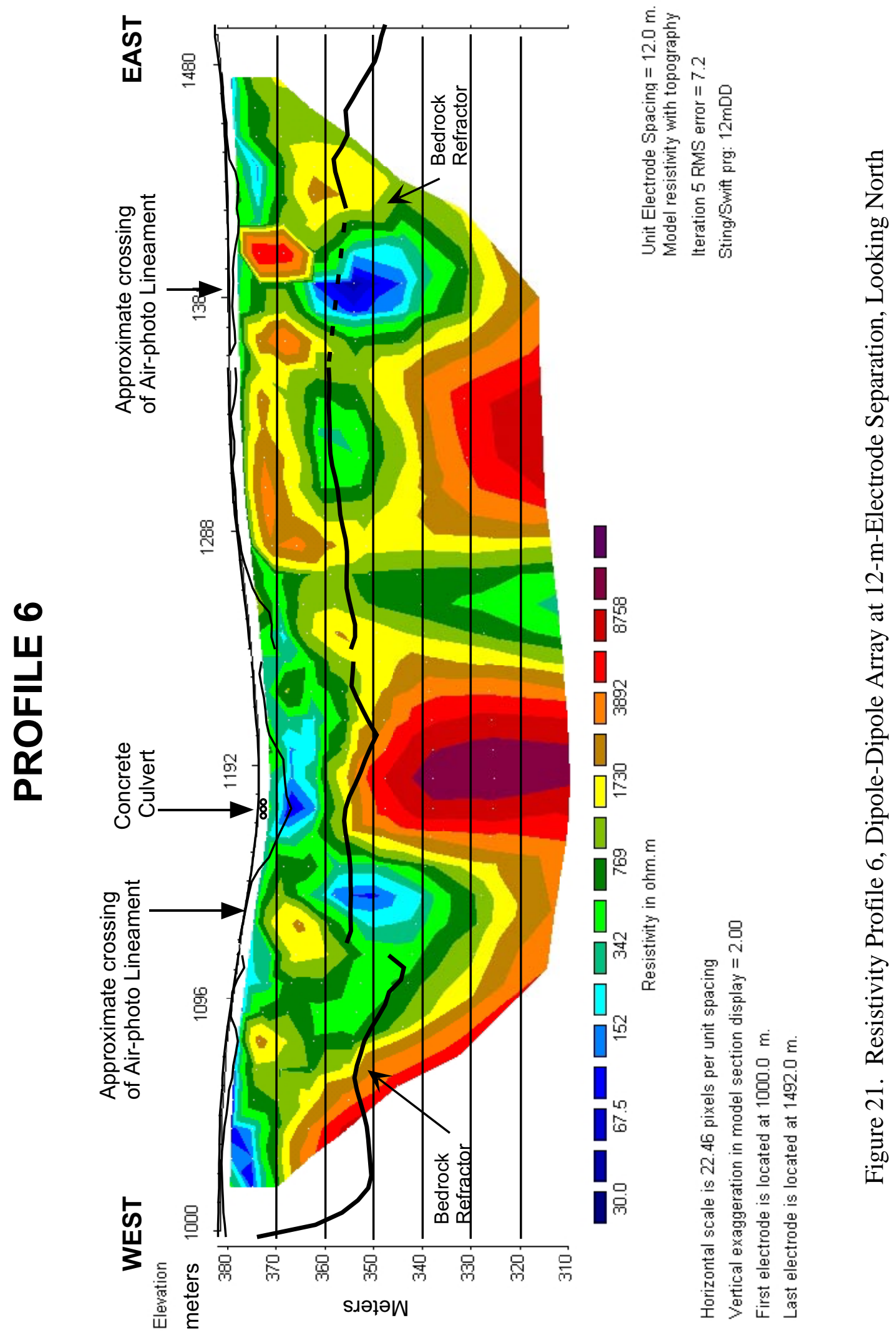


\title{
HWP-1-99
}

$\mathrm{NE}$

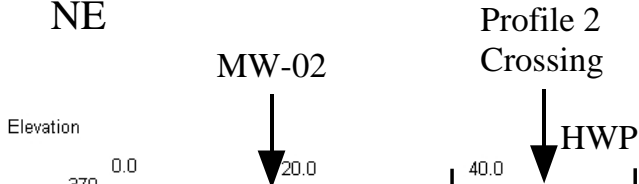

MW-01 is approx.

SW

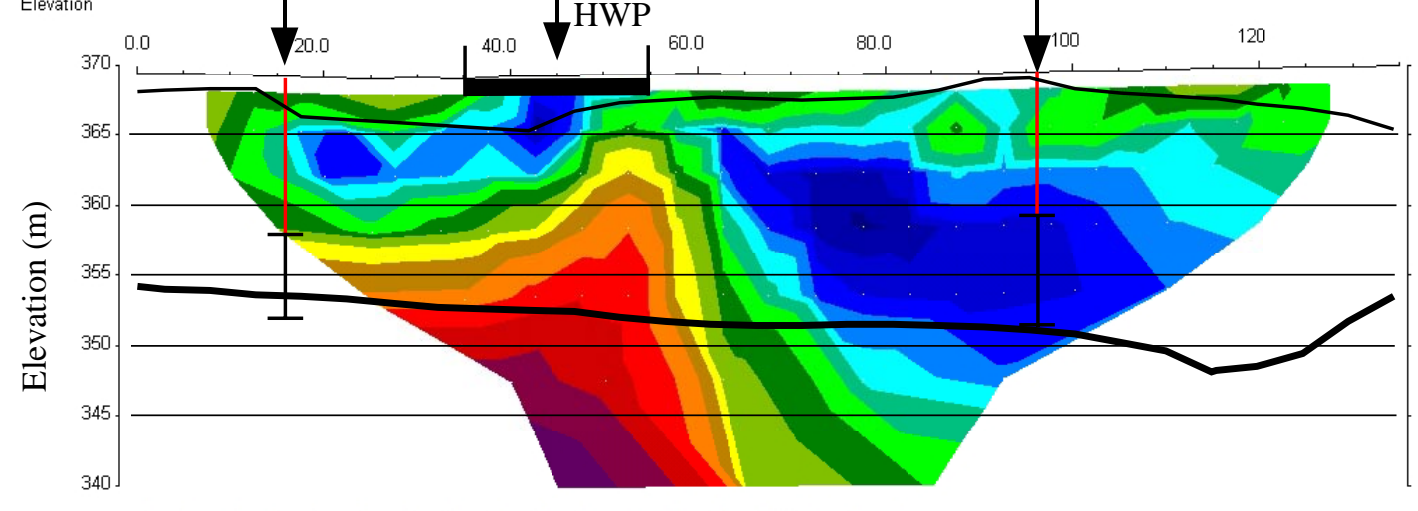

${ }_{5.0} \square{ }_{15.3} \varpi{ }_{46.9} \square{ }_{144} \square{ }_{440} \square \underset{1347}{\square} \underset{4125}{\square}$

Resistivity in ohm.m

Unit Electrode Spacing $=5.0 \mathrm{~m}$ Model resistivity with topography Iteration 5 RMS error $=9.3$

Horizontal scale is 33.70 pixels per unit spacing

Vertical exaggeration in model section display $=1.50$

Sting/Swift prg: $5 \mathrm{mSch}$

First electrode is located at $0.0 \mathrm{~m}$.

Last electrode is located at $135.0 \mathrm{~m}$.

\section{HWP-2-99}

SE

Profile 1

\author{
Crossing
}

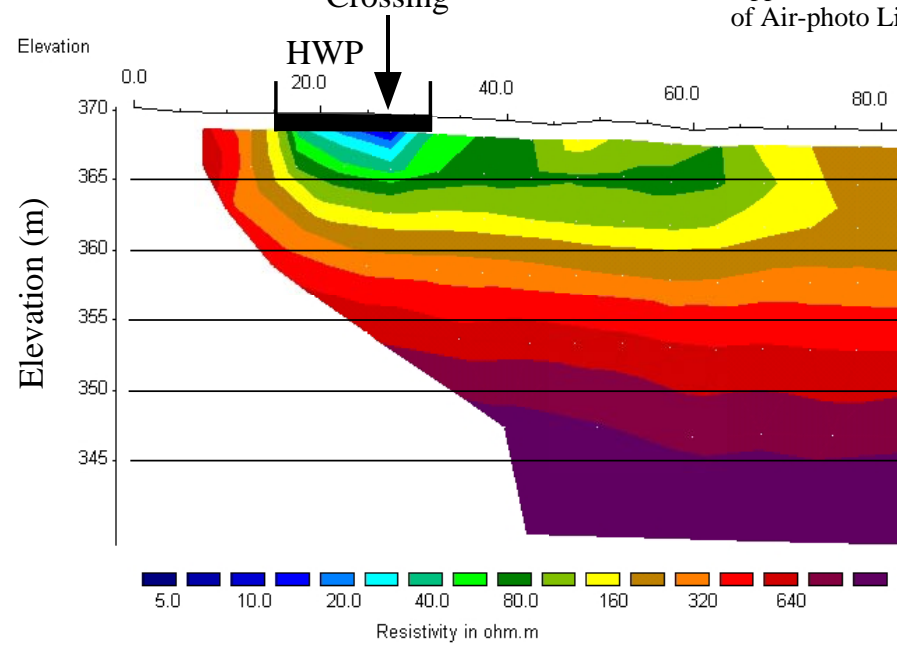

Horizontal scale is 33.70 pixels per unit spacing Model resistivity with topography

Vertical exaggeration in model section display $=1.5$

Iteration 5 RMS error $=4.4$

First electrode is located at $0.0 \mathrm{~m}$.

Last electrode is located at $135.0 \mathrm{~m}$

Figure 22. Resistivity Profiles at the Hazardous Waste Pit 


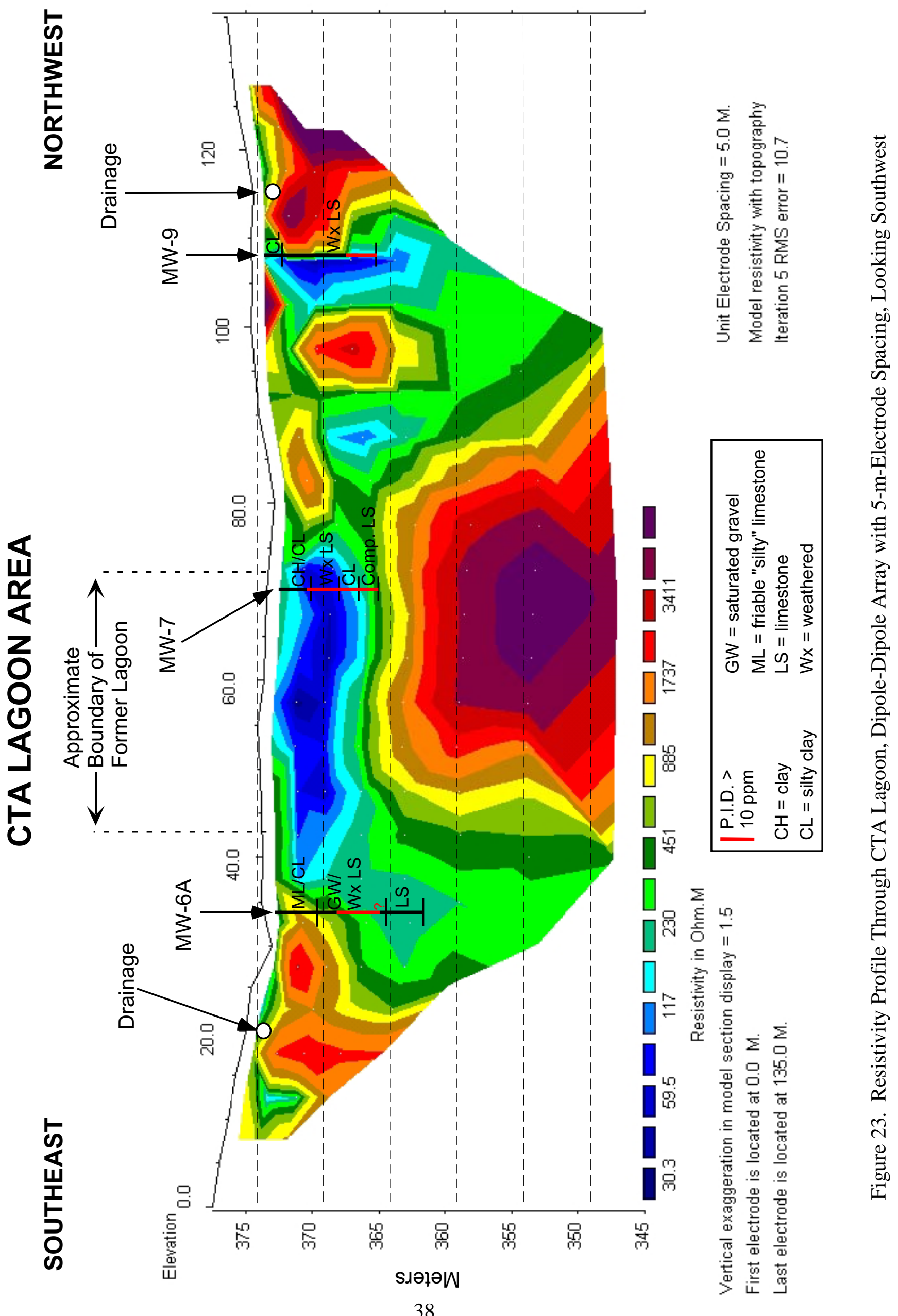


Table 8. Seismic Velocities from Downhole Measurements

\begin{tabular}{c|c|c|c|c}
\hline \multirow{2}{*}{ Well ID } & $\begin{array}{c}\text { Shot } \\
\text { Offset (ft) }\end{array}$ & $\begin{array}{c}\text { Bedrock } \\
\text { Thickness (m) }\end{array}$ & \multicolumn{2}{|c}{ Velocity (m/s) } \\
\cline { 3 - 5 } IA-MW-1 & 2 & 4.6 & $457-1,219$ & 3,505 \\
& 15 & & $609-762$ & 3,657 \\
IA-MW-2 & 2 & 3.7 & $609-1,372$ & 5,334 \\
& 15 & & $305-762$ & 4,267 \\
IA-MW-3 & 2 & 4.6 & $457-1,372$ & 3,810 \\
& 15 & & $457-762$ & 3,962 \\
IA-MW-4 & 2 & $>18$ & $365-1,219$ & $2,438-3,505$ \\
& 15 & & $365-914$ & $2,895-3,962$ \\
MW-26 & 3 & $>15$ & $365-914$ & $3,048-3,657$ \\
& 15 & & $457-1,067$ & $2,743-3,354$ \\
MW-27 & 15 & $>50$ & 609 & $3,353-5,943$ \\
\hline
\end{tabular}

\section{Profile 1}

Profile 1 is located along the north boundary road to the ETA/CTA (see Figure 2) and was collected by using electrodes placed at intervals of $10 \mathrm{~m}$. An additional short segment was acquired using a 12-m-electrode spacing (maximum spacing available with current system) to verify the initial results provided by the $10-\mathrm{m}$-electrode spacing. The resistivity model sections are shown in Figures 14 and 15. Also shown in these figures are bedrock refractor surfaces and the locations of wells and cultural features along the profile.

The electrical-resistivity model obtained for Profile 1 by using the 10 -m-electrode spacing is shown in Figure 14. In the western third of the profile, the bedrock surface is interpreted as the top of three extremely high-resistivity $(>3,200 \mathrm{ohm}-\mathrm{m})$ anomalies (dark red colors) that have elevations ranging from 34 to $350 \mathrm{~m}$. These anomalies form three lobes, with (1) the westernmost of these lobes having the lowest elevation. The tops of the eastern two lobes are consistent with the indicated top of bedrock from wells IA-MW-2 and IA-MW-3 and (2) the bedrock surface modeled by using the refraction data. Also, these latter two features are approximately located where air-photo-derived lineaments cross the profile (see Figure 2).

In the middle of the profile $(1500 \mathrm{X}-1850 \mathrm{X})$, the interpreted bedrock surface is represented by three pinnacle-shaped high-resistivity $(1,000-3,000 \mathrm{ohm}-\mathrm{m})$ features. The general character represented by the resistivity data is indicative of a large fracture zone. No well control exists to corroborate this interpretation. Note that the refraction data in this area show distinct vertical offsets, indicating that the refraction-modeling algorithm is having problems resolving the structure. 
The bedrock surface in the eastern third of the profile is represented by high-resistivity (8001,600 ohm-m) block that has an apparent westward dip. The top of this high resistivity is consistent with the depth to the top of the competent LS encountered in wells MW-25 and MW-26. If well MW-27 is used in a three-point problem, then the true dip of the bedrock surface is probably more to the NW or NNW here. Note, also, that the bedrock refractor here also follows the general westward dip.

The overburden-residuum material has an average background resistivity ranging from 100 to 400 ohm-m (green shades). Two low-resistivity regions are observed: one 1370X-1460X and the other between $1570 \mathrm{X}$ and $1760 \mathrm{X}$. These zones are probably saturated and clay-dominated areas. Those anomalies due to the presence of culverts are indicated on the cross section. The others are most likely floating blocks of dolomite and chert or are epikarst features. The borehole logs for wells MW-24 and MW-25 indicate the presence of highly weathered and fractured LS at these depths.

Figure 15 shows the resulting electrical model obtained for the short profile segment acquired by using the 12-m-electrode separation. The presence of the high-resistivity lobe centered near $1300 \mathrm{X}$ (with flanking areas of lower resistivity) corroborates the model produced by using the $10-\mathrm{m}-$ electrode spacings. The coarser electrode spacing, however, produces lower detail in the overburden sediments than that of the $10 \mathrm{~m}$ survey.

\section{Profiles 2 and 7}

Profiles 2 and 7 were collected along the north-south access road that bisects the ETA. Profile 2 was acquired in the Fall of 1998 by using an electrode spacing of $5 \mathrm{~m}$, starting on the flank of a hill and transecting a valley to the north. A metal and concrete culvert is located at $295 \mathrm{X}$ and was oriented perpendicular to the line. Profile 7 was acquired in the summer of 1999 by using an electrode spacing of $12 \mathrm{~m}$ and was extended south from where Profile 2 started. The profiles overlap by approximately $230 \mathrm{~m}$.

Figure 16 shows the modeling results obtained for Profile 2. Flooring the section is highresistivity material ( $>2,000 \mathrm{ohm}-\mathrm{m}$, red to maroon colors) that most likely corresponds to the top of the underlying limestones at approximately $345 \mathrm{~m}$ in elevation. The interpreted bedrock refractor places the competent rock approximately 5-7 m below the top of this high-resistivity material. Also, the modeled resistivities are consistent with those for competent limestone (Telford et al. 1995; Ward 1990); however, the values quickly increase toward infinity at depth, suggesting either modeling or data limitations. A photolineament crosses the profile adjacent to a saddle-shaped feature in the interpreted bedrock surface (north of 320X). Note that the break in the refractor surface represents the change between two different spreads (models) and may not be as distinct as shown.

The overburden sediments are represented by moderately resistive material (100-300 ohm-m) represented by the cyan-green colors. The thickness of this layer, character of the fabric, and resistivity values are very similar to those imaged in Profile 1 (Figures 14 and 15), suggesting an equivalent interpretation. Again, slightly more resistant zones are modeled within the overburden and can be interpreted as blocks of weathered limestone, chert, or epikarst remnants. The blocks with the highest resistivity values are located beneath the flank of the hill and form a discontinuous layer similar to that imaged in Profile 1. Also observed on the flank of the hill is an intermediate 
band of resistivity (1,700-2,000 ohm-m, yellow colors) that may be a modeling artifact. The high resistivity response on the very southern end of the line is part of a larger block of residual material observed in its entirety on Profile 7 (see Figure 17).

Modeling results for Profile 7 after three inversion iterations are shown in Figure 17. Highresistivity material interpreted as the top of bedrock forms the bottom-most layer on the model and includes values greater than $1,700 \mathrm{ohm}-\mathrm{m}$. The refraction model obtained for Profile 2 is plotted on the north quarter of Profile 7, and is consistently deeper by approximately $10 \mathrm{~m}$ than the top of the high-resistivity material. This high-resistivity layer deepens from approximately $350 \mathrm{~m}$ in elevation on the north to 335-340 $\mathrm{m}$ by the middle of the line.

A distinct break in the bedrock character is observed near 1192X (possible fracture), and the bedrock surface abruptly rises back up to $350 \mathrm{~m}$ in elevation farther to the south. The elevated bedrock surface is coincident with where a photo-lineament is indicated. Note that Well IA-MW-4 places the bedrock at approximately $11.5 \mathrm{~m}$ in depth, which computes to about $370 \mathrm{~m}$ in elevation. The downhole seismic data for this well (see Appendix A) indicate that the competent bedrock occurs at 15-18 $\mathrm{m}$ in depth and would correlate approximately with the green to yellow color transition as shown in Figure 17. The increase in bedrock elevation is also supported by direct outcrop evidence where bedded chert layers were observed near the south end of the profile.

As with Profiles 2 and 1, the overburden material is defined by low resistivities (blue to green colors) with floating blocks of more electrically resistant material interpreted as either weathered limestone or epikarst remnants. Two significant "floaters" are observed at $1084 \mathbf{X}$ and $1264 \mathbf{X}$, and two low-resistivity zones are observed near $1036 \mathbf{X}$ and $1168 \mathbf{X}$.

\section{Profile 3}

Profile 3 was collected along a line parallel to, and $30 \mathrm{~m}$ south of, Profile 1 between $1138 \mathbf{X}$ and 1450X (Figure 2). The coordinates system used on this profile are the same as those used for Profile 1 (see Figures 14 and 15). The profile passes immediately north of the incinerator complex, and a dipole-dipole electrode array and 12-m-electrode spacing were used. Figure 18 shows the resulting resistivity model section for this profile. No seismic refraction data were collected along this profile, and bedrock control is provided by well IA-MW-1 located near $1282 \mathrm{X}$.

The bedrock surface is interpreted near the top of the low-to-high resistivity transition zone (green red color change) and ranges from 345 to $355 \mathrm{~m}$ in elevation. Well IA-MW-1 indicates a bedrock elevation of approximately $352 \mathrm{~m}$, which is slightly higher than that determined by the model. The surface of the bedrock exhibits two depressions, the first centered near 1306X and the second beneath the fill used for the incinerator plant (1402X).

Little character is observed within the overburden, except for a zone of high-and lowresistivities anomalies (1330X to $1440 \mathrm{X})$ that are most likely associated with the construction of the incinerator buildings. 


\section{Profile 4}

Figure 19 shows the resistivity model obtained for Profile 4 after three inversion iterations and a modeling error of approximately $6 \%$. Also shown are the locations of cross-lines 5,1 , and 3 , as well as the position of the railroad track, and the refractor horizons obtained in the northern third of the profile. A north-to-south decrease in elevation of the interpreted bedrock surface is the dominant feature observed on Profile 4. In the northern third of the profile, the bedrock surface is interpreted to average approximately $350 \mathrm{~m}$ in elevation (green to yellow color transition), whereas by cross lines 1 and 3, this same color transition is approximately $5 \mathrm{~m}$ lower in elevation $(345 \mathrm{~m})$. Note the good correlation between the top of the high resistivity and the position of the bedrock determined by the refractor surface. One problem point is the intersection with Profile 5, where the indicated bedrock elevation of 338-340 $\mathrm{m}$ is lower than that modeled by Profile 5. This phenomenon probably can best be explained as a 3-D effect and should be used as a caution against over-interpreting the data without borehole control. Note that the model is consistent at the intersections with Profiles 1 and 3 .

The overburden on Profile 4 (Figure 19) is rather featureless, except for the zone of higher resistivity at the south end of the profile. As with previous interpretations, this zone is most likely a block of weathered limestone/dolomite, cherty zone, or some epikarst feature.

\section{Profile 5}

Figure 20 shows the model results for Profile 5 after three inversion iterations. The line was run west to east and located approximately $30 \mathrm{~m}$ south of Profile 1 . The profile coordinates are the same as those used for Profile 1 (see Figures 14 and 15), and the bedrock surface is interpreted in the green to yellow color transition zone where the resistivities consistently rise above $800 \mathrm{ohm}-\mathrm{m}$. On the basis of this interpretation, the bedrock surface slopes down from approximately $350 \mathrm{~m}$ in elevation at $1186 \mathrm{X}$ to about $345 \mathrm{~m}$ near $1306 \mathbf{X}$. Toward the east, the bedrock surface forms a high in the bedrock near $(1350 \mathbf{X})$, and slopes downward as it exits the profile. A gentle sag in the bedrock surface is centered near $1306 \mathbf{X}$ and roughly coincides with where a photo-lineament intersects the profile.

The overburden shows little variation in the western two-thirds of the profile, with the notable exception of a high-resistivity zone centered near $1270 \mathrm{X}$. This high-resistivity zone is similar to those observed on the other profiles and is interpreted as an epikarst feature. A low-resistivity zone is observed on the eastern end of the profile within the overburden.

\section{Profile 6}

The electrical resistivity model obtained for Profile 6 is shown in Figure 21 where five iterations were required. The bedrock refractor obtained for the corresponding seismic line is plotted as a heavy black line across the section, and the location of a series of culverts is also indicated. There is no borehole control for this profile, and interpretations of the resulting color contours are extended from that derived for other profiles where control exists. Blue to green colors represent areas of low resistivity, and yellow to red colors high-resistivity. 
The resistivity model in Figure 21 is marked by a chaotic character and does not exhibit the distinct change from overburden to bedrock as observed on some of the other profiles (see, for example, Figures 16, 18, and 20). A pinnacle-shaped high-resistivity anomaly near $1180 \mathrm{X}$ tops out at the elevation indicated by the bedrock refractor. However, no strong correlation between the bedrock surface and resistivity model exists on the cross section. This phenomenon may possibly be due to the presence of clay-filled fractures and cavities, which would be the source for the lowresistivity anomalies. Note that a photo lineament crosses the profile at an area of low resistivity, which may be due to clay-filled fractures.

\section{Profiles HWP-1 and HWP-2}

Profiles HWP-1 and HWP-2 were acquired over the hazardous waste pit (HWP) between the engine test stands (see Figure 2). The results from HWP-1 are shown in the upper half of Figure 22, and those for HWP-2 are shown in the lower half. The positions of nearby wells, the location of the hazardous-waste pit, and the point of intersection for both profiles are also indicated on Figure 22. The corresponding refraction model for HWP-1 is plotted as a heavy black line on the cross section. Note that the color scale is not the same for both profiles (HWP-1 required higher contour numbers), and that blue to green colors represent areas of low resistivity and yellow to red colors represent areas of high-resistivity.

Profile HWP-1 was run NE-SW along the access road to the waste area, with the profile's center coordinate located southwest of the waste pit. A high-resistivity block with a southwest-facing escarpment is located below the HWP at depths of 5-12 m below ground level. At the NE end of this profile, the green to yellow color transition $(\approx 450 \mathrm{ohm}-\mathrm{m})$, marking the top of this block, exits the profile at approximately $15 \mathrm{~m}$ in depth. The high-resistivity block ends immediately southwest of the HWP where a zone of low-resistivities $(<50 \mathrm{ohm}-\mathrm{m})$ dominates the cross section. Low resistivities of this magnitude are also observed beneath and NE of the HWP, suggesting a causal relationship here.

The resistivity cross section for HWP-1 does not appear to be mapping the geology. This conclusion is inferred from the lithologic descriptions given for Wells MW-01 and MW-02. Well MW-02 was located directly on the line, and MW-01 was located approximately $15 \mathrm{~m}$ northwest of $97 \times$. Both wells encountered fractured bedrock at approximately $11 \mathrm{~m}$ in depth, whereas competent rock was encountered at approximately $17 \mathrm{~m}$ for Well MW-01 and $14 \mathrm{~m}$ for MW-02. Thus, the bedrock surface should be subhorizontal (slight dip to SW) along this profile, which is similar to what the refractor surface is showing. The only way to rectify the resistivity model with the geology is to include the presence of conductive pore-fluid, which masks the geology in the southwestern half of the cross section.

HWP-2 was acquired on a transect perpendicular to HWP-1, crossing the HWP and the valley. The first two electrodes on the SE end ( $0 \mathbf{X}$ and $5 \mathbf{X})$ were hammered into friable, weathered rock. Well MW-03 is adjacent to the profile position at $95 \mathbf{X}$, near the northwestern end of the profile. Horizontal and diffuse features dominate the resistivity model for Profile HWP-2. High resistivities (400-500 ohm-m) modeled near the surface on the SE end of the profile correlate with the exposed weathered rock, and the orange to red color-transition (300-400 ohm-m) agrees with where Well MW-03 encountered weathered bedrock at approximately 10-m depth. Near the HWP, the 
resistivities are markedly lower, approaching the magnitude of those observed on HWP-1. However, the extent of the extremely low resistivity zone $(<50 \mathrm{ohm}-\mathrm{m})$ is much less and does not appear to fully mask the geology here.

The sharp contrast from low to high resistivity observed on the northeastern end of HWP-1 is not imaged on HWP-2. One explanation is that the high resistivity is a processing artifact because of the presence of the overlying electrically conductive zone (here, the modeling software overestimates the value for the higher-resistivity material). Alternately, the presence of a conductive pore fluid and thicker zone of porous rock (via secondary porosity) could cause the resistivity values of the bedrock to be lower on HWP-2.

\section{Profile CTA-1}

This profile was collected across the primary lagoon in the CTA, as shown in Figure 2. The profile is oriented SE-NW and centered on the lagoon, and Figure 23 shows the resulting 2Dresistivity model. Red colors equal high resistivity, blues are resistivity lows. Geologic/chemical logs from three wells are also plotted on the cross section, and although the logs from all three borings suggest contamination based on P.I.D. readings, none of these borings appear to have penetrated below the contaminated zone. A red bar on the boreholes indicates the location of the contaminated zone.

The central high-resistivity zone most likely correlates with the top of a competent (hard drilling?) limestone unit. All of the shallow high-resistivity zones may be cultural, including exhaust pipes at $10 \mathbf{X}$ and $90 \mathbf{X}$ and a concrete trough to the hazardous waste pit near 103X. Some part of these anomalies may be indicating epikarst or weathered top of rock. The high resistivity adjacent to Well MW-6 correlates with a sequence of friable limestone, gravel, and weathered limestone. Both wells MW-6 and MW-7 encountered weathered limestone at approximately $8 \mathrm{ft}$ in depth but show drastically different resistivity results. The primary explanation is that the degradation of the contamination (VOC) is producing more conductive pore fluid. The electrically conductive pore fluid then acts as the dominant control on the resistivity model and masks the underlying and higherresistive geology.

\subsection{Frequency Domain Electromagnetics}

EM electrical conductivity profiles collected by using the EM34 instrument are shown in Figure 24. The total length of the profile was approximately $1,280 \mathrm{~m}$ and only vertical-dipole coil data at 20 and $40 \mathrm{~m}$ were collected. Figure 24 shows the resulting profiles with both sets of data plotted at the same scale. Four anomalies are identified with culverts located near 1280X, 1430X, $1680 \mathrm{X}$, and $2140 \mathrm{X}$. An additional culvert is suspected near 1370X, although no distinctive anomaly is present. Except for the anomaly at $1680 \mathrm{X}$, the culverts generate the distinctive high-low-high anomaly signature associated with buried utilities and pipes.

The 20 -m coil data (Figure 24) averages $4 \mathrm{~ms} / \mathrm{m}$ across the transect with notable highs located between 1300X-1460X $(9 \mathrm{~ms} / \mathrm{m})$ and 1540X-1900X $(6-9 \mathrm{~ms} / \mathrm{m})$. The first of these high zones may in part be due to the presence of a culvert at $1370 \mathbf{X}$ and to an increase in clay content or overburden thickness. The resistivity model shown in Figure 14 supports the latter. The second highconductivity zone is more certainly associated with an increase in overburden thickness and an increase in clay content. Near coordinate 2100 , the EM data remain relatively flat (discounting the 
anomaly associated with the culvert) and indicate that the overburden is thinner here. This conclusion is corroborated by the Wells MW-25 and MW-26, which show the bedrock surface being at a higher elevation at MW-26 and by the refraction and resistivity models (Figures 6 and 14), which also show the bedrock elevated.

The 40-m coil data shown in Figure 24 averaged approximately $1 \mathrm{~ms} / \mathrm{m}$, which is close to the resolution limit of the EM-34 instrument. The apparent rise in conductivity values on the eastern end of the profile $(2100 \mathrm{X}-2260 \mathrm{X})$ is attributed to instrument drift caused by low battery power. The high-conductivity zones observed in the $20-\mathrm{m}$ data are noticeably reduced in magnitude, suggesting that they truly arise from overburden sources. This interpretation is used because the $40-\mathrm{m}$ coil data should be sensing to a greater depth and including more of the bedrock in the resulting conductivity value.

The decrease in the $40-\mathrm{m}$ conductivity near $1750 \mathrm{X}$ could be attributed to the presence of a pinnacle-shaped, high-resistivity feature (see Figure 14), which tops near $14 \mathrm{~m}$ in depth. This depth is beyond the effective depth for the $20-\mathrm{m}$ data given in Table 5 and thus would explain why the $20-\mathrm{m}$ data do not exhibit the same decrease in conductivity.

\subsection{Ground-Penetrating Radar}

The investigation depth of the ground-penetrating radar profile was limited by the highconductivity clays underlying the road surface to approximately $2-3 \mathrm{ft}$, and thus did not image the top of bedrock (30-45 ft depth). 


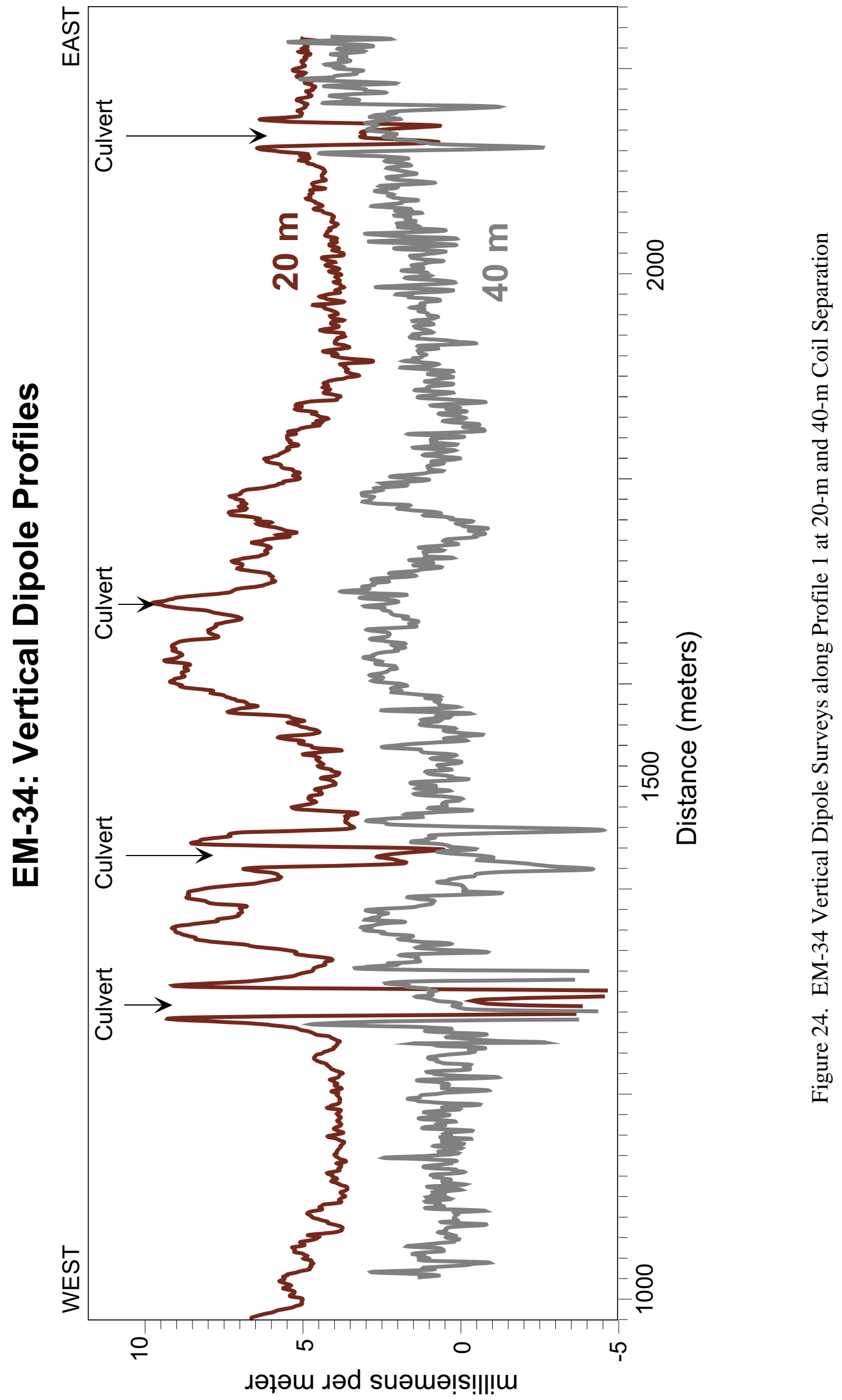




\section{CONCLUSIONS}

Geophysical profiling using primarily seismic refraction and 2-D resistivity techniques was able to map the character of the overburden and bedrock in the ETA of Camp Crowder. Sites visited included areas north of the incinerator complex, the hazardous waste pit located between the engine test stands, and the southern most boundary road. Additional data were acquired in the CTA over the primary lagoon and along the north boundary road. Geologic control was provided by lithologic descriptions obtained from boreholes adjacent to the survey lines and from downhole seismic profiling.

The basic interpretation resulting from analysis of the data indicate that a mantle of friable, heavily fractured, and/or weathered rock overlies competent bedrock. This weathered horizon acts as a transition zone between the overburden sediments and underlying competent bedrock. The seismic refraction data are most likely imaging the top of the competent bedrock zone below the weathering layer, whereas the resistivity data are marking the top of the weathering horizon with a transition zone from low to high resistivity. Combined, and with adequate borehole control, these two techniques may be able to directly map the thickness of the weathered zone. Evidence for this basic interpretation can be derived from Profile HWP-1. On its northeast end, Well MW-02 encountered weathered bedrock at a depth where the resistivity model contains a transition from low to high resistivity. The corresponding bedrock refractor appears at a depth consistent with where the lithologic description indicates competent rock.

Often, more than one technique is required to resolve the geologic structure. For example, Figure 25 is a composite figure showing the resistivity model obtained for Profile 1, the resulting bedrock refractor surfaces, the EM-34 profile, an NP Survey conducted by Karst Geophysics, and lithologic information obtained from boreholes adjacent to the profile. This figure is also a good example in that it shows the range of complexities encountered at Camp Crowder. In the western third of the profile (Figure 25), the bedrock surface is marked by a sharp transition from low to high resistivity that closely coincides with where the seismic data define the top of rock. Contrast these data with resistivity anomalies in the center (near the ETA-CTA boundary) where little correlation between the seismic and resistivity data exist. One likely explanation is the presence of more heavily weathered and fractured rock that has a significant component of clay.

Figure 25 also shows the resistivity model's ability to map epikarst features. Wells MW-24 and MW-25 indicate the presence of epikarst at shallow depths. These points correspond to isolated "floaters" of intermediate resistivity that appear within the overburden. The interpretation of these features is that they are floating limestone blocks, chert zones, or tripoli and tripoli-like deposits. This interpretation has not been confirmed by the current borehole data.

Contaminated zones may be present where the resistivity profiles are marked by extremely low-resistivity anomalies that mask the underlying geology. This situation is likely the case for the CTA-1 profile (Figure 23) and is probably true for the HWP-1 and HWP-2 profiles. The presence of VOC degradation products could produce an increase in electrical conductivity of the pore water and thus decrease the resistivity. Direct evidence of this phenomenon is shown on Profile CTA-1 (Figure 23). Here, the resistivity data indicate low resistivities in the depth range where contaminants were encountered during drilling. Indirect evidence is found on the HWP-1 profile, where lowresistivities mask the geology (inferred from the seismic and borehole control). Another source for these low resistivities may be clay-filled fractures and or conduit systems. 
Seismic reflection data probably imaged the top of bedrock, Warsaw-Burlington-Keokuk contact, and the top of the aquitard (Northview, Compton, and Chattanooga units). Sporadic reflection events were also observed within the sequence of limestones and dolomites between the Warsaw and aquitard. Intervals with shaly partings in which either a change in velocity and/or density could occur may explain these reflectors. No direct evidence of solution activity was observed on the resulting sections. 

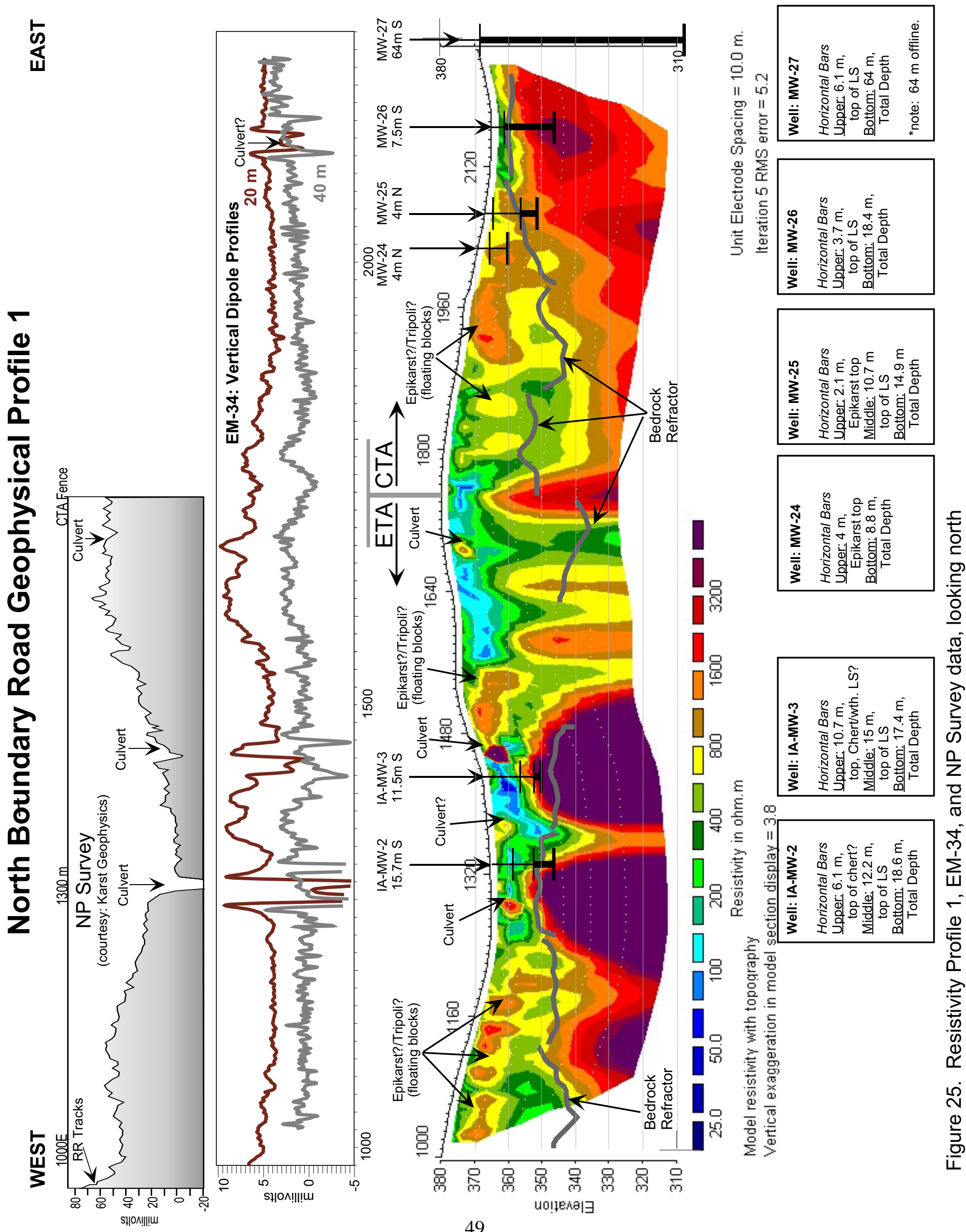


\section{RECOMMENDATIONS}

Geophysical surveys conducted at Camp Crowder by ANL provide information on the character and configuration of the bedrock. Specific recommendations are as follows:

1. Additional borings designed to target specific features observed in the geophysical data should be conducted to verify or refute the interpretations. These borings should be designed to decipher the nature of the high-resistivity "floaters" or blebs observed in the resistivity data, to understand why the seismic data are consistently modeling a lower bedrock surface, and to examine changes in the bedrock character observed in the resistivity data. Table 9 lists potential drill targets by geophysical profile line.

2. The seismic refraction data should be reprocessed by using an alternative algorithm, such as a refraction tomography algorithm, which may have an advantage of being able to image more complex structure. The goal would be to see if a better picture of the epikarst could be derived.

Table 9. Recommended Drilling Targets

\begin{tabular}{c|c|c|l}
\hline Profile \# & $\begin{array}{c}\text { Profile } \\
\text { Coordinate }\end{array}$ & $\begin{array}{c}\text { Depth } \\
\text { (m) }\end{array}$ & \multicolumn{1}{|c}{ Description } \\
\hline \multirow{3}{*}{1} & $1170 \mathbf{X}$ & $40-45$ & Low-resistivity halo, possible conduit, resistive "floater" \\
& $1360 \mathbf{X}$ & $35-40$ & $\begin{array}{l}\text { Possible fracture, bedrock low } \\
\end{array}$ \\
& $1440 \mathbf{X}$ & $30-35$ & Resistivity high, bedrock high \\
& $1620 \mathbf{X}$ & $40-50$ & Possible fracture \\
\hline \multirow{3}{*}{ or 5} & 1270 or $1300 \mathbf{X}$ & $30-35$ & Where main photo-lineament crosses line \\
\hline \multirow{3}{*}{6} & $1132 \mathbf{X}$ & $45-50$ & Possible fracture trace, low-resistivity halo \\
& $1264 \mathbf{X}$ & $55-60$ & Possible fracture \\
& $1324 \mathbf{X}$ & $40-45$ & Low-resistivity halo \\
& $1384 \mathbf{X}$ & $40-45$ & Photo-lineament, low-resistivity halo \\
\hline \multirow{3}{*}{7} & $1150 \mathbf{X}$ & $50-55$ & Photo-lineament, resistivity high in rock \\
& $1185 \mathbf{X}$ & $50-55$ & Break in bedrock surface (fracture?) \\
& $1264 \mathbf{X}$ & $40-45$ & Low-resistivity halo \\
\hline
\end{tabular}




\section{REFERENCES}

Frano, Glenn, 1999, Camp Crowder, Neosho, Missouri, Photogeologic Analysis: 1999, Prepared for U.S. Army Environmental Center, U.S. Army Corps of Engineers, Engineer Research and Development Center, Topographic Engineering Center, Alexandria, Va.

Interpex Limited, 1993, Seistrix $3^{\mathrm{TM}}$ User's Manual, reflection seismic data processing software, Interpex Limited, Golden, Colo.

Loke, M.H., 1998, "Rapid 2D Resistivity \& IP Inversion Using the Least-Squares Method," RES2DINV ver. 3.3 Software Manual, distributed by Advanced Geosciences, Inc., Austin, Texas, $66 \mathrm{pp}$.

Loke, M.H., and Barker, R.D., 1996, "Rapid Least-Squares Inversion of Apparent Resistivity Pseudosections by a Quasi-Newton Method,” Geophysical Prospecting (44) 131-152.

McNeill, J.D., 1990, "Use of Electromagnetic Methods for Groundwater Studies, pp. 191-218 in Geotechnical and Environmental Geophysics, S.H. Ward (editor), Society of Exploration Geophysicists, Tulsa, Okla.

McNeill, J.D., 1980a, Electrical Conductivity of Soils and Rocks, Technical Note TN-5, Geonics Ltd., Mississauga, Ontario Canada, 22 pp.

McNeill, J.D., 1980b, Electromagnetic Terrain Conductivity Measurements at Low Induction Numbers, Technical Note TN-6, Geonics, Ltd., Mississauga, Canada, 15 p.

Pakiser, L.C., and Black, R.A., 1957, "Exploring for Ancient Channels with the Refraction Seismograph, Geophysics," 22(1): 32-47.

RIMROCK Geophysics, 1992, SIPT2 Refraction Processing Software, (version 3.2 [computer software]) Boulder, Colo.

Rust Environment and Infrastructure, 1993, site investigation report former on Air Force Plant \#65, Rocketdyne Test Site, Neosho, Missouri.

Scott, J.H., 1973, “Seismic Refraction Modeling by Computer,” Geophysics, 38(2): 271-284.

Scott, J.H., 1977, SIPT-A Seismic Refraction Inverse Modeling Program for Time-Share Terminal Computer Systems, U.S. Geol. Surv. Open-File Report 77-366, 27 pp.

M.D. Thompson, et al., 1997, Geophysical Studies of Groundwater Pathways and Dissolution Cavities in the Lowlands, Combat Maneuver Training Center, Hohenfels, Germany, Argonne National Laboratory, Interim Report (unpublished).

Telford, W.M., Geldart, L.P., and Sheriff, R.E., 1995, Applied Geophysics, second ed., Cambridge University Press, New York, N.Y., 770 pp. 
Vandike, J.E. and C.Y. Brookshire, 1996, The Movement of Shallow Groundwater in the Camp Crowder Area, Newton County, Missouri, Missouri Department of Natural Resources.

Vineyard, J.D., and G. Feder, 1982, Springs of Missouri, Missouri Department of Natural Resources, Water Resources Report 29, 212 pp.

Ward, S.H., 1990, "Resistivity and Induced Polarization Methods," pp. 147-189 in Geotechnical and Environmental Geophysics, S.H. Ward (editor), Society of Exploration Geophysicists, Tulsa, Okla.

Waters K.H., 1981, Reflection Seismology, A Tool for Energy Resources Exploration, John Wiley and Sons, New York, N.Y., 453 pp.

Whitfield, J.W., 1996, "Geologic Map of the Neosho East 7.5 Minute Quadrangle," unpublished map files, Missouri Department of Natural Resources, Division of Geology and Land Survey, $1: 24,000$.

Wilkinson, R., 1998, personal communication on boreholes adjacent to the ETA, Camp Crowder, Mo. 


\section{APPENDIX A}

The following figures, A1-A7, show the raw-arrival times, corrected arrival times, and the average and interval velocity with depth for Wells IA-MW-1, IA-MW-2, IA-MW-3, IA-MW-4, MW-26, and MW-27. For Figures A1-A4, two sets of downhole seismic logs are presented, the first with the shot point $15 \mathrm{ft}$ from the borehole, and the second with the shot point $2 \mathrm{ft}$ from the borehole. See Figure 5 for a cartoon showing the recording layout. 

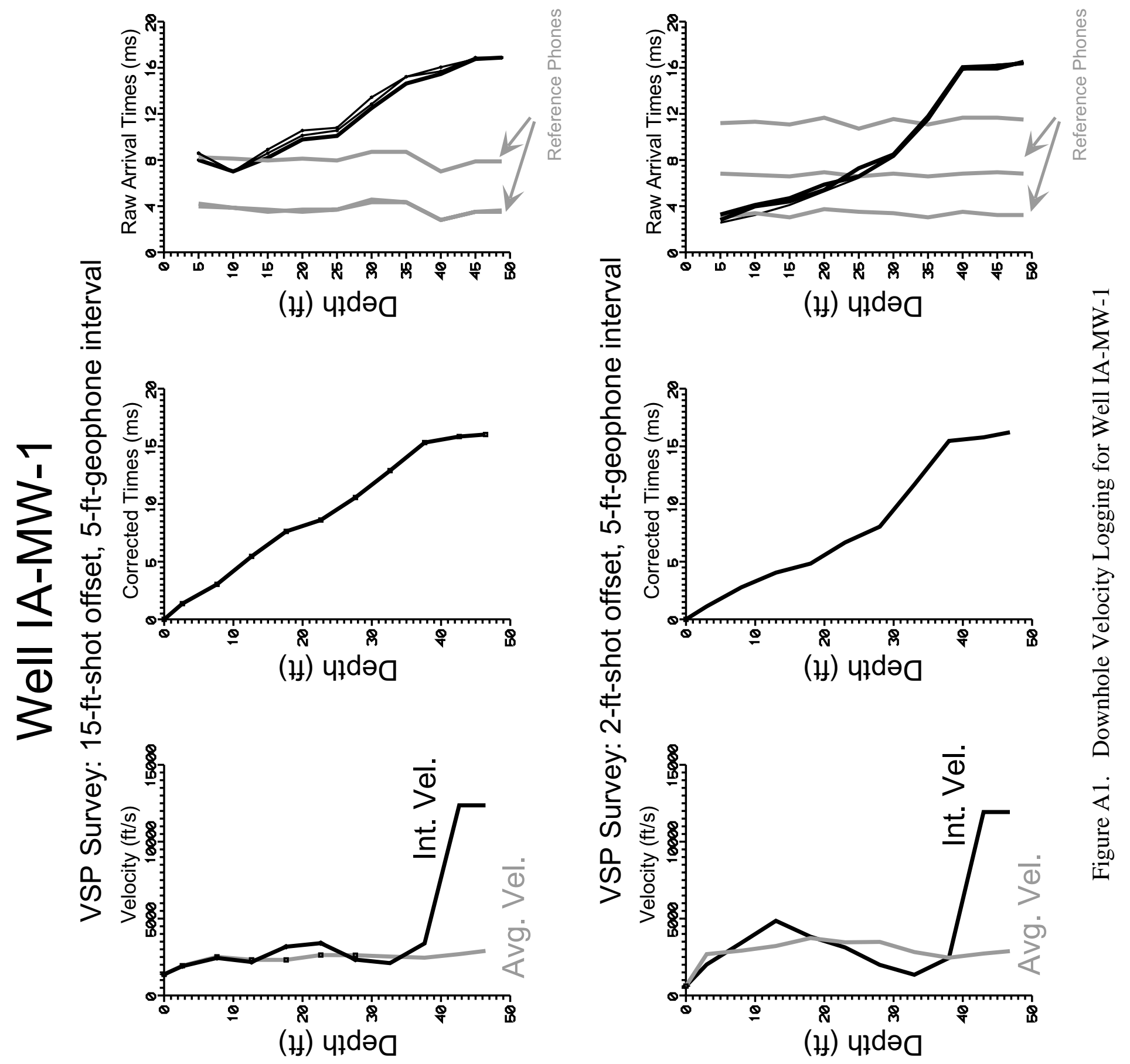


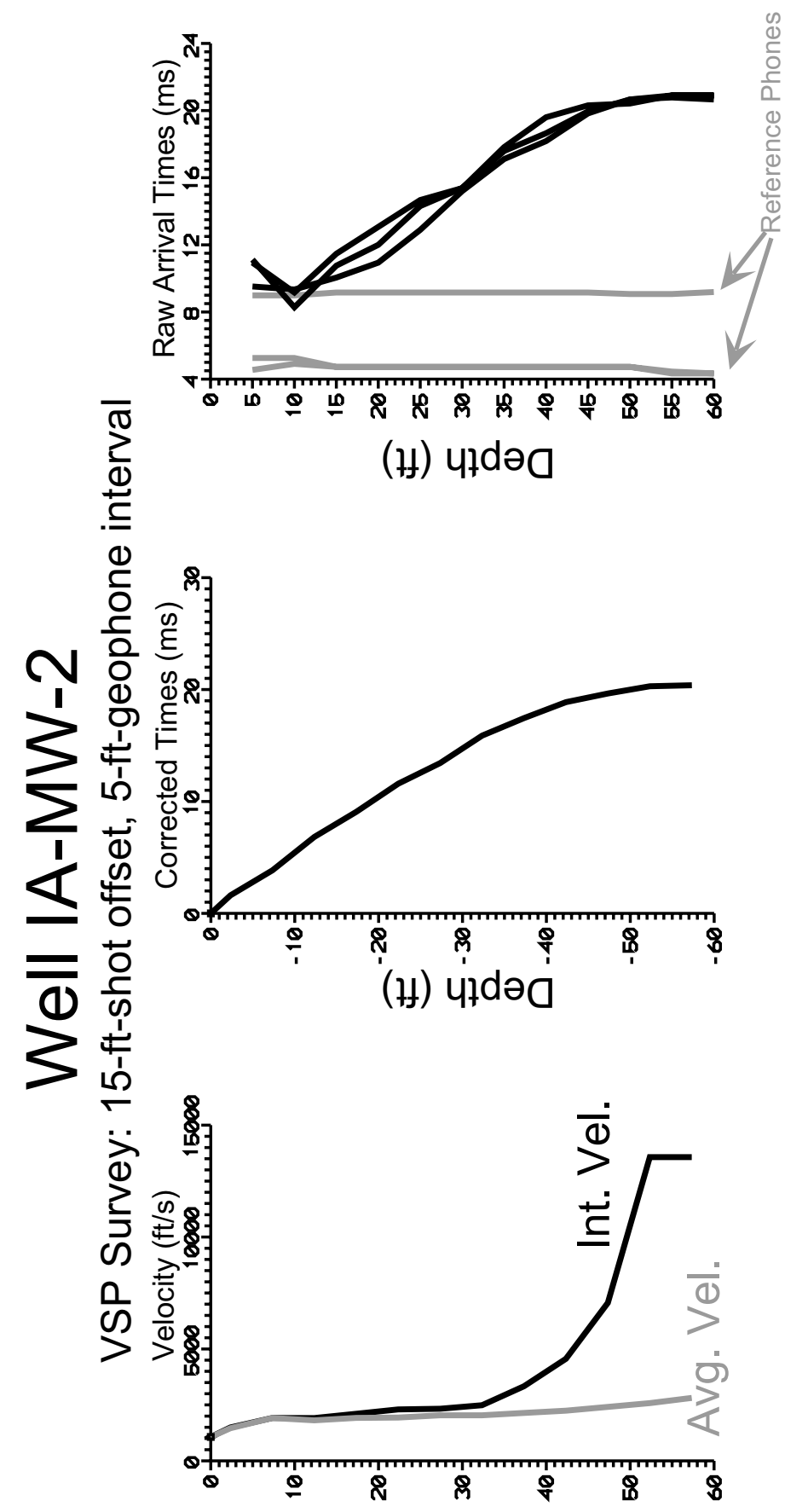

(ł) $47 \mathrm{~d} \partial 0$

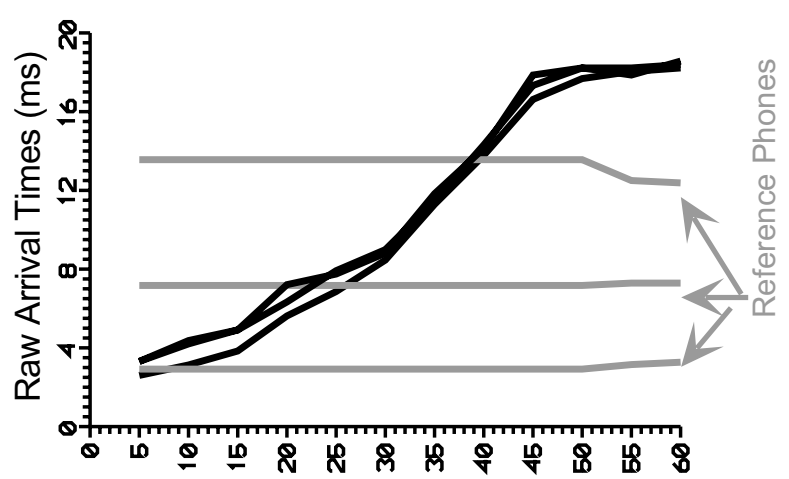

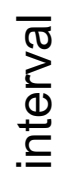

(ł) पाdə0

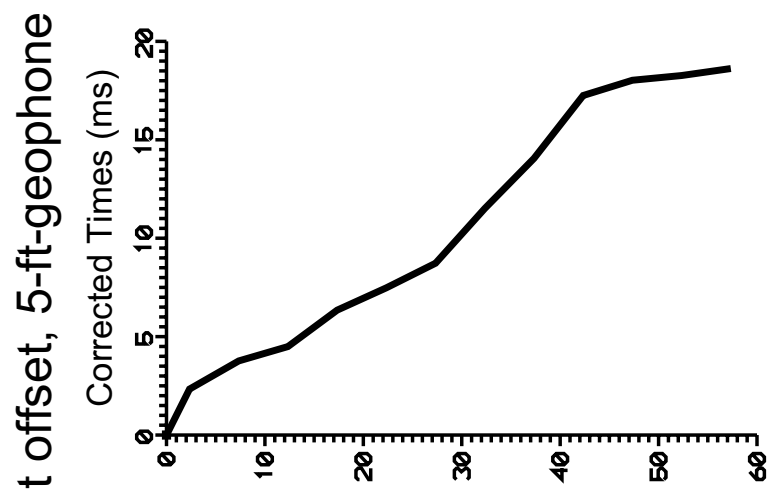

(अ) $47 \mathrm{~d} ә 0$

옹

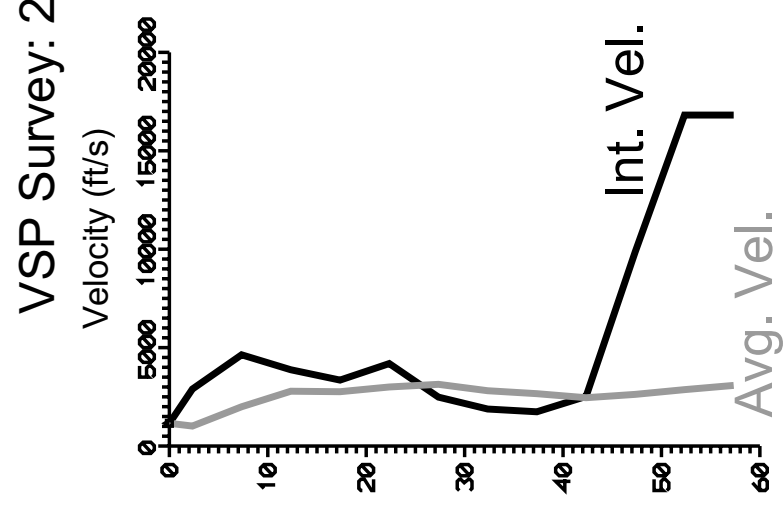

(अ) 4ұdə0 


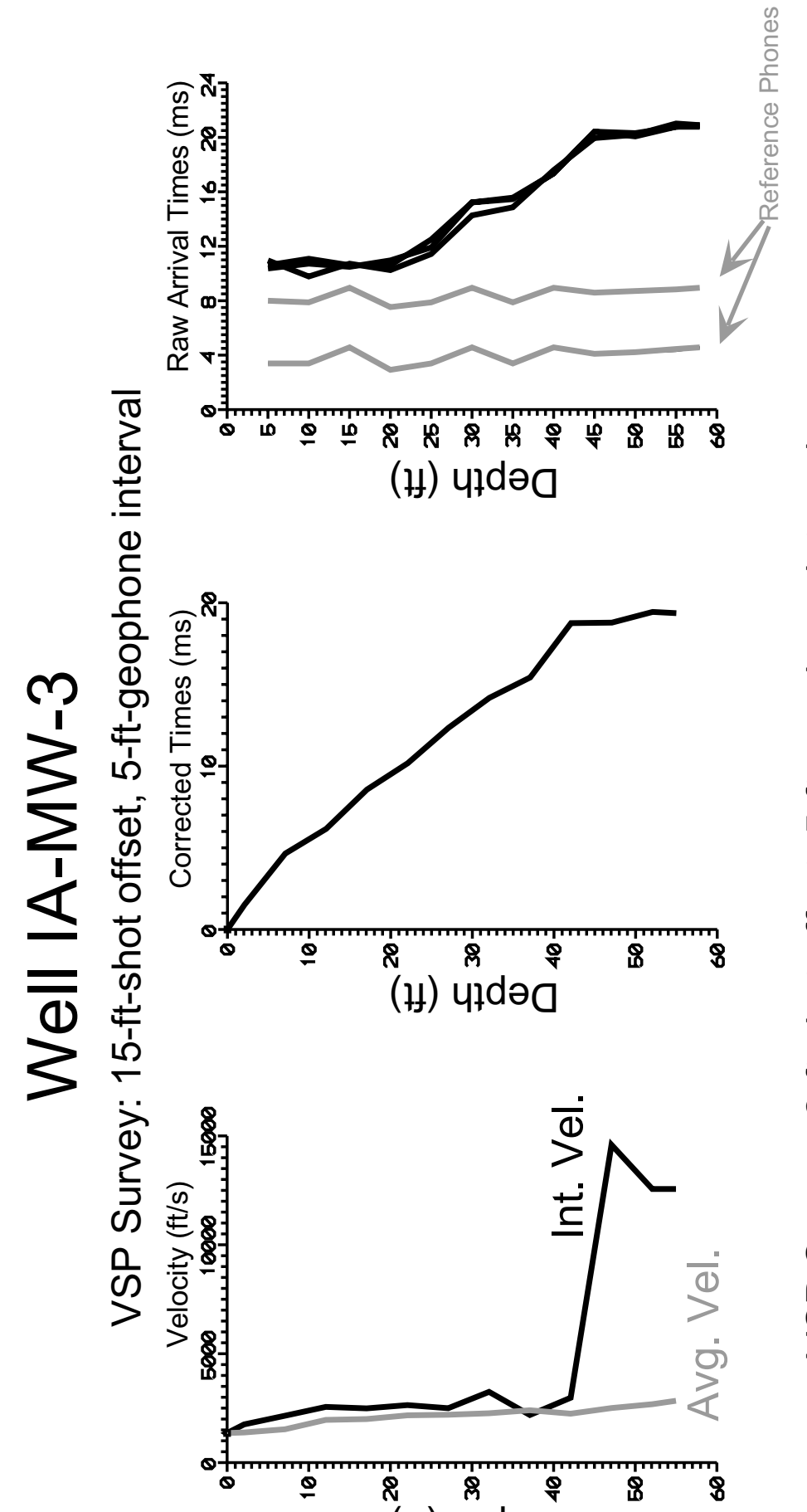

(ঋ) प1də0

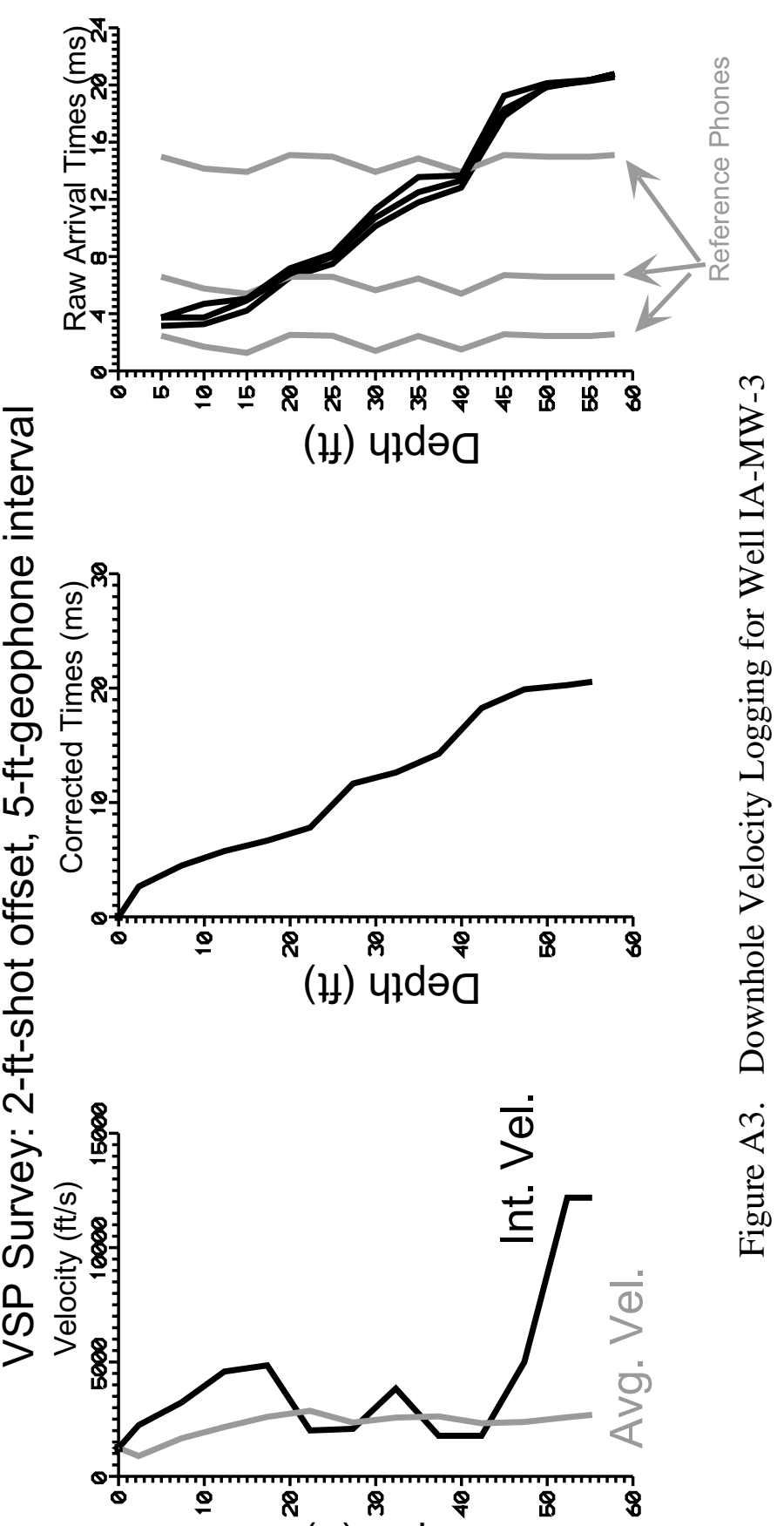

(ł) प1də0 


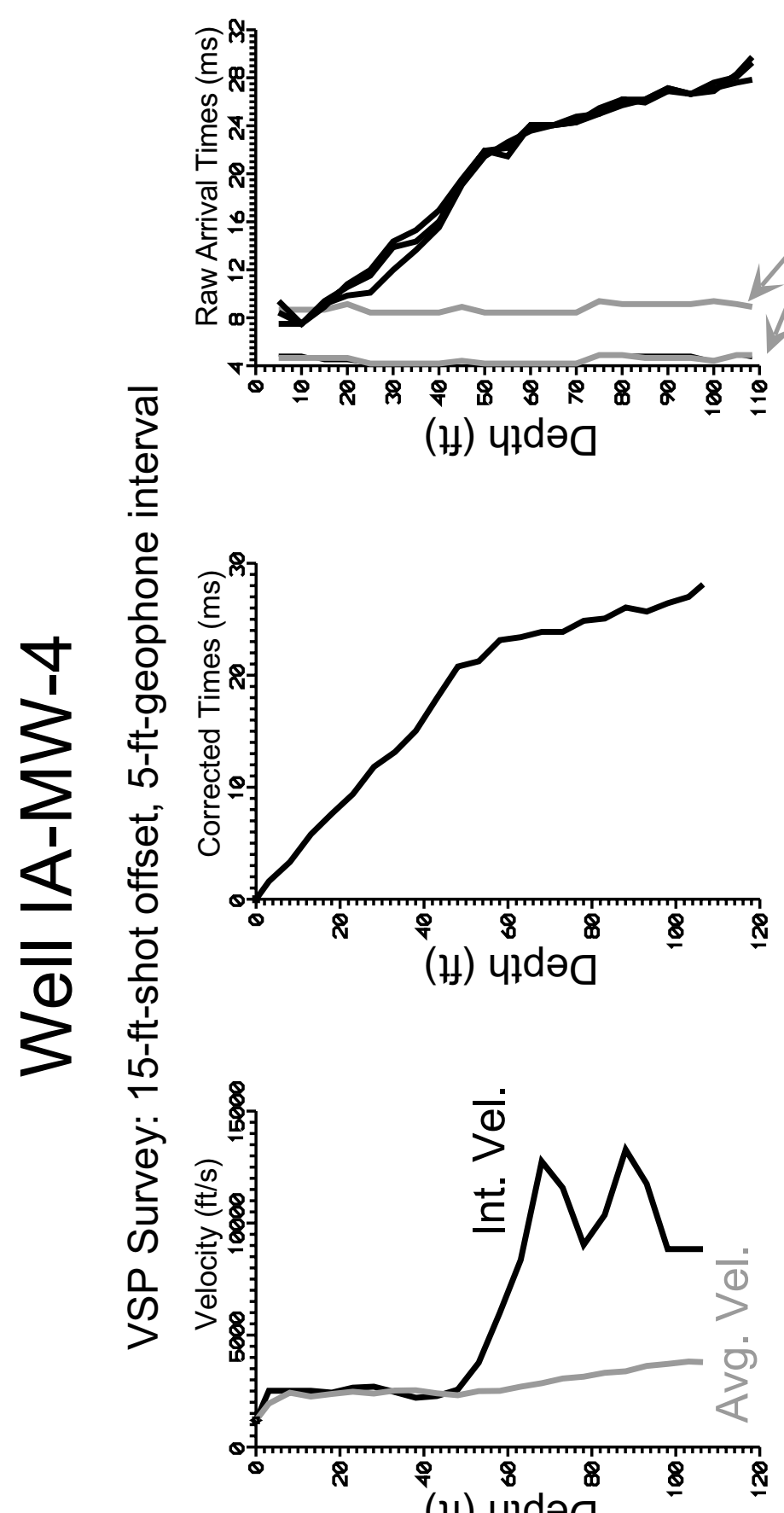

(अ) पұdəव

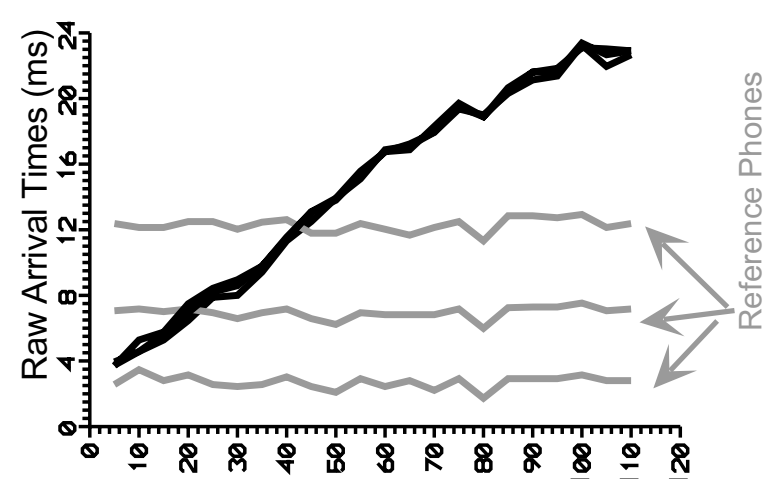

$\stackrel{\pi}{\stackrel{\pi}{d}}$

(ł) प1dəح

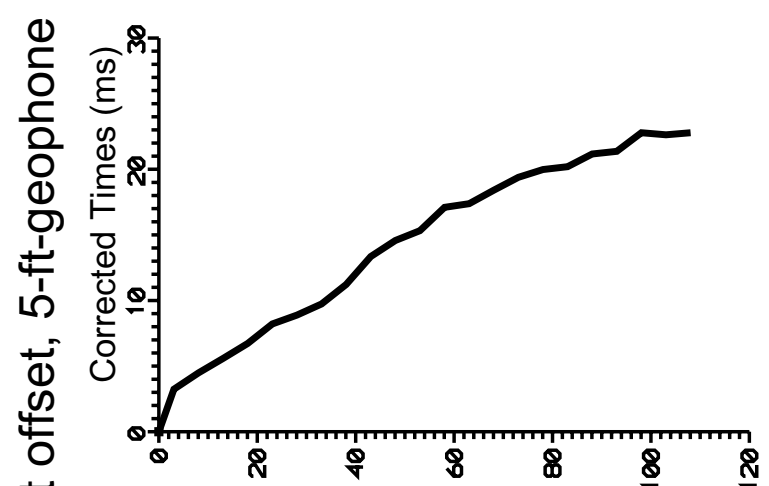

(ł) पा dəO

$\frac{\overline{0}}{9}$

$\stackrel{4}{4}$

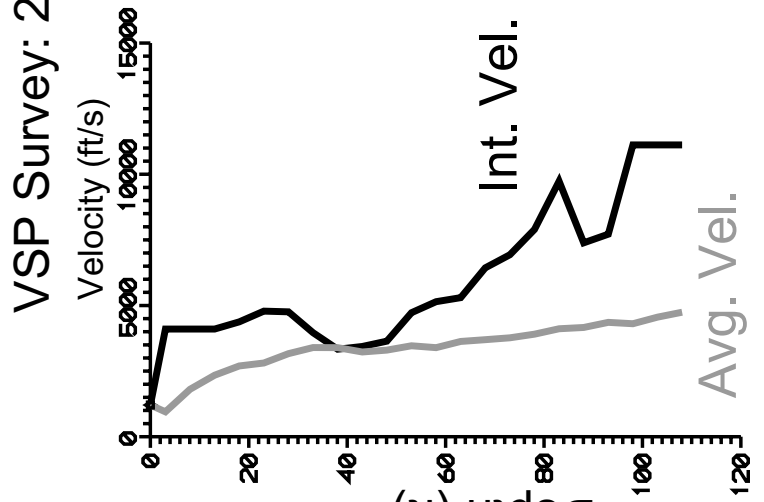

(ओ) $41 \mathrm{~d} \partial 0$ 


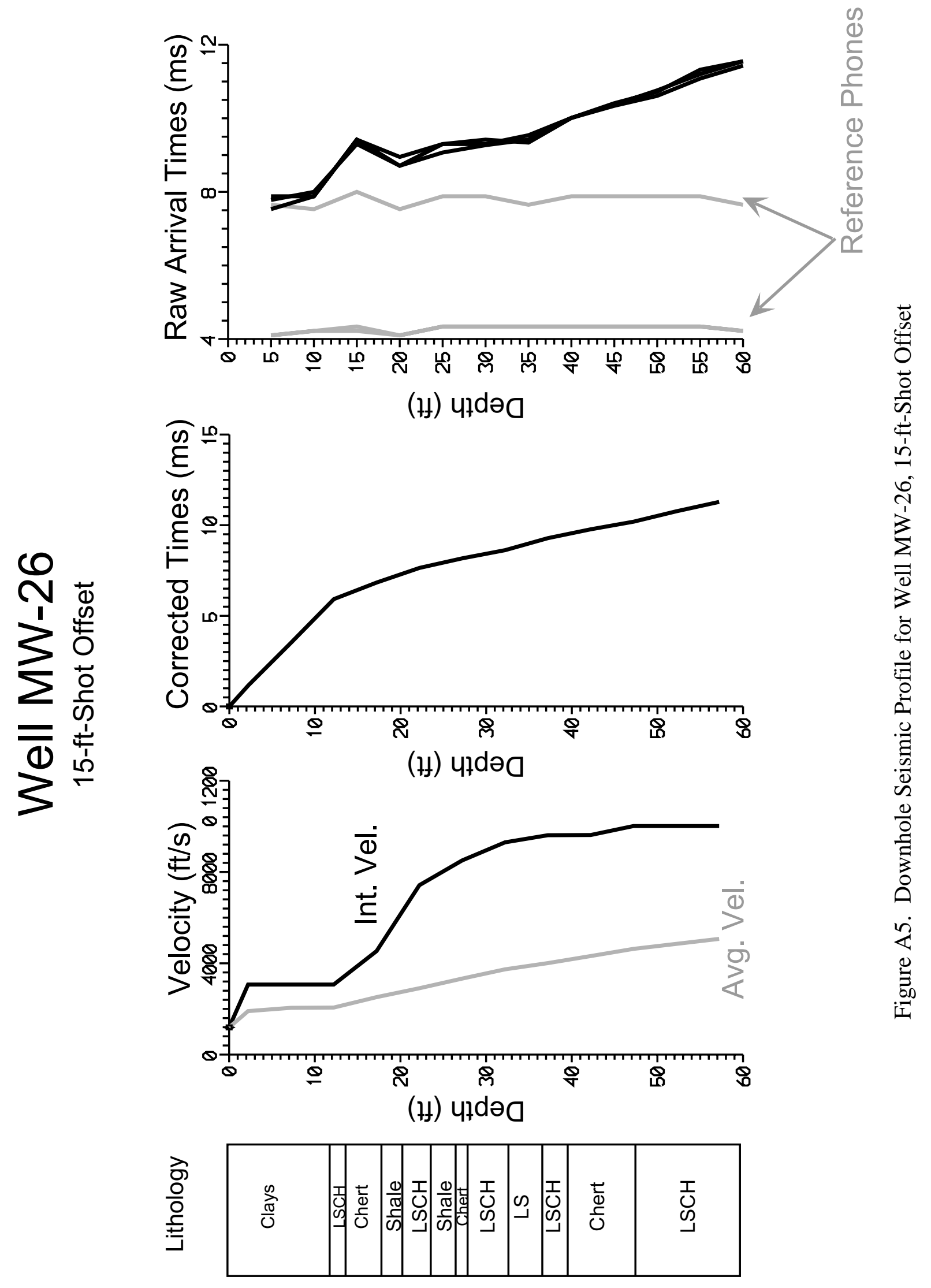




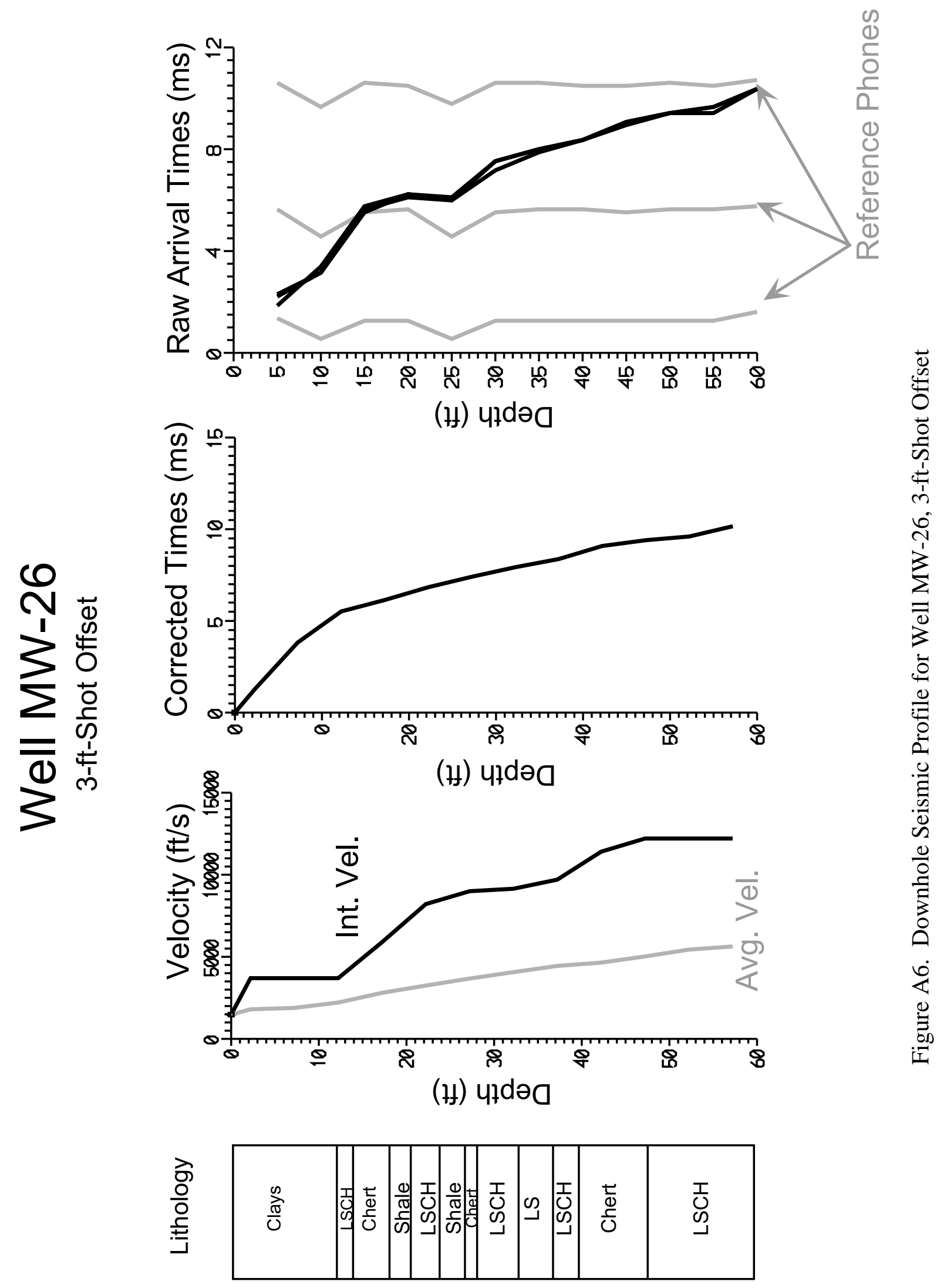




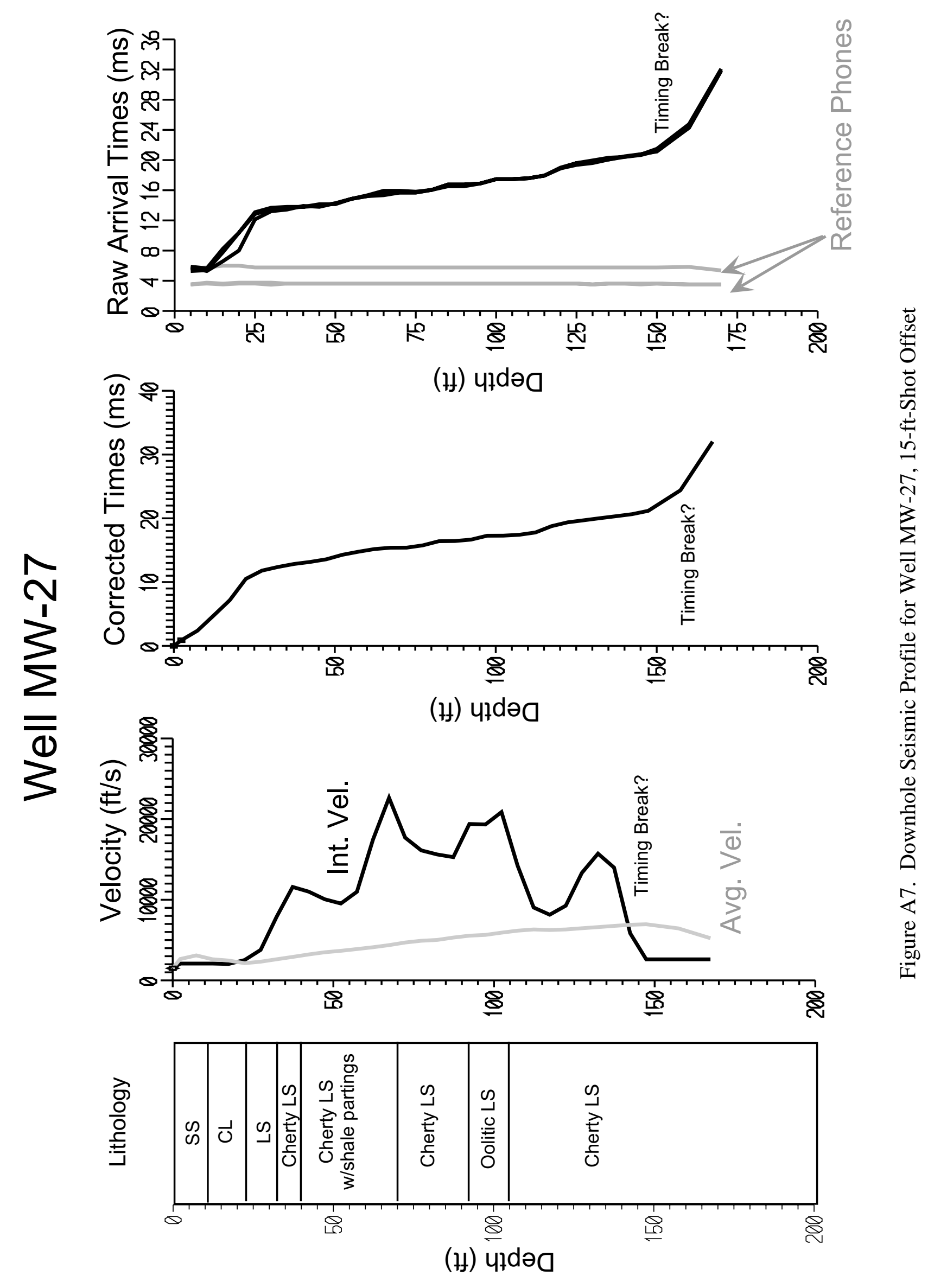

